\title{
Examining Relationships among Person Factors, Psychosocial Factors, and Coping Patterns in People Living with Type 2 Diabetes Mellitus in North Central Appalachia
}

Melissa A. McCoy

West Virginia University, mam0068@mix.wvu.edu

Follow this and additional works at: https://researchrepository.wvu.edu/etd

Part of the Endocrinology, Diabetes, and Metabolism Commons, Family Practice Nursing Commons, and the Psychiatric and Mental Health Nursing Commons

\section{Recommended Citation}

McCoy, Melissa A., "Examining Relationships among Person Factors, Psychosocial Factors, and Coping Patterns in People Living with Type 2 Diabetes Mellitus in North Central Appalachia" (2021). Graduate Theses, Dissertations, and Problem Reports. 10316.

https://researchrepository.wvu.edu/etd/10316

This Dissertation is protected by copyright and/or related rights. It has been brought to you by the The Research Repository @ WVU with permission from the rights-holder(s). You are free to use this Dissertation in any way that is permitted by the copyright and related rights legislation that applies to your use. For other uses you must obtain permission from the rights-holder(s) directly, unless additional rights are indicated by a Creative Commons license in the record and/ or on the work itself. This Dissertation has been accepted for inclusion in WVU Graduate Theses, Dissertations, and Problem Reports collection by an authorized administrator of The Research Repository @ WVU.

For more information, please contact researchrepository@mail.wvu.edu. 
Examining Relationships among Person Factors, Psychosocial Factors, and Coping Patterns in People Living with Type 2 Diabetes Mellitus in North Central Appalachia

\author{
Melissa A. McCoy \\ Dissertation submitted to the School of Nursing at West Virginia University \\ in partial fulfillment of the requirements for the degree of \\ Doctor of Philosophy \\ In \\ Nursing \\ Laurie A. Theeke, PhD, FNP-BC, GCNS-BC, Chair \\ Roger D. Carpenter, PhD, RN, NE-BC, CNE \\ Jennifer A. Mallow, PhD, FNP-BC \\ Kesheng Wang PhD, MA, BS \\ Catherine Chua, DO, FAAFP, FMNM, CPE \\ Department of Nursing \\ Morgantown, WV \\ November 30, 2021
}

Key words: Type 2 Diabetes Mellitus, Person Factors, Psychosocial Factors, Coping Patterns, Appalachia, Prevalence

Copyright 2021 Melissa McCoy 


\begin{abstract}
Examining Relationships among Person Factors, Psychosocial Factors, and Coping Patterns in People

Living with Type 2 Diabetes Mellitus in North Central Appalachia
\end{abstract}

Melissa A. McCoy

Background: Diabetes is a complex, debilitating illness that imposes disease burden on the individual and society. T2DM is more prevalent in the Appalachian region than in any other Region of the United States. If diabetes is poorly controlled, patients are at risk for negative health outcomes. A gap exists in the literature related to understanding of the relationships among person factors, psychosocial factors, and coping patterns. Another gap in the literature is sex differences among these variables.

Purpose: The purpose of this study is to examining relationships among person factors, psychosocial factors, and coping patterns in people living with T2DM in north central Appalachia.

Method: A convenience sample of 40 men and 40 women who receive chronic management care for T2DM at a small hospital-based rural clinic, Davis Family Care was recruited. Participants were seen between February 2021-August 2021 and met the following inclusion criteria: adults between the age of 18 and 64 years old, able to read and write English, and diagnosed with T2DM. Data was analyzed using the appropriate statistical test based on variable type to seek relationships. Chi-square was conducted on categorical variables. Independent-Sample $t$ tests was conducted on continuous variables. Pearson correlation coefficient, Pearson's $r$, was used when variables were normally distributed. Continuous variables that were not normally distributed, Spearman correlation was utilized. For continuous variable of the sum score of coping patterns, a general linear model (GLM) was employed. Linear regression was also employed with coping subscales as the dependent variable and the independent variables were determined by significant relationship to the outcome variable. The enter method was investigated first and then the stepwise method.

Results: The largest segment of the sample included those aged 60-64 (31.3\%), white (97.5\%), who are married or partnered with spouse present (60\%), with a high school education (30\%), an income level less than $\$ 30,000$ (61.3\%), and unemployed (63.7\%). Most common comorbidities were high blood pressure (55\%), hyperlipidemia (53.8\%), depression (27.5\%), lung disease $(20 \%)$, anxiety $(17.5 \%)$, coronary artery disease (12.5\%), arthritis (12.5\%), and stroke (1.3\%). Nineteen people had zero comorbidities and one person had all eight comorbidities. Average number of comorbidities in addition to T2DM was 2.11 ( $S D=1.916)$. The average $A 1 C$ was $8.21(S D=2.54)$, with participants measuring an average $\mathrm{BMI}$ of 37.38 (SD = 8.74). Participants reported living with 1.45 people in the home on average and traveling an average of $10.22(S D=11.31)$ miles to Davis Family Care. Participants reported having T2DM for a mean of 8.62 years $(S D=7.97)$ and being prescribed a mean of 9.4 medications a day $(S D=$ 6.521). Positive correlation was identified among perceived stress of anxiety, depression, diabetes distress, and loneliness. In general, sex differences were identified as female sex in psychosocial factors such as anxiety, depression, and diabetes distress. General linear modeling revealed positive frame of mind to be predictive of four positive coping subscales (active, planning, positive reframing, and acceptance). Diabetes distress was identified as predictive for behavioral disengagement coping and self-blame coping. Female sex was predictive for planning, positive reframing, religion, use of instrumental support, venting, self-distraction, and self-blame coping. Positive frame of mind was predictive for humor and religion coping. 
Conclusions: People with T2DM in Appalachia are living with a cluster of psychological factors, anxiety, depression, diabetes distress, and loneliness. These factors, along with the known sex differences in coping further complicate the care of persons with T2DM. Findings of this study are foundational to further research that targets diabetes distress and is sex specific. 


\section{ACKNOWLEDGEMENTS}

There are so many people I need to acknowledge and thank because without them this manuscript would not have been possible. First, I would like to thank God for making this dream a reality and for being with me on this PhD journey. Thank you to my chair, Dr. Laurie Theeke, for tirelessly working with me, encouraging me and for unwavering support. You could always tell when I was overwhelmed or did not understand. You made time to work with me and helped guide me. You invested and nurtured me so I could grow as a nurse scientist. You are a leader, role model, mentor, and an exemplar for us all. Thank you to Dr. Mindy Chua for removing obstacles and supporting me so I could conduct research at Davis Family Care. Thank you to Dr. Jennifer Mallow for your kind words, support and willingness to step up whenever I needed help. Thank you, Dr. Kesheng Wang for your expertise as a statistician. You worked countless hours on modeling with me. You took the time to teach me different statistical techniques and were patient with me when I had difficulty

understanding. Thank you, Dr. Roger Carpenter for your expertise on diabetes and coping. Thanks also to Dr. Mary Jane Smith, I am fortunate to have met you. You changed the way I think. The lens I look through to see the world is different because of you. I am forever appreciative. I am grateful to have been chosen and financially supported as a Jonas Scholar 2018-2020. Lastly, thank you to the Anna Mary Miller Scholarship and the National League for Nursing (NLN) Foundation for Nursing Education Scholarship for funding my dissertation. 


\section{DEDICATION}

This dissertation is dedicated to my husband, Chad McCoy, and my daughter, Joslyn

DeWeese. Our family sacrificed so much so that I could complete the PhD program. I would not have made it without your love, support and encouragement every day. I am blessed to have you two in my life. I love you Chad and Joslyn. Chad, here's to new adventures ahead and spending the rest of our lives together. Joslyn, you can do anything you want and I will always be by your side loving, encouraging and supporting you. 


\section{TABLE OF CONTENTS}

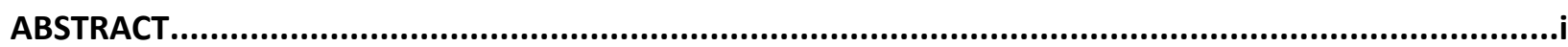

ACKNOWLEDGEMENTS

DEDICATION

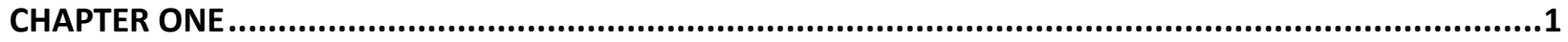

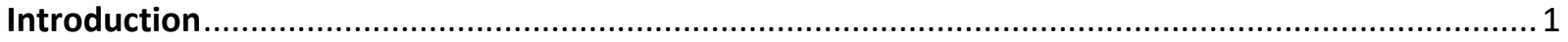

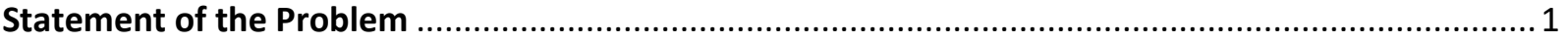

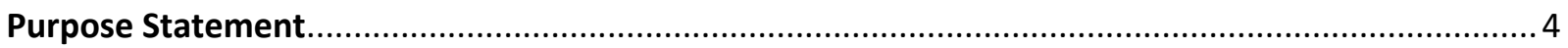

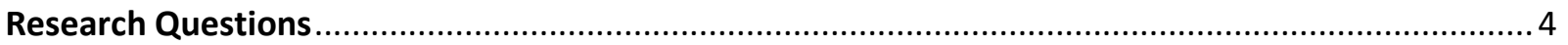

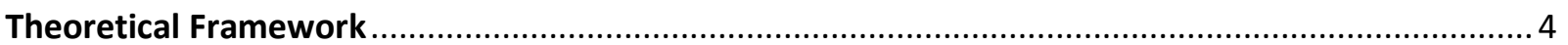

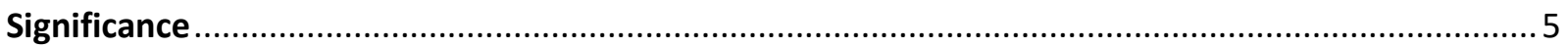

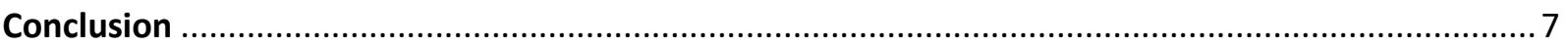

CHAPTER TWO

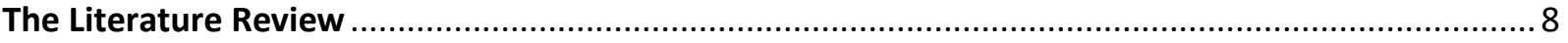

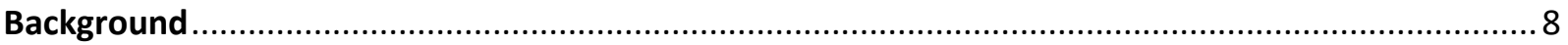

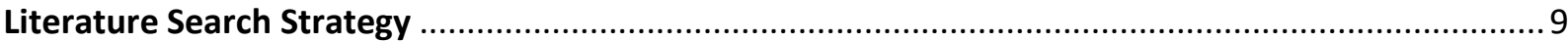

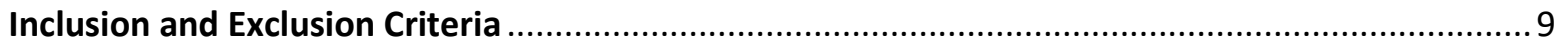

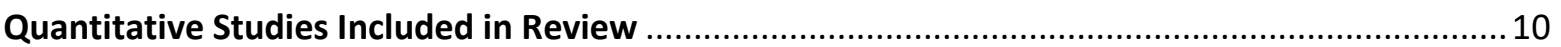

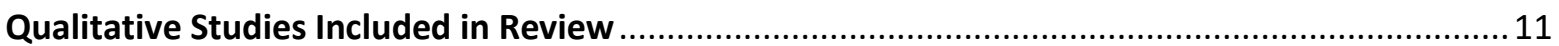

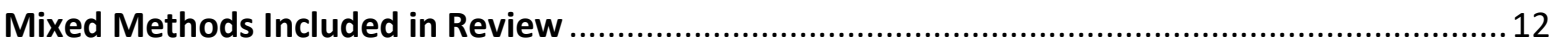

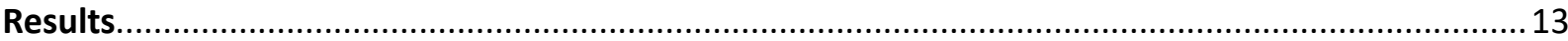

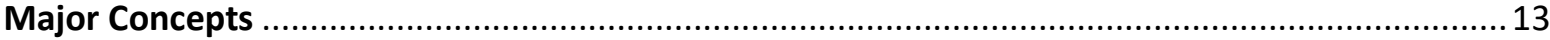

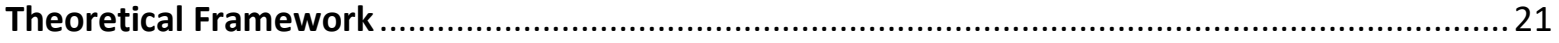

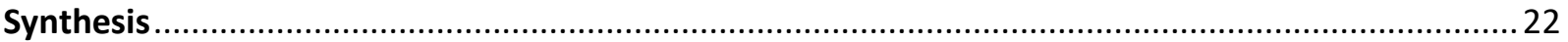

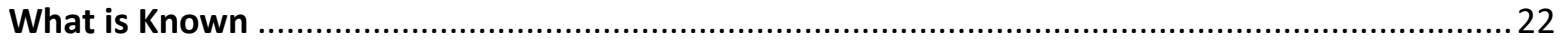

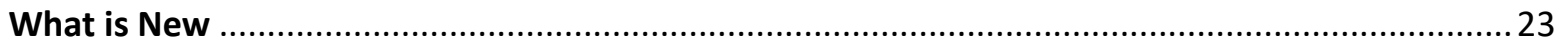

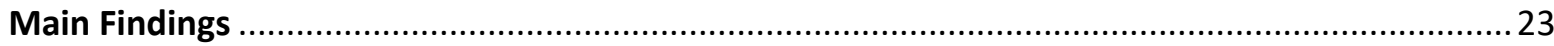

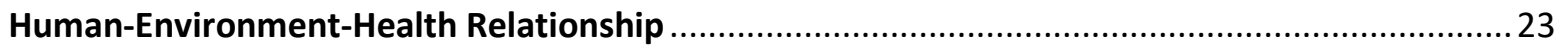

Summary

CHAPTER THREE

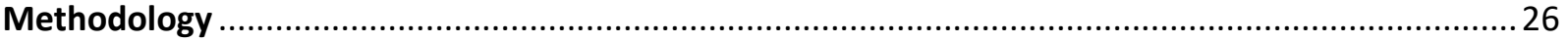

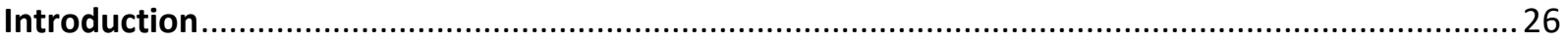




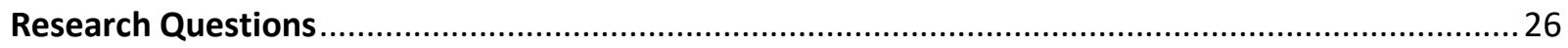

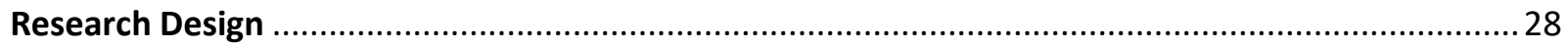

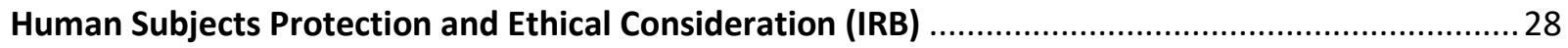

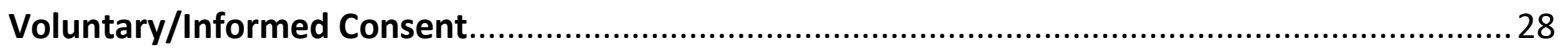

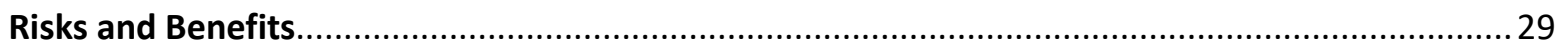

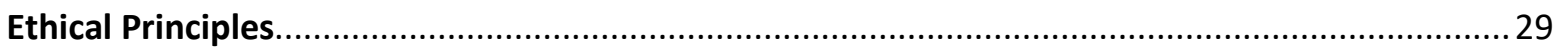

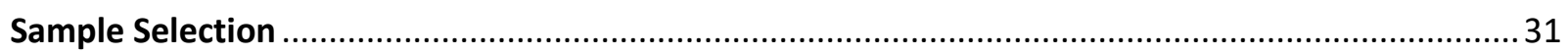

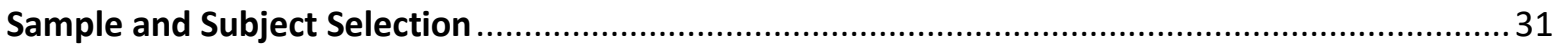

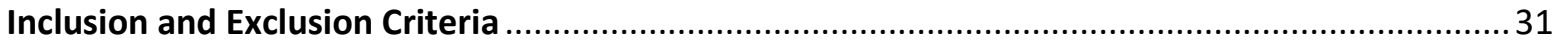

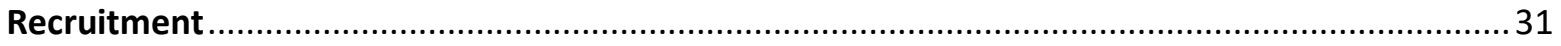

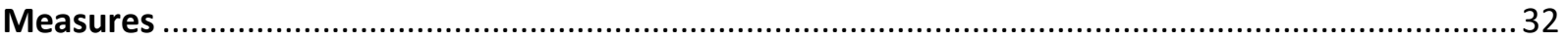

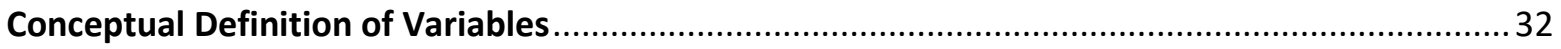

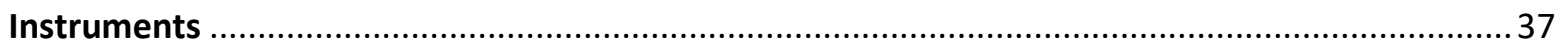

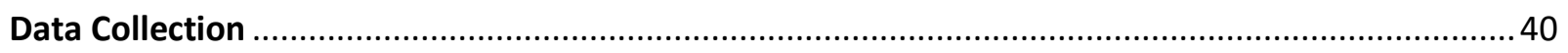

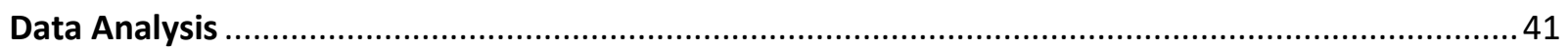

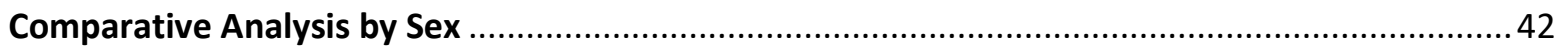

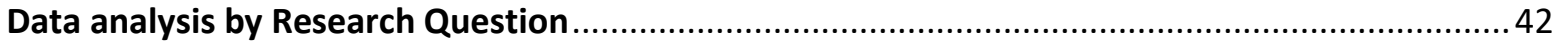

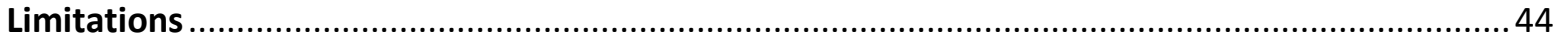

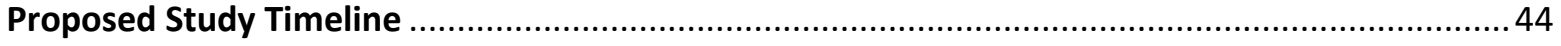

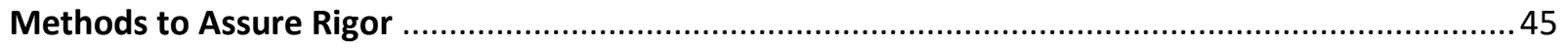

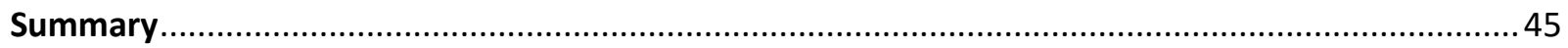

CHAPTER FOUR

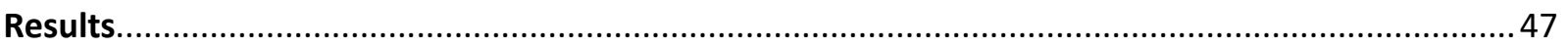

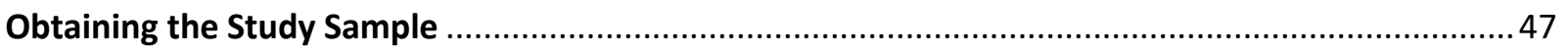

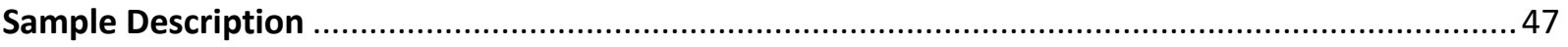

Differences in Psychosocial Variables and Coping Styles by Sex ....................................................50

Differences by Sex in Categorical Variables .......................................................................... 50

Mean Comparisons Based on Sex for Continuous Variables .......................................................54

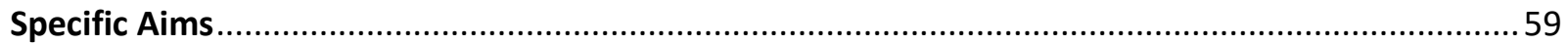

Specific Aim 1: Relationships among Person Factors, Psychosocial Factors and Coping Patterns. 59

Specific Aim 2: Sex Differences for Psychosocial Factors and Coping Patterns ...........................68

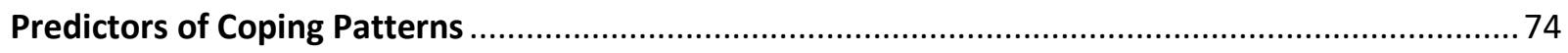

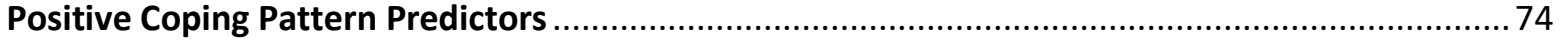




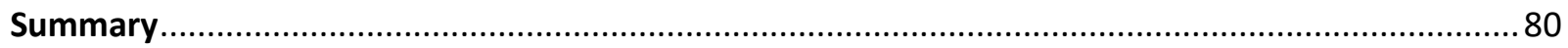

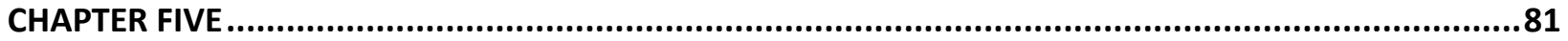

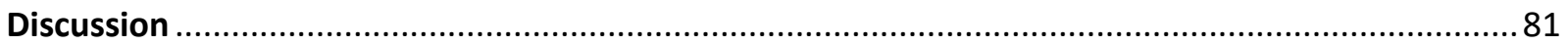

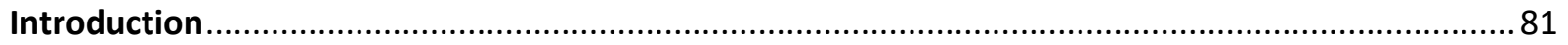

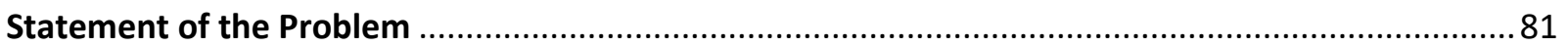

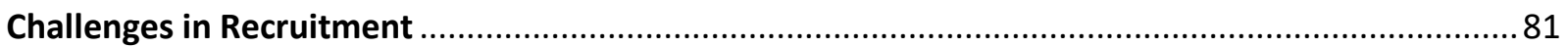

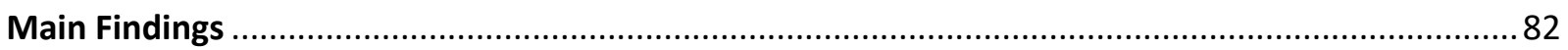

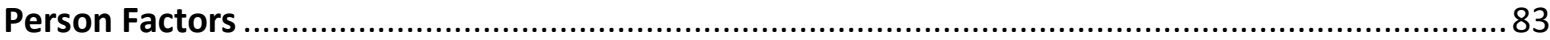

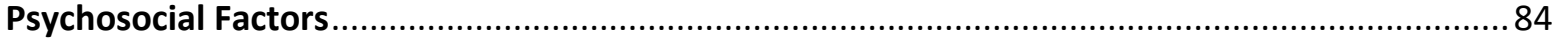

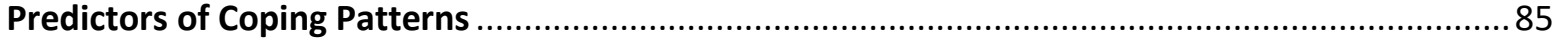

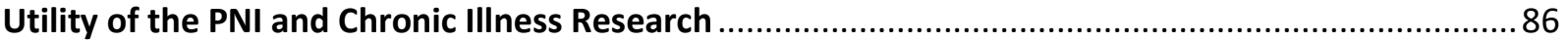

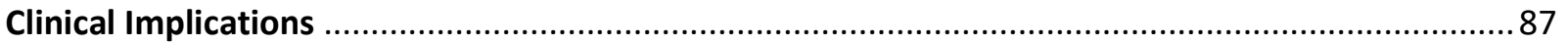

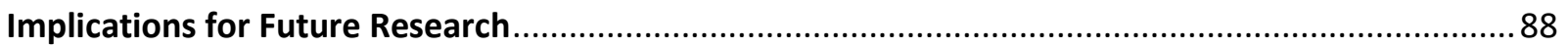

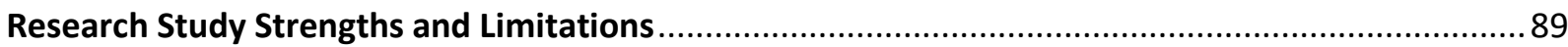

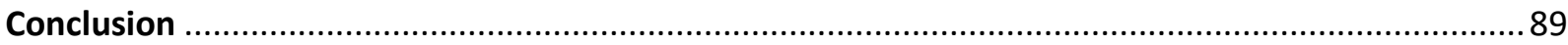

APPENDIX

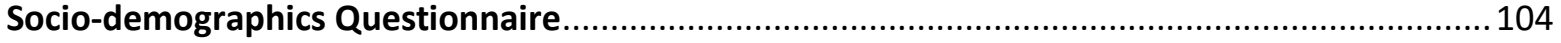

PROMIS---Emotional Distress---Anxiety----Short Form A ….................................................. 107

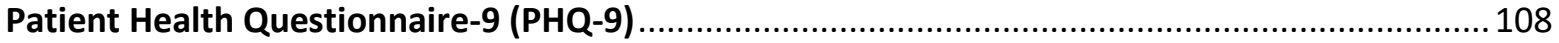

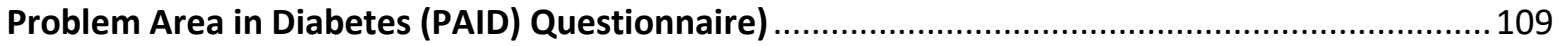

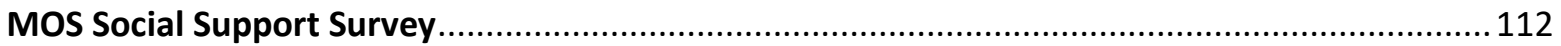

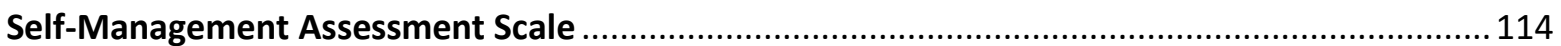

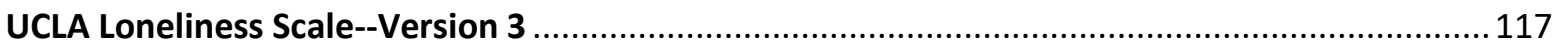

Brief COPE 


\section{CHAPTER ONE \\ Introduction}

The purpose of this chapter is to introduce the problem of stress and how it influences health behaviors and outcomes in people living with type 2 diabetes mellitus (T2DM) in Appalachia. The Psychoneuroimmunology Paradigm (PNI) is the theoretical framework guiding the study (McCain, Gray, Walter, \& Robins, 2005). This study contributes to knowledge from the disciplinary perspective of nursing because it addresses the problem of stress within the conceptual confluence of humanenvironment-health-relationships. The relevant area of inquiry addressed in this study is stress, coping, and adaptation throughout the life process which congruent with knowledge derived from the discipline of nursing.

\section{Statement of the Problem}

Stress influences perceptions and behaviors, and through these pathways, influences health outcomes for people living with T2DM in Appalachia. T2DM is a complex, chronic, and debilitating illness that elicits stress and imposes financial burden on individuals, families, and society. Originally Hans Selye defined stress as "non-specific responses that can be resulted from a variety of stimuli" (Selye, 1936). Selye's theory was incomplete when considering the holistic perspective of nursing as it focused on the physical response to stress, not psychological reactions or responses to stress. In 1984, Lazarus and Folkman originally suggested that stress occurred when external demands on a person exceeded personal ability to cope. Lazarus \& Folkman redefined stress as an event that a person perceives as potentially dangerous to his or her well-being (Lazarus \& Folkman, 1987). Stress on humans is a longstanding historical problem. Knowing that stress is related to ability to cope and that it can negatively influence health outcomes in people with T2DM there is a critical need to understand coping. As human beings develop and interact with their environment, they develop various coping patterns. The coping patterns people chooses can impact the outcome. For this study, the conceptual definitions of stress 
and coping are derived from the Lazarus \& Folkman (1987) Transactional Model of Stress and Coping (TSMC).

Stressors known to influence outcomes in people with T2DM include person factors of age, gender, income, education, employment status, marital status, and living situation, psychosocial factors of anxiety, depression, diabetes distress, social support, self-management, and loneliness, and coping patterns. These stressors have been identified as problematic for people living with T2DM diabetes in Appalachia. The interaction of these stressors can subsequently influence health (McCoy \& Theeke, 2019).

Coping is broadly defined as an adaptation or response to a stressful situation by Lazarus and Folkman (1984). Coping is a behavior. Once the situation is perceived stressful, a person decides what coping pattern to employ to reduce the potential harm (Vitaliano, Russo, Carr, Maiuro, \& Becker, 1985). Coping patterns have been determined to play a fundamental influential role in physical and psychological well-being (Coelho, Amorim, \& Prata, 2003) and they are known to differ by gender (Gåfvels, \& Wändell, 2006).

T2DM is most prevalent in the Appalachian region compared to other U.S. Regions. The state of West Virginia (WV) is situated entirely in the rural Appalachian Region and, notably, WV ranks 2nd nationally for T2DM, reporting that one of every ten adults are diagnosed with diabetes (Disease DoHPac, 2019). In WV it is reported that incidence of diabetes was highest among adults aged 45 and older, those with less than a high school education and those with an annual household income of less than $\$ 25,000$ (West Virginia Department of Health and Human Resources, 2017). Diagnosis of T2DM requires adjustments in the patient's lifestyle to maintain health.

People living in Appalachia experience many preventable differences in the burden of disease including chronic illnesses, social determinants of health, and psychosocial disparities. People living in Appalachia as they are faced with disparity in social determinants of health including lower 
socioeconomic status, living rurally with low resources, lower educational levels, and high prevalence of multiple chronic conditions. Specifically, in WV, chronic kidney disease and hypertension are the second highest in the nation and over one forth (26\%) of people are diagnosed with depression, the highest in the nation (West Virginia Department of Health and Human Resources, 2017); all of which result in complex health challenges (WHO, 2019; ARC, 2019; CDC, 2019). Thus, understanding social determinants and psychosocial factors are potentially important sources to improve care of people living with diabetes and other chronic illnesses in rural WV (WHO, 2019). These stressors of person factors and psychosocial factors are known risk factors for not coping well (McCoy \& Theeke, 2019).

T2DM is a complex, debilitating illness that imposes disease burden and financial burden on individuals and society. Diabetes is a global health problem. Diabetes-related health outcomes are affected by modifiable and non-modifiable determinants of health which include social, economic, and physical environment factors, as well as individual characteristics and behaviors (Powers, Bardsley Cypress, Duker, Funnell, Fischl, Maryniuk, Siminerio \& Vivian (2015). If T2DM is poorly controlled, patients are at significant risk for numerous negative health outcomes such as atherosclerotic cardiovascular disease, heart failure, chronic kidney disease and many other diabetes-related complications, many of these complications are preventable (ADA, 2019). It is recommended that persons with T2DM adhere to national care national guidelines by incorporating aspects of lifestyle management into daily routines (ADA, 2019) to prevent negative sequelae of T2DM. However, engaging in daily care routines requires balance of key psychosocial factors (Powers et al, 2015) known to influence self-care including; stress perception, anxiety symptoms, depressive symptoms, diabetesrelated distress, social support, self-management ability, and loneliness.

The disciplinary perspective relates to human-environment interactions that produce stress, and the coping and adaptive strategies promote health, healing, and well-being. Knowing that stress and coping patterns have the ability to influence health outcomes makes it critical that nurses generate 
knowledge to inform practice. This broad view of stress, coping, and health acknowledges the perception and experience of health (Smith, 2019).

\section{Purpose Statement}

The purpose of the proposed study is to employ a quantitative, descriptive, prospective, crosssectional design to examine relationships among stressors and T2DM. More specifically, the study design includes examining relationships among person factors, psychosocial factors, and coping patterns in people living with T2DM in north central Appalachia.

\section{Research Questions}

This study purpose will be met by answering the following research questions:

1. What are the relationships among person factors (age, sex, income, education, employment status, marital status, and living situation), psychosocial factors (perceived stress including anxiety, depression, diabetes distress, social support, self-management, and loneliness) and coping patterns in patients living with T2DM in north central Appalachia?

2. What are the sex differences between adult men and women on psychosocial factors (perceived stress including anxiety, depression, diabetes distress, social support, selfmanagement, and loneliness) and coping patterns in patients living with T2DM in north central Appalachia?

\section{Theoretical Framework}

The overarching theoretical framework underpinning this study design is the Psychoneuroimmunology Paradigm (PNI) described by McCain et. al., (2005). This framework was developed from the disciplinary perspective of nursing and, therefore, is well-suited to nursing research. People living with T2DM are in a multidimensional environment of Appalachia in which there are known specific challenges that are linked to health disparity and negatively impact health outcomes. The 
relevant area of inquiry congruent with the concept of the disciplinary perspective of nursing addressed in this study is stress, coping, and adaptation throughout the life process (Smith, 2019).

The purpose of the PNI is to examine factors that are known to influence health in the context of an experienced stressor, adaptational responses to that stressor, including coping patterns, and health outcomes including psychosocial functioning, quality of life, and physical health. The PNI considers the lived experience of concurrent exposure to individual, environmental, and relationship factors, a stressor, a coping response to a stressor, and overall health. The model gives a representation of logical relationships among variables linked to health outcomes. The PNI framework details potential relationships among psychosocial and physiological components of stress response, emphasizing the physiological activation of neuroendocrine and immune responses to stressors, the interaction with psychosocial-spiritual factors, and subsequent influence on health (McCain et. al., 2005).

The organizing concepts in the framework guide the purpose and research questions for the proposed study. This study will employ the PNI paradigm which emphasizes the relationships among person factors (age, sex, income, education, employment status, marital status, and living situation), perceived stress (diagnosis of chronic illness of T2DM), psychosocial factors identified as significant to diabetes from the scientific literature (perceived stress including anxiety, depression, diabetes distress, social support, self-management, and loneliness) are moderated by coping patterns. This framework provides an organizing structure for how these concepts work together to describe health outcomes, all based in disciplinary perspective of the human-environment-health relationship which is the perspective of nursing (Smith, 2019).

\section{Significance}

This study contributes to nursing knowledge by addressing the concepts of stress and coping in the context of the PNI paradigm and by accounting for the conceptual confluence of human-environmenthealth relationship. The relevant area of inquiry addressed in this study is stress, coping, and adaptation 
throughout the life process. The proposed study offers a holistic approach to the care of patients living with T2DM in Appalachia, the experienced multidimensional environment. This study is innovative because these variables have not been studied in a comprehensive way to fully explicate the nature of the relationships. People living diabetes should be assessed for psychosocial factors such as anxiety, depression, diabetes distress, social support, self-management, and loneliness. This is a disruptive innovation as it refers to a new process or new idea (Innovation Enterprise Channels, 2019). This includes considering the whole person in their environment. There is a critical need for interventions that reflect comprehensive, precise, and collaborative care. Coping and adaptive strategies are possessed by the person. Findings will contribute to the discipline of nursing because it is related to human-environment-health (Smith, 2019).

The diagnosis of T2DM and living with this chronic illness imposes lifestyle changes and thus produces stress that is additive to the current condition of stressors produced from daily humanenvironment interactions. These individuals are attempting to adapt to the uncertainty of the new diagnosis of T2DM with what they view as the most effective coping pattern (Smith, 2019). The coping and adaptive strategies that are possessed by a person are utilized to promote health, healing, and wellbeing. Coping patterns are derived from a blend of perceived source of stress, optimistic or pessimistic outlook, and personality characteristics. Coping patterns reflect the collection of responses to the stress that the person has available and can use successfully or be taught through modeling (Sahler \& Carr, 2009). Knowing the relationships between person factors, psychosocial factors, diagnosis of T2DM, coping patterns, and health outcomes has the potential to inform and change nursing practice. New knowledge that contributes to understanding these factors and relationships among them will be foundational to the development of future interventions for stress, coping, and adaptation throughout the lived experience of T2DM. 
The findings of this study have potential to offer some direction for community and state-based policy. Social determinants of health such as poverty, access to care, and social support have an influence over well-being (Smith, 2019). Policymakers need to consider that person factors of a socioeconomic nature contribute to the health of people living with T2DM (Bonilla, Rodriguez-Gutierrez, \& Montori, 2016). This study is important because it has the potential to identify modifiable targets for intervention (Gonzalez-Zacarias, Mavarez-Martinez, Arias-Morales, Stoicea, \& Rogers, 2016). Effective interventions are needed to diminish negative psychosocial factors while facilitating coping. This is essential to improved health outcomes for persons with T2DM.

\section{Conclusion}

In conclusion, this study will address the problem of stress, and describe factors that are influential to health outcomes for people living with T2DM in Appalachia, using the guiding theoretical framework of the PNI paradigm. The findings of this study have the potential to make a significant contribution to nursing knowledge by conducting the relevant inquiry of stress, coping, and adaptation throughout the life process (Smith, 2019) through the lens of the conceptual confluence of humanenvironment-health relationship.

The literature review that follows in Chapter Two is a comprehensive integrated review that will provides a synthesis of findings related to the major concepts included in the proposed study. The purpose of the integrated literature review is to describe what is known about stressors related to T2DM, specifically emphasizing the relationships among person factors, psychosocial factors, and coping patterns in people living with T2DM in north central Appalachia. 


\section{CHAPTER TWO \\ The Literature Review}

The purpose of the integrated literature review will follow in line with the purpose to explore stressors related to T2DM specifically the relationships among person factors, psychosocial factors, and coping patterns in people living with T2DM in north central Appalachia. The following concepts will be explored: stress, person factors, psychosocial factors, and coping patterns. The question guiding the integrated literature review is what is the current knowledge on stress, person factors, psychosocial factors, and coping patterns in adults with T2DM? The integrated literature review will be organized in the following way: discussion of the background of the problem, literature search strategy, results, synthesis, and summary.

\section{Background}

Diabetes is one of the major causes of disease morbidity and mortality in the United States and throughout the world (Carpenter, Theeke, Mallow, Theeke, \& Gilleland, 2017). Diabetes is a complex, debilitating illness that imposes disease burden and financial burden on the individual and society. If diabetes is poorly controlled, then patients are at risk for significant and numerous negative health outcomes such as atherosclerotic cardiovascular disease, heart failure, chronic kidney disease and many other diabetes-related complications, many of these complications are preventable (ADA, 2019).

In the United States there are 29.1 million people (9.3\%) living with diabetes (Disease DoHPac, 2019). Appalachians are 1.4 times more likely to have diabetes than non-Appalachians (Carpenter, 2012). Diabetes is more prevalent in Appalachia than in urban areas in the United States. Health inequities in patients with diabetes and complications from diabetes are well documented (CDC, 2019). West Virginia is situated in Appalachia (Carpenter et al., 2017). Notably, West Virginia is the $2^{\text {nd }}$ highest ranked nationally for diabetes where one out of every ten adults has diabetes (Disease DoHPac, 2019).

Diabetes is one of the most stressful chronic illnesses and people living with T2DM experience life challenges that requires lifestyle changes. The stressor of diabetes places significant demands on 
people living with T2DM and serves as stress. Building on previous work of concept development, a published systematic review was conducted that synthesized findings from quantitative studies that explored relationships among psychosocial determinants of health and coping in adult men and women with T2DM (McCoy \& Theeke, 2019). The next layer of knowledge discovery will include an integrated review of quantitative, qualitative and mixed methods studies. The question guiding the integrated literature review is; What is the current knowledge on stress, person factors, psychosocial factors, and coping patterns in adults with T2DM?

\section{Literature Search Strategy}

A comprehensive literature search process was performed by searching the following databases: Academic Search Complete, APA PsycARTICLES, APA Psycinfo, CINAHL with Full Text, ERIC, Health and Psychosocial Instruments (HaPI), Health Source: Nursing/Academic Edition, Medline, and Social Work Abstracts. An advanced search was conducted with Psychology (subject term) (Medline MeSH term for

Psychosocial factors) AND adaptation, psychological (subject term) (Medline MeSH term for coping) AND Diabetes Mellitus, Type 2 (subject term) AND Coping (field not specified because limited it to 18 articles) (CINHAL Heading for coping).

Initial results yielded 156 articles. The search was limited by English (146) and limited by age: all adult 19+ (122). Five additional articles were discovered on Google search. Joanna Briggs Institute and Cochrane database were also searched, but no articles that met the inclusion criteria were found. Inclusion and Exclusion Criteria

Inclusion criteria included: english speaking, adults with T2DM, and measure of psychosocial factor relative to coping. Exclusion criteria included: type 1 diabetes mellitus only, insulin use in type 1 diabetes mellitus (insulin use in T2DM only if included if relevant to adults with T2DM), only included one gender and/or family/spousal coping. 
All articles were screened to make sure the inclusion criteria were met. This resulted in twentyfour quantitative studies, five qualitative studies, and four mixed methods studies that were evaluated to develop a synthesis of meaningful findings of stress, person factors, psychosocial factors and coping in people with T2DM. Studies critiques were detailed and included querying the manuscripts for commonalities or differences in use of conceptual or theoretical frameworks to guide the studies, methods used to operationalize psychosocial factors and coping, overall study design and methods used to describe relationships among stress, person factors, psychosocial factors and coping, commonalities and differences in findings for the relationships among stress, person factors, psychosocial factors and coping patterns in people with T2DM.

\section{Quantitative Studies Included in Review}

A total of twenty-four published articles are included; twenty primary reports of quantitative research studies published between 1996 and 2019, one meta-analysis (Duangdao \& Roesch, 2008) and two systematic reviews (Thorpe, Fahey, Johnson, Deshpande, Thorpe \& Fisher, 2013; McCoy \& Theeke, 2019). The included articles reflect a global perspective on coping with T2DM as they include two reports each from Canada (Burns, Deschenes \& Schmitz, 2016; Macrodimitris \& Endler, 2001), Iran (Shayeghian, Aguilar-Vafaie, Besharat, Amiri, Parvin, Gillani \& Hassanabadi, 2015; Shamsalinia, Pourghaznein \& Parsa, 2015), Romania (Mocan, lancu, \& Băban, 2018), Sweden (Gåfvels \& Wändell, 2006; Sandén-Eriksson, 2000), and the United States (Shah, Gupchup, Borrego, Raisch \& Knapp, 2012; Duangdao \& Roesch, 2008; Thorpe et. al., 2013; Smalls, Walker, Hernandez-Tejada, Campbell, Davis \& Egede, 2012; Whitebird, Kreitzer, Vazquez-Benitez, \& Ensatd, 2018; McCoy \& Theeke, 2019). One report each was generated from KwaZulu-Natal South Africa (Ramkisson, Pillay \& Sibanda, 2017), Jordan (AlAmer, Ramjan, Glew, Randall \& Salamonson, 2016), Taiwan (Huang, Lai, Lu, Chen, Chi, Lu \& Chen 2016), Poland (Kalka, 2014), Norway (Karlsen, Oftedal \& Bru, 2012), Mexico (Garay-Sevilla, Porras \& Malacara, 2011), China (Zhang, Tse, Ye, Lin, Chen \& Chen, 2009), Portugal (Coelho, Amorim \& Prata, 2003), Japan 
(Nakahara, Yoshiuchi, Kumano, Hara, Suematsu \& Kuboki, 2006), Netherlands (Koopmanschap, 2002), and Croatia (Pipernik-Okanovic, Roglic \& Metelko, 1996).

The main findings of the current knowledge based on quantitative studies on psychosocial state and coping in adults with type 2 diabetes mellitus include: people living with diabetes need a strong social support since increased social support has been found to lead to decreased emotional distress, positive coping styles lead to better psychological and physical health, negative coping leads to negative psychological and physical health, and gender differences (McCoy \& Theeke, 2019). Additionally, most of the studies used Lazarus and Folkman's definition of coping and study instruments that were derived from the Transactional Model of Stress and Coping (TMSC) Theory (Lazarus \& Folkman, 1984).

\section{Qualitative Studies Included in Review}

The search yielded seventeen qualitative articles published from 1994-2014. After evaluation five met the inclusion criteria. The included articles reflect a global perspective on coping with T2DM as they include reports from Dominican Republic (Rodriguez, Wallace \& Barrington, 2018), Japan (Yamakawa \& Makimoto, 2007), Western Sweden (Stuckey, Mullan-Jensen, Reach, Burns, Piana, Vallis, Wens, Willaing, Skovlund \& Peyrot, 2014), Sweden (Hornsten, Sandstrom, \& Lundman, 2004), and the United States (Handron \& Leggett-Frazier, 1994).

The main findings of the qualitative studies included the following findings. Psychosocial themes that emerged from interviews concerning psychosocial stressors among people living with T2DM were sense of isolation from family members, codependency, experiences of loss, secondary stressors not related to diabetes, overuse if defense mechanisms, low self-esteem, irritability and depression (Handron \& Leggett-Frazier, 1994). Personal understandings of illness among people living with T2DM were formulated in six categories: image of disease, meaning of diagnosis, integration of illness, space for the illness, responsibility for care, and future prospects (Hornsten et. al., 2003). Three categories emerged regarding positive experiences of T2DM (positive appraisal, diversion, and bonding (Yamakawa 
\& Makimoto, 2007). Stuckey et. al., (2014) endorsed supporting people with diabetes by improving communication from health care professions about the diagnosis of diabetes. Rodriguez et. al., (2018) found that stress relating to T2DM began at diagnosis and persisted throughout management. Stress was produced by concerns about healthy food and medication access, fears about illness-induced injury, and the cyclical process of experiencing stress. Two ways of coping were identified: external and internal. External was related to their enrollment in the diabetes program and the second was internal, which consisted of not thinking about diabetes to avoid stress. Participants identified diabetes care and free medication services as external stress-reducers. Internally, participants' mitigated stress by not thinking about diabetes ("no dar mente").

\section{Mixed Methods Included in Review}

A total of four mixed methods studies met the inclusion criteria and were published between 2005-2018. These articles included reports from a Mid-South city in the United States (Decoster \& Cummings, 2005), Bronx NY (Tanenbaum, Ritholz, Binko, Baek, Shreck, \& Gonzales, 2013), Louisville KY (Hood, Irby-Shasanmi, de Groot, Martin \& LaJoie, 2018), and the Netherlands (van Dijk-de Vries, van Bokhoven, de Jong, Metsemakers, Verhaak, van der Weijden, \& van Eijk, 2016).

Six main findings were synthesized:

1. Whites reported significantly more problem-focused methods.

2. Males reported fewer coping methods, less emotion-focused coping and more problem-focused coping than females.

3. Emotion-focused coping was associated with poorer self-assessed diabetic control and problem-focused coping was associated with better self-assessed diabetic control (Decoster \& Cummings, 2005). 
4. Participants reported overlapping symptoms of diabetes and depression, burden of diabetes treatment, emotional impact of diabetes, and the bidirectional influence of depression and diabetes (Tanenbaum et. al., 2013).

5. Focus groups described regimen distress and emotional burden as the primary distress types. Emphasis was placed on the need for clinicians to prioritize mental health aspects of T2DM. A desire for culturally appropriate peer support groups as a psychosocial support resource was requested (Hood et. al., 2018).

6. People living with T2DM do not perceive discussion of psychosocial well-being as an integral part of diabetes management. Younger patients were more open to discussing psychosocial problems with the nurse than patients over 65 (van Dijk-de Vries et. al, 2016).

\section{Results}

\section{Major Concepts}

The major concepts include stress, person factors, psychosocial factors, coping patterns and the relationship among the major concepts. Sociodemographic, economic, psychological, and environmental factors are connected with T2DM management and health outcomes (Gonzalez-Zacarias, MavarezMartinez, Arias-Morales, Stoicea \& Rogers (2016). People living in Appalachia are faced with disparity in social determinants of health including lower socioeconomic status, living rurally with low resources, lower educational levels, and high prevalence of multiple chronic conditions. Known factors that are influential to coping such as marital status, socioeconomic status, and living situation.

\section{Stress}

T2DM is a complex, debilitating illness that imposes stress and financial burden on individuals and society. Stress in this study is the diagnosis of T2DM, the demands of managing a chronic illness, and all the changes the person will soon experience. Diagnosis of this chronic disease imposes 
adjustments in the patient's lifestyle. Stress is an event that the person evaluates as potentially dangerous to his or her well-being (Lazarus \& Folkman, 1987).

Knowing that stress can negatively influence health outcomes in people with T2DM there is a critical need to understand coping. McCoy \& Theeke (2019) found that understanding coping in people living with T2DM has been instrumental in adaptation to self-care. The purpose of coping is to manage or avoid anxiety caused by a stressful situation (Gåfvels \& \& Wändell, 2006). For persons living with T2DM who have anxiety, depression, or diabetes related distress, it is important to understand coping because coping patterns have been determined to play a fundamental influential role in physical and psychological well-being (Coelho, et. al., 2003).

Lazarus and Folkman's TMSC is well-recognized as the theoretical underpinning for coping. In the TMSC, the cognitive appraisal of stressors is recognized to be a determinant of subsequent health status. Likewise, the PNI paradigm accounts for individual person factors based on determinants of health and encourages discernment of patterns and consequences of stress and coping as psychosocial moderators of health.

\section{Person Factors}

The literature supports that potential stressors of T2DM can include person factors of age, sex, income, education, employment status, marital status, and living situation, psychosocial factors of anxiety, depression, diabetes distress, social support, self-management, and loneliness, and coping patterns are problematic for people living with T2DM in Appalachia.

Age. People living with T2DM are undergoing different challenges and human developmental processes as they live with this chronic illness. There are different age groups such as young adults, midlife adults, older adults, and old-old adults. It is necessary to understand these differences because younger adults diagnosed with a chronic illness will likely need adequate coping strategies that endure for many years. Similarly, different age groups will not experience the same challenges as others. 
In one study, younger patients were found to be more open to discussing psychosocial problems with the nurse than patients over the age of 65 . A mixed method study examined the readiness of patients to discuss psychosocial issues with the nurse. Patients did not perceive discussion of psychosocial well-being as an integral part of diabetes management (van Dijk-de Vries et. al., 2016). In the proposed study population, it is hoped that the findings will lead to discussion of psychosocial problems integrated in the care of people living with T2DM.

Gender and Sex. The literature revealed self-identified gender differences related to support and coping further complicate the care of people with T2DM. Knowing these differences exist in coping, assessment of biological sex and self-reported gender need incorporated in study designs (Clayton, 2018). Women have been found to lower social support which has been linked to poor health outcomes. Women also have been identified as utilizing negative coping styles which further contribute to poor health outcomes and poor quality of life (Koopmanschap, 2002). Recognizing that differences in coping exist between men and women, precise interventions for coping may be needed in adults with T2DM (McCoy \& Theeke, 2019).

Income, Education, and Employment. Socioeconomic factors like education and income tend to impact health outcomes (CardioSmart, 2016). Health outcomes of people living with T2DM were associated with socioeconomic status, self-efficacy, and quality of life (Walker, Smalls \& Egede, 2015). The median household income in WV is $25 \%$ less than the national median and the poverty rate is $18.4 \%$, higher than the national rate of $15.6 \%$ (ARC, 2017). People living in Appalachia as they are faced with disparity in social determinants of health including lower socioeconomic status, living rurally with low resources, lower educational levels, and high prevalence of multiple chronic conditions (WHO, 2019).

Health outcomes are worse in less educated people (Dupre, Silberberg, Willis, \& Feinglos, 2015). People who were single, lower education level and lower income level had a greater risk of death 
compared to those with higher socioeconomic status (CardioSmart, 2016). In WV it is reported that diabetes was highest among adults aged 45 and older, those with less than a high school education and those with an annual household income of less than $\$ 25,000$ (West Virginia Department of Health and Human Resources, 2017).

Walker et. al., (2015) found a significant positive correlation existed between employment status and glycemic control. It is reasonable to conclude that employment status correlates with income and with social support because of interaction with work colleagues.

Marital Status. Management of T2DM is influenced by marital status in that partner or spouse participation often have better glycemic control and health outcomes (Gonzalez-Zacarias et. al., 2016). Marital status has a direct link to available social support. Overall, it is consistently reported in studies of people with diabetes that greater social support from family, friends, and community are linked to better outcomes in people with diabetes (Rad, Bakht, Feizi \& Mohebi, 2013).

Living Situation. There is a documented relationship that exists between partner support and health outcomes with people living with T2DM. Assessment of the person's living situation can provide insight into what support the person may have available. Relationships and social networks are important in how individuals manage their diabetes and cope with the chronic illness of T2DM. Relationships are essential to coping and managing a chronic illness (Leustek \& Theiss, 2018).

\section{Psychosocial Factors}

Multiple psychosocial social factors have been identified as being problematic for people living with T2DM. These psychosocial factors include anxiety, depression, diabetes distress, social support, self-management, and loneliness. These psychosocial factors require complex care (McCoy \& Theeke, 2019).

Anxiety. There is a higher prevalence of anxiety in people with T2DM, compared to those without T2DM (Smith, Beland, Clyde, Gariepy, Page, Badawi, et al., 2013). People living with T2DM are 
at greater risk for developing anxiety and diabetes-related distress than individuals without type 2 diabetes mellitus (Burns et al., 2016). Studies have reported that depression and/or anxiety was associated with poor self-management (Gonzalez, Wittenberg, Safern, Blais, Cagliero, \& Meigs, 2007).

Depression. People with a diagnosis of diabetes are twice as likely to develop depression (Anderson, Freeland, Clouse, \& Lustman, 2001; Shah et. al., 2012) which is concerning because it has been reported that, people with diabetes and depressive symptoms cope more poorly when compared to those without depressive symptoms (Shah et. al., 2012). In West Virginia one forth (26\%) of people are diagnosed with depression, the highest in the nation (West Virginia Department of Health and Human Resources, 2017).

Diabetes Distress. Stress is a cause and distress is a perceived stress that is caused by living with T2DM. This chronic illness of T2DM is a stressor. Diabetes-related distress is an emotional distress specific to diabetes of feeling over-whelmed by the diabetes regimen (Polonsky, Anderson, Lohrer, Welch, Jacobson, Aponte, \& Schwartz, 1995). Different from anxiety but equally important is diabetesrelated distress (Burns et. al, 2016) which is the psychological distress related to being diagnosed with T2DM. Diabetes-related distress stems from concerns or worries associated with living with the condition of diabetes. People with distress report negative emotional responses to the diagnosis such as self-blame (Karlsen et. al., 2012).

Social Support. Increased social support has been reported to decrease emotional distress (Ramkisson et. al., 2017)and better glycated hemoglobin (A1C) levels (Shayeghian et. al., 2015). The authors discovered a positive relationship between self-efficacy and positive health outcomes (i.e. good glycemic control, adherence, and self-management). This model displayed social support indirectly influenced $\mathrm{A} 1 \mathrm{C}$ indirectly through self-efficacy.

Self-Management. Studies have reported that depression and /or anxiety was associated with poor self-management (Gonzalez et. al., 2007). Healthy coping strategies of diabetes self-management, 
education, support groups, problem solving skills were all beneficial to health outcomes (Thorpe et. al., 2013). In order to prevent the known negative health consequences of diabetes, people with diabetes must improve their self-management ability and make lifestyle adjustments (Coelho, et. al., 2003).

Loneliness. Loneliness has been found to be significant to older adults in Appalachia. Loneliness is a psychosocial factor that can impact one's health (Theeke, Goins, Moore, \& Campbell, 2012).

Loneliness has been predictive of depression (Theeke, Goins, Moore, \& Campbell, 2012; Cacioppo, Hawkley, \& Thisted, 2010). Few studies have been found to examine loneliness and diabetes, but there could be a link between depression and decreased social support that could lead to loneliness (Petitte, Mallow, Barnes, Petrone, Barr, \& Theeke, 2015).

\section{Coping Patterns}

Coping has been studied extensively in people living with T2DM. Coping is broadly defined as a response to a stressful situation. Lazarus \& Folkman (1984) defined coping as continuously changing cognitive and behavioral efforts to manage internal and/or external demands that are difficult for an individual. Coping is conceptually defined as a process of executing a response to a stressful situation. The conceptual definition of coping has been consistent with the TMSC but has been operationalized differently.

Coping is a behavior and can be a modifiable factor. Once the situation is perceived stressful a person decides what coping pattern to employ to reduce the potential harm (Vitaliano, Russo, Carr, Maiuro, \& Becker, 1985). The aim of coping is to manage or avoid anxiety caused by a situation (Gåfvels \& Wändell, 2006). Coping patterns may differ yet they have been determined to play a fundamental influential role in physical and psychological well-being (Coelho, et. al., 2003).

The synthesis of empirical evidence on coping patterns includes positive coping, negative coping, and gender differences. These categories were conceived after critique and in-depth discussion of commonalities and differences in study (McCoy \& Theeke, 2019). 
findings.

Positive Coping. Positive coping is viewed as a positive emotion or action-based response to diabetes and defined as an effective coping style that directly impacts better health benefits by lower glycosylated hemoglobin levels in patients with T2DM (Shayeghian et. al., 2015). Examples of effective coping styles are active coping, planning, positive reframing, and acceptance. Positive coping contributes to better health outcomes (Shayeghian et. al., 2015). Problem-focused coping was determined to moderate stressors and negative situations Duangdao \& Roesch (2008), coping through an emotional approach led to positive diabetes outcomes (Smalls et. al., 2012), and positive coping was inversely correlated with A1C (Shayeghian et. al., 2015). The positive emotion of hope was reported as being related to positive religious coping, marital status, and social support (Shamsalinia et. al., 2015). In addition, a positive emotional state has the potential to increase self-efficacy and may lead to positive health outcomes (Nakahara et. al., 2006). Finally, the included systematic review concluded that healthy coping strategies of diabetes self-management, education, support groups, problem solving skills were all beneficial to health outcomes (Thorpe et.al., 2013).

Negative Coping. Negative coping is defined as an emotion-focused coping strategy that increases anxiety and depression symptoms. Emotional preoccupation, which focuses on an emotional response on the illness and palliative coping to lessen the unpleasantness of the illness was correlated with depression and anxiety (Macrodimitris \& Endler, 2001). Negative coping leads to diabetes being viewed as a threat which is a contributor to a worse quality of life (Coelho et. al., 2003). Negative coping styles are reported to be significantly linked to increased anxiety and depression (Zhang et. al., 2009). In addition, negative religious coping was associated with a negative relationship of hope in older adults with T2DM (Shamsalinia et. al., 2015) and results from a path analysis demonstrate that avoidance coping leads to greater diabetes-related distress and depression symptoms (Shah et. al., 2012). 


\section{Gender Differences in Coping with T2DM}

Four studies addressed gender differences in coping with T2DM. Women with T2DM reported lower social support than men which is problematic since social support has been linked to worse outcomes. Gender differences for the coping strategies of resignation, protest, and isolation (based on the General Coping Questionnaire) were higher in women which is also problematic because they are determined to be negative coping styles. Further, poorer health-related quality of life has been reported in women with T2DM (Koopmanschap, 2002) and a second study reported that both diabetic and non-diabetic women had a poorer quality of life when compared to men (Coelho et. al., 2003). One study reported that men reported higher rates for supportive coping styles (Garay-Sevilla et. al., 2011). Relationship of Person Factors, Psychosocial Factors, and Coping Patterns

There is a gap in the literature on the understanding of the relationship among person factors, psychosocial factors, and coping patterns. Pipernik-Okanovic et al., (1996) found that perceived coping abilities were better with those with more familial support. When caring for people with depressive symptoms, anxiety, or distress, it is important for healthcare providers to understand coping because coping patterns have a fundamental role in physical and psychological well-being (Coelho, et. al., 2003). Zhang et al. (2009) reported that negative coping styles led to significantly increased anxiety and depression. Duangdao \& Roesch (2008) concluded that coping patterns aimed at addressing negative feelings and stressors commonly associated with diabetes management would have potential to improve psychological health in people with T2DM. Acceptance of the diagnosis of T2DM varies, can be influenced by psychosocial factors (anxiety, depressive symptoms, stress, diabetes distress), and may depend partially on coping abilities or response (Garay-Sevilla et al., 2011). These factors, along with the known gender differences in support and coping, further complicate the care of people with T2DM (McCoy \& Theeke, 2019). 


\section{Theoretical Framework}

The conceptual framework of the study where definitions of stress and coping were derived from the TMSC Theory (Lazarus \& Folkman, 1987). The theoretical framework underpinning this study is the Psychoneuroimmunology Paradigm (PNI). (McCain, Gray, Walter, \& Robins, 2005). The purpose of the PNI is to identify consequences of stress and coping patterns on health.

The PNI has been used as a theoretical framework to study the following chronic illnesses: cancer, HIV (McCain et. Al., 2005) and loneliness (Theeke \& Mallow, 2013). There has been research regarding Psychoneuroimmunology in the role of inflammation in disease. Researchers have discovered a wide range of chronic illnesses that are applicable to this phenomenon such as heart disease, diabetes, multiple sclerosis, Alzheimer's, and autoimmune disorders (Kendall-Thackett, 2010). The majority of the studies on diabetes have been from the medical domain. Logically, the PNI can be applied as a framework for nursing research to the chronic illness T2DM.

This study will focus on the psychobehavioral component of the paradigm which examine the relationships between person factors (age, sex, income, education, employment status, marital status, and living situation), psychosocial factors (perceived stress including anxiety, depression, diabetes distress, social support, self-management, loneliness) and coping patterns. Loneliness was a key psychosocial factor that has a major impact on health outcomes of patients with chronic illnesses in rural Appalachians (Theeke, Carpenter, Mallow, \& Theeke, 2019; Theeke, Mallow, Moore, McBurney, Rellik \& VanGilder, 2016; Theeke \& Mallow, 2013) which will be tested in this proposed study. The study variables are mapped to the PNI model below. See Figure 1. 


\section{Figure 1}

PNI Model

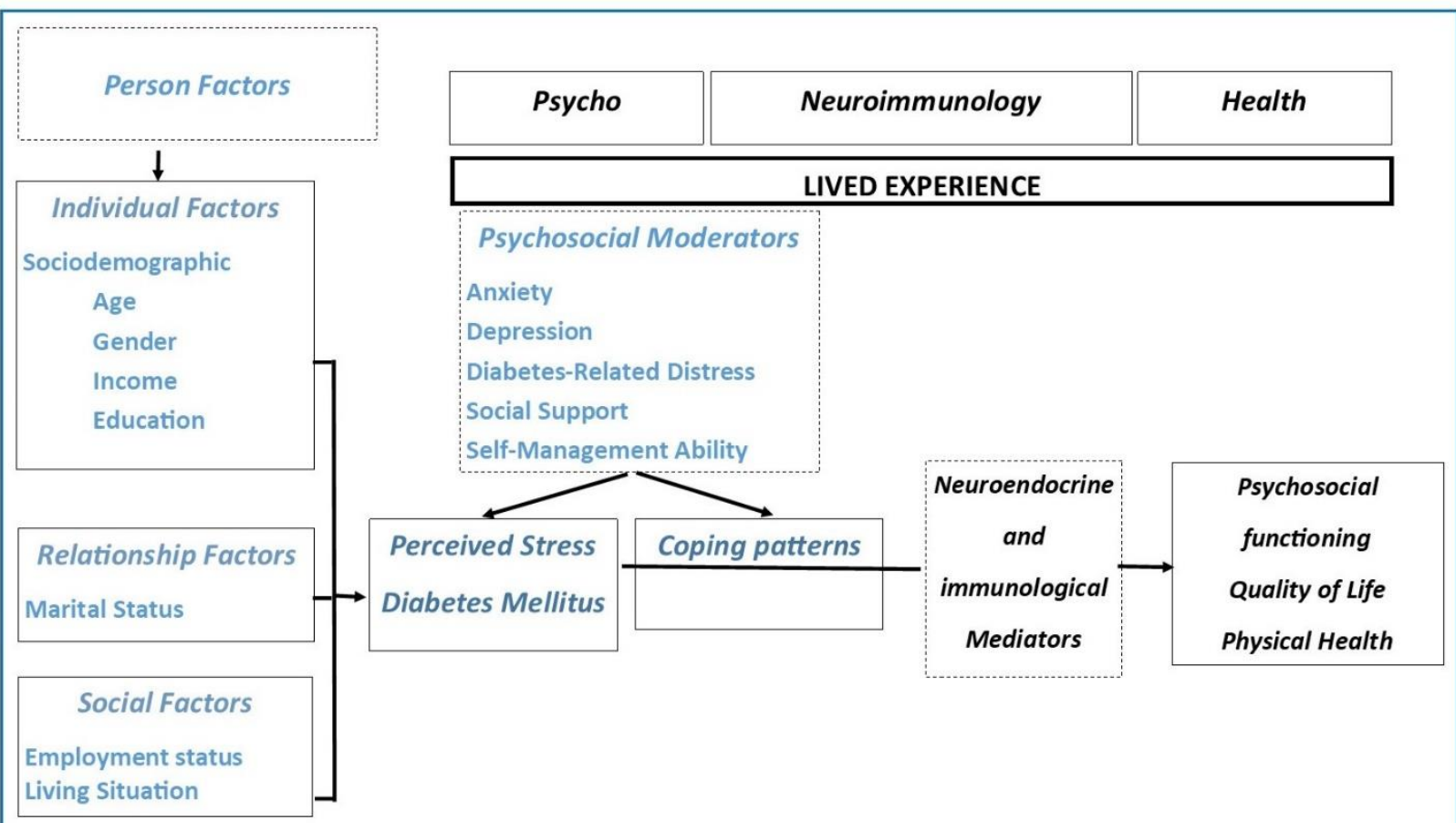

A Conceptual Model of Key Study Variables (Blue) Mapped to Major Concepts of the PNI Paradigm

\section{Synthesis}

\section{What is Known}

What is known about this phenomenon is that the last systematic review to include the relationships among psychosocial factors and coping in adult men and women with T2DM was in 2019 (McCoy \& Theeke) and before that in 2013 (Thorpe et al., 2013). A meta-analysis was conducted in 2008 by Duangdao \& Roesch (2008). Also, that problem-focused coping did not reveal a significant relationship to T2DM. Moreover, coping methods aimed at addressing negative feelings and stressors commonly associated with diabetes management would have the potential to improve psychological health in people with T2DM (McCoy \& Theeke, 2019). 


\section{What is New}

What is new and adds to the current literature includes three main findings: First, gender differences in support and coping further complicate the care of people with T2DM. Second, knowing that poorer psychological states and low social support negatively influence outcomes in people with T2DM dictates a critical need for comprehensive, precise, and collaborative care. Finally, diminishing negative psychosocial factors while facilitating coping is essential to improved health outcomes for people with T2DM (McCoy \& Theeke, 2019).

\section{Main Findings}

The main findings of the current knowledge based on quantitative studies on psychosocial state and coping in adults with T2DM include: people with diabetes need a strong social support since increased social support has been found to lead to decreased emotional distress, positive coping styles lead to better psychological and physical health, negative coping leads to negative psychological and physical health, and gender differences (McCoy \& Theeke, 2019). Additionally, most of the studies used Lazarus and Folkman's definition of coping and study instruments that were derived from the TMSC Theory (Lazarus \& Folkman, 1984).

\section{Human-Environment-Health Relationship}

There were several gaps in the literature identified to include the relationships among person factors (age, sex, income, education, employment status, marital status, and living situation), psychosocial factors (perceived stress including anxiety, depression, diabetes distress, social support, self-management, and loneliness) and coping patterns in patients living with T2DM in north central Appalachia. Another gap in the literature are the sex differences between adult men and women on psychosocial factors (perceived stress including anxiety, depression, diabetes distress, social support, self-management, and loneliness) and coping patterns in patients living with T2DM in north central Appalachia. Literature has examined these concepts individually but not in a comprehensive way. The 
gap in the literature that this study will fill is examining this phenomenon in a comprehensive, collective, holistic way through the lens of the disciplinary perspective of nursing as a human-environment-health relationship. This study will fill the gap of more precise findings on sex as a biological variable (Clayton, 2018 ) in research designs to improve health outcomes specific to sex. To improve health outcomes the National Institute of Health $(\mathrm{NIH})$ expects sex to be factored in to research designs (NIH, 2015). Finally, the gap of cultural competence will be examined in the multidimensional environment of north central Appalachia.

The human-environment-health relationship is the interconnectedness of human health with the multidimensional environment of north central Appalachia (Smith, 2019). This human-environmenthealth relationship is more than isolated and more than looking at the phenomenon singularly. This approach is integrated in how these concepts go together in totality.

The human-environment-health relationship specifically examines stress, coping, and adaptation throughout the life process. The PNI paradigm captures the multidimensional nature of the environment where people with T2DM lives. The environment includes the challenges of living in rural Appalachia, income status, and social support. All of these factors influence well-being (Smith, 2019).

This study will answer the research questions which adds to the body of knowledge of nursing. The disciplinary perspective of nursing looks through the lens of human-environment-health and how all concepts come together and relate to coping. The human-environment interactions that produce stress, and the coping and adaptive strategies promote health, healing, and well-being (Smith, 2019). Stress and coping patterns have the ability to influence health outcomes makes it critical that new knowledge is generated to inform practice.

\section{Summary}

In summary, Chapter two presented the background and an integrated review of the literature of what is the current knowledge on person factors, psychosocial factors, and coping patterns in adults 
with T2DM? A synthesis of the findings was summary to include what was known, what was new about the phenomenon, the main findings and examination of the human-environment-health relationship in the literature. These findings will contribute to the disciplinary perspective of nursing.

Chapter three will describe the methodology used to conduct this study. A descriptive, prospective, cross-sectional design will be applied to explore stressors related to T2DM specifically the relationships among person factors, psychosocial factors, and coping patterns in people living with T2DM in north central Appalachia. 


\section{CHAPTER THREE \\ Methodology}

\section{Introduction}

Chapter Three describes the research design and methodology for the study of the problem stress influences health outcomes for people living with T2DM diabetes mellitus in Appalachia. The purpose of the proposed study was to employ a quantitative, descriptive, prospective, cross-sectional design to explore stressors related to T2DM specifically the relationships among person factors, psychosocial factors, and coping patterns in people living with T2DM in north central Appalachia. This chapter is organized by a description of the research questions, research design, human subjects protection, discussion of the sample, description of the study variables and instruments, procedure for data collection, plan for data analysis, methods to assure rigor, and a summary of the chapter.

\section{Research Questions}

a. This study has the following research questions:

1. What are the relationships among person factors (age, sex, income, education, employment status, marital status, and living situation), psychosocial factors (perceived stress including anxiety, depression, diabetes distress, social support, self-management, and loneliness) and coping patterns in patients living with type 2 diabetes mellitus in north central Appalachia?

2. What are the sex differences between adult men and women on psychosocial factors (perceived stress including anxiety, depression, diabetes distress, social support, selfmanagement, and loneliness) and coping patterns in patients living with type 2 diabetes mellitus in north central Appalachia?

b. The study has the following aims and hypotheses:

Specific Aim 1: Identify and describe relationships among person factors, psychosocial factors (perceived stress including anxiety, depression, diabetes distress, social support, self- 
management, and loneliness) and coping patterns in patients living with type 2 diabetes mellitus in north central Appalachia.

Hypotheses for Aim 1 (1-4) were derived from prior studies and scientific literature review:

1. There will be a positive correlation among perceived stress of anxiety, depression, diabetes distress, and loneliness.

2. Perceived stress of anxiety, depression, diabetes distress, and loneliness will be inversely associated with social support and self-management ability.

3. Perceived stress of anxiety, depression, diabetes distress, and loneliness will be associated with poorer coping patterns.

4. Positive coping patterns will be positively related to social support and self-management ability.

Specific Aim 2: Examine and describe the sex differences for psychosocial factors (perceived stress including anxiety, depression, diabetes distress, social support, self-management, and loneliness) and coping patterns among adult patients living with type 2 diabetes mellitus in north central Appalachia.

Hypotheses for Aim 2 (5-8) were derived from prior studies and scientific literature review:

5. Women will have higher reports of anxiety, depressive symptoms, and social support when compared to men.

6. Men will have higher reports of loneliness when compared to women.

7. There will be no sex differences in diabetes distress and self-management ability.

8. Women will display more positive coping patterns when compared to men. 


\section{Research Design}

A quantitative, descriptive, correlational, prospective, cross-sectional, quantitative design of a convenience sample was utilized to explore the relationships among person factors, psychosocial factors, and coping patterns in people living with T2DM in north central Appalachia. This research design was chosen to address the research questions. Data were collected during February 2021-August 2021. The selected design was appropriate to meet the study aims as cross-sectional studies are appropriate for describing phenomena and describing relationships and looking at associations among phenomena. The participants for this study were obtained by using a convenience sample, a nonprobability sampling technique where the most conveniently available people are recruited to participate (Polit \& Beck, 2012). Individuals were in a specific location, Davis Health System, at the time of sampling. The researcher was aware that a convenience sample can produce limitations such as sampling bias, over-represented, or under-represented sample.

\section{Human Subjects Protection and Ethical Consideration (IRB)}

\section{Voluntary/Informed Consent}

Prior to conducting this study, approval was obtained through the West Virginia University Institutional Review Board (IRB). No vulnerable populations were included in this study. Participation was voluntary, and participants could withdraw at any time. No consent forms were obtained. A cover letter was used instead to describe the study and to gain consent. Individuals of any race, sex, sexual orientation, and socioeconomic status were eligible to enroll. In addition to members of the research team, research assistants and data collectors completed the certification for protection of human participants $(\mathrm{CITI})$ training.

\section{Privacy and Confidentiality}

Privacy was ensured and confidentiality of the participants was maintained. The participant was assigned a study number, which was placed on the packet of questionnaires. There was a private exam 
room that was utilized to provide a place where participants had the opportunity to complete the packet of questionnaires. Data were de-identified by the Principal Investigator (PI). All members of the research team adhered to the WVU IRB policies including adherence to the Health Insurance Portability and Accountability Act (HIPAA). Questionnaires were in a confidential manila envelope. Data from the questionnaires were stored on an encrypted universal serial bus (USB) and in a locked drawer in the home of the Primary Investigator (PI).

\section{Risks and Benefits}

The risk of participation in this study was minimal. Some participants may experience a mild emotional response to questionnaire questions. While this was unlikely to occur, a plan was developed to referred participants to their health care provider or a health care provider in a Davis Health System clinic for appropriate care. No participants needed to be referred at the time of data collection.

The findings have the opportunity to provide relevant and pertinent data that can be useful to other people living with T2DM in the future and can also be used as a foundation for an intervention. Data obtained from the questionnaires were used to answer the research questions and to add to the current knowledge of person factors, psychosocial factors, and coping of people living with T2DM with the hope to improve health outcomes in people living with T2DM. The participant benefited by receipt of a \$15 gift card once questionnaires were completed. There were no other direct benefits for the participants.

\section{Ethical Principles}

The three major ethical principles are respect for persons, beneficence, and justice (National Commission for the Protection of Human Subjects of Biomedical and Behavioral Research, 1978). Nurses have a moral obligation to adhere to the ethical principles that are required when conducting research. Institutional Review Boards (IRB) are in place to ensure ethical principles are upheld when conducting research. The IRB is a safeguard for the participants and the researcher. 


\section{Respect for Persons}

Respect for persons includes voluntary consent to participate, informed consent, privacy and confidentiality, and the right to withdraw from participating without penalty (Roberts \& Hyatt, 2019). The purpose of the study was shared with the participant. The researcher was clear and truthful about what the participant could expect to happen. It is the responsibility of the researcher to maintain anonymity and confidentiality of the participant. Data are secured to maintain integrity and confidentiality; for example, the data were stored in a locked file cabinet and on an encrypted USB drive. Participation was voluntary, and participants could withdraw at any time without penalty.

\section{Beneficence}

Beneficence includes risks justified by potential benefits, study design minimizes risks, and conflicts are managed to reduce bias (Roberts \& Hyatt, 2019). Based on the principle of beneficence, the researcher decreased risk through providing privacy, confidentiality, and healthcare if needed. Benefit was maximized through payment for time and the report of this study will be provided to the health system.

\section{Justice}

Justice is when the study does not exploit vulnerable populations, the study or exclude people who may benefit from participation, and participation is borne equally by society (Roberts \& Hyatt, 2019). The principle of justice is being reasonable, fair, equal, and nonexploitive in conducting research. Thus, with justice there is equal participation for subjects in the research study (National Commission for the Protection of Human Subjects of Biomedical and Behavioral Research, 1978). Exclusion of participants were based on the exclusion and inclusion criteria in a fair, equal, and nonexploitive manner. 


\section{Sample Selection}

\section{Sample and Subject Selection}

A convenience sample of 80 patients ( 40 men and 40 women) was

recruited from Davis Family Care and Population Health in Davis Health System located in Randolph County, WV. In order to examine and describe the sex differences, the convenience sample was balanced by sex. It is noteworthy that Davis Medical Center is the only hospital in Randolph County, West Virginia. Participants were not recruited from a specialty endocrinology clinical. Participants were patients of a family practice in the health system that provides chronic care management.

The sample size was determined based on the potential of 250 patients over the course of one year in the accessible population for sampling. When seeking to select a representative sample of the accessible population, a computed sample size calculation that considers a $95 \%$ confidence interval, $p$ value less than .05 and a 10\% margin of error yielded an adequate sample determination of 70 participants. A sample size of 80 to allow for a 10 to $15 \%$ attrition rate. The first 40 men and 40 women solicited in Davis Family Care at Davis Health System who met the inclusion/exclusion criteria and agree to participate were enrolled.

\section{Inclusion and Exclusion Criteria}

Inclusion and Exclusion criteria were as follows: adults between the age of 18 and 64 years old, able to read and write English, and diagnosed with T2DM have the potential to be included and people who are unable to complete questionnaires, diagnosed with a moderate to severe cognitive impairment, dementia, or Alzheimer's disease, or are pregnant were excluded.

\section{Recruitment}

Flyers were placed at Davis Health System's Davis Family Care/Population Health Department waiting room in Randolph County, WV. This is the only hospital in Randolph County, West Virginia. There currently is not an endocrinologist at Davis Medical Center. Known successful strategies for 
recruiting research participants in rural Appalachia were used (Carpenter $\&$ Theeke, 2018). A report was generated weekly based on the inclusion criteria to assess patients who are scheduled to be seen at Davis Family Care and Population Health at Davis Medical Center. The PI informed the nurses which patients were to be approached for recruitment. Other planned sources of recruitment, if there were less than 80 participants, would have included word of mouth and posting flyers in the community at churches, Kroger, and Walmart. Contingency plan in regard to COVID-19 if unable to obtain sample size includes direct mailings of flyers, health fairs and Rotary blood draws, and/or newspaper advertisement. Participants were screened based on inclusion and exclusion criteria. After talking to nurses and physician's at Davis Family Care it was determined that the participants would be more responsive to paper/pencil questionnaires rather than an electronic version. Also, in light of COVID-19 paper/pencil did not require routine cleaning of an electronic device. The questionnaires of the instruments were at a 14-point font for ease of reading. A packet of questionnaires was distributed for the participant to complete. Questionnaires were staggered in an order to decrease participant fatigue and to attempt to obtain complete data. Three nonparticipants completed the form in 18 minutes, 14 minutes and 25 seconds, and 13 minutes. These volunteers had a doctorate, bachelor's, and no degree respectively. The average time was calculated to be fifteen minutes; therefore, it was anticipated that the participant would spend approximately fifteen minutes completing the questionnaires. Upon completion of the questionnaires, participants received a $\$ 15$ gift card.

\section{Measures}

Data were collected on the following variables: psychosocial factors (anxiety, depression, diabetes distress, social support, self-management, and loneliness) and coping patterns.

\section{Conceptual Definition of Variables}

The following are descriptions of how each concept was operationalized. Stress was defined the same as in the TSMC Theory by Lazarus \& Folkman (1987). Stress is an event that the person evaluates 
as potentially dangerous to his or her well-being (Lazarus \& Folkman, 1987).

Anxiety and depression were conceptualized as follows: anxiety was a feeling of fear, worry, nervousness or restlessness and depression was conceptualized by feeling down or hopeless, trouble falling asleep, feeling tired, and/or trouble concentrating. Anxiety can also include somatic symptoms such as heart racing and dizziness (Patient-Reported Outcome Measurement Information SystemAnxiety, 2018). Depression negatively affects how you feel, think and act and was conceptually defined as a change in mood, a feeling of sadness or a loss of interest in pleasure (APA, 2019).

Diabetes-related distress was an emotional distress response specific to diabetes of feeling overwhelmed by the diabetes regimen. Diabetes-related distress includes areas of anger, interpersonal distress, and frustration with aspects of diabetes-related regimen (Polonsky, Anderson, Lohrer, Welch, Jacobson, Aponte, \& Schwartz, 1995). Stress was a cause and distress was a perceived stress that is caused by living with T2DM. This chronic illness of T2DM was a stressor and the diagnosis was the perceived stress.

Social support was conceptually defined as the support of others. Specifically, examining various dimensions of social support to include emotional support, tangible support, affectionate support, and positive social interaction (Sherbourne \& Stewart, 1991).

Self-management was based on the Theory of Social Production Functions where the ability to self-manage is related to the dimensions of well-being specified physical well-being and social wellbeing. These internal abilities are needed to manage losses in functioning that lead to a decreased reserve capacity for coping in such a way that physical and social wellbeing are maintained or restored when lost. Theses abilities look at initiative, resources and management of resources, attention, multifunctionality, and maintain a positive frame of mind (Cramm, Strating, de Vreede, Steverink, \& Nieboer, 2012). 
Loneliness was the discrepancy between a person's preferred and actual level of social contact (Peplau, Perlman, 1982). Loneliness was conceptually defined as a psychological construct that measure feelings of social isolation. It is also a biopsychosocial stressor that can adversely affect health (Theeke \& Mallow, 2013).

In line with the general definition proposed by Lazarus, coping was conceptually defined as a process of executing a response to a stressful situation (Lazarus \& Folkman, 1984). Based on a review of literature, Lazarus and Folkman's TMSC is the predominant theoretical underpinning of measures of coping. TMSC is a framework for appraising the process of coping with stressful events. TMSC defines stress as an event that the person evaluates as potentially dangerous to his or her well-being. For this study, the conceptual definition of coping was derived from the Lazarus \& Folkman (1987) TSMC.

McCoy and Theeke (2019) conducted a systematic review of the relationships among psychosocial factors and coping in adults with type 2 diabetes mellitus. This review revealed that coping patterns could be categorized as positive coping or negative coping. Positive coping was viewed as a positive emotion or action-based response to diabetes and defined as an effective coping style that directly impacts better health benefits by lower glycosylated hemoglobin levels in patients with type 2 diabetes (Shayeghian, Aguilar-Vafaie, Besharat, Amiri, Parvin, Gillani \& Hassanabadi, 2015). Within the context of Brief COPE (Carver, 1997) examples of effective coping styles are active coping, planning, positive reframing, and acceptance. Positive coping contributes to better health outcomes (Shayeghian, Aguilar-Vafaie, Besharat, Amiri, Parvin, Gillani \& Hassanabadi, 2015). Negative coping was defined as an emotion-focused coping pattern that increases anxiety and depression symptoms. Emotional preoccupation, which focuses on an emotional response on the illness and palliative coping to lessen the unpleasantness of the illness was correlated with depression and anxiety (Macrodimitris \& Endler, 2001). Within the context of the Brief COPE (Carver, 1997) negative coping patterns would be denial, substance use, behavioral disengagement, and self-blame. It is logical to consider that negative coping 
is a poorer coping pattern contributing to negative health outcomes. Within the context of the Brief COPE (Carver, 1997) additional coping styles not categorized as positive or negative were selfdistraction, use of emotional support, use of instrumental support, venting, humor, and religion. Operational Definition of Variables

The appropriateness of the instrument was chosen based on reliability and validity as well as the instruments are appropriate for the theoretical framework. If a short form was available and displayed good reliability and validity, then that version was chosen to decrease participant burden while completing the instruments. A simple measure of gobbledygook (SMOG) score for readability reveals a literacy level of third grade to around sixth grade. A chart of the variables, instrument, alpha, number of items and SMOG score can be found in Table 1.

\section{Table 1}

Operationalization of Self-Reported Study Variables

\begin{tabular}{|c|l|c|c|c|}
\hline Variables & \multicolumn{1}{|c|}{ Instrument } & $\boldsymbol{\alpha}$ & $\begin{array}{c}\text { \# } \\
\text { Items }\end{array}$ & SMOG \\
\hline Anxiety & $\begin{array}{l}\text { PROMIS-Emotional Distress Anxiety Short } \\
\text { Form 8a }\end{array}$ & .95 & 8 & 5.0 \\
\hline Depression & Patient Health Questionanaire-9 (PHQ-9) & .89 & 9 & 6.0 \\
\hline Diabetes Distress & Problem Areas in Diabetes (PAID) & .95 & 20 & 6.1 \\
\hline Social Support & $\begin{array}{l}\text { Medical Outcomes Survey Social Support } \\
\text { (MOS) }\end{array}$ & .91 & 18 & 5.0 \\
\hline Self-Management & $\begin{array}{l}\text { Self-Management Assessment Scale Short } \\
\text { Version (SMAS-S) }\end{array}$ & .90 & 18 & 3.6 \\
\hline Loneliness & Revised 20 items UCLAS Scale & $\begin{array}{c}.96 \\
.50-.90 \\
\text { Eleven of the } \\
\text { scales were } \\
\text { greater than } \\
.60\end{array}$ & 20 & 3.0 \\
\hline & Brief COPE & $\begin{array}{c}28 \\
.02\end{array}$ & \\
\hline
\end{tabular}

Anxiety was operationally measured with the Patient-Reported Outcomes Measurement Information System (PROMIS) anxiety-short form 8 anxiety. The PROMIS assessed feelings of fear, worry, nervousness or restlessness (Patient-Reported Outcome Measurement Information System- 
Anxiety, 2018).

Depression was operationally measured by the Patient Health Questionnaire-9 (PHQ-9). The PHQ-9 was designed to measure over the past 2 weeks, how often has the patient been bothered by little pleasure in doing things, feeling down or hopeless, trouble with asleep, feeling tired, changes in appetite, feeling bad about yourself, and/or trouble concentrating, problems with moving or speaking, and thoughts that you would be better off dead or of hurting yourself in some way (Spitzer, Williams, \& Kroenke, 1999).

Diabetes-related distress was operationalized with Problem Areas in Diabetes (PAID) scale which measures the person's perception of how they live with T2DM. PAID is a measure of psychological adjustment specific to diabetes. This tool assesses emotional distress specific to diabetes of feeling over-whelmed by the diabetes regimen including areas of anger, interpersonal distress, and frustration with aspects of diabetes-related regimen (Polonsky, Anderson, Lohrer, Welch, Jacobson, Aponte, \& Schwartz, 1995).

Social support was operationalized by Medical Outcome Survey (MOS) social support survey. The MOS examines various dimensions of social support to include emotional support, tangible support, Affectionate support, and positive social interaction (Sherbourne \& Stewart, 1991). Self-management was operationalized by the Self-Management Ability Scale (SMAS-S) which measures physical well-being and social well-being. The tool assesses initiatives, investing in resources for long-term benefits, maintaining a variety in resources, ensuring resource multifunctionality, selfefficaciously manage resources, and maintaining a positive frame of mind (Cramm, Strating, de Vreede, Steverink, \& Nieboer, 2012).

Loneliness was operationalized by the Revised UCLA Loneliness Scale Version 3. The Revised UCLA Scale Version 3 was designed to measure feelings of loneliness and social isolation. Items are phrased in questions of feelings (Russell, 1996). 
Coping, a response to a stressful situation was measured by the Brief COPE on how people with T2DM cope with this chronic illness. The scales of the Brief COPE evaluate positive coping patterns of active, planning, positive reframing, and acceptance coping, and negative coping patterns of denial, substance use, behavioral disengagement, and self-blame coping (Carver, 1997).

\section{Instruments}

Data were collected on the person factors of age, sex, income, education, employment status, marital status, and living situation. Additionally, data were collected on psychosocial factors of anxiety, depression, diabetes distress, social support, self-management, and loneliness, and coping patterns. The following variables were collected to describe the sample from the demographic sheet and examine person factors: age, sex, height, weight, ethnicity, marital status, education, income, number of people living in the home, employment status, distance from clinic, duration of illness, list of medications, and comorbidities. A weekly report from Davis Health System was generated and included measures of the participant's last A1C, and body mass index (BMI). Demographic data was collected with a self-report form that will be in the packet. All instruments are included in the Appendix.

Anxiety was assessed by the National Institute of Health (NIH) PROMIS anxiety-short from 8 Anxiety, The NIH initiative goal was to develop, validate, and standardize the way self-reported outcomes were measured in research. A series of tests were developed to measure physical, psychological and social well-being. Cronbach's alpha was .95 for Anxiety. Patterns of convergent and discriminant validity were documented (Lanting, Saffer, Koehle, \& Iverson, 2013). Each question has five possible responses. The score ranges from 8-40. The raw score is converted to a T-score from a standardized table. The T-score rescales the raw score into a standardized T-score with a mean of 50 and a standard deviation of 10. The higher the score the more anxiety (Patient-Reported Outcome Measurement Information System-Anxiety, 2018). 
Depression was assessed with the Patient Health Questionnaire-9 (PHQ-9) developed by Spitzer, Williams, \& Kroenke in 1999 by a Pfizer grant. This is nine questions self-report questionnaire based on the nine DMV-IV criteria for depressive diagnoses. Each item is scored 0-3 for a total of 0-27. The total score is assessed for level of depression. A score of 1-4 is classified as minimal depression, a score of 5-9 mild depression, a score of 10-14 moderate depression, a score of 15-19 moderately severe depression, and a score of 20-27 severe depression. The higher the score the greater the depression. Cronbach's alpha is .89. Construct and criterion validity were established (Kroenke, Spitzer, \& Williams, 2001). Diabetes distress was measured by Problem Areas in Diabetes (PAID) scale (Polonsky et. al., 1995). PAID is a 20-item measure of emotional distress that is specific to diabetes. Each item is scored on a 5-point scale of 0-4. The score is added up and multiplied by 1.25 for a possible total score of 0 100. Scores of 40 or higher indicate greater emotional distress. Extremely low scores of 0-10 with poor glycemic control indicate denial. Internal reliability for all 20 items is 0.30 or higher. Cronbach's alpha was 0.95 for the total scale. Concurrent and discriminant validity is well documented (Welch, Jacobson \& Polonsky, 1997; Polonsky et al., 1995).

Social Support was assessed MOS social support survey (Sherbourne \& Stewart, 1991). This was developed from various dimensions of social support. Cronbach's alpha is .91 and construct validity was established. This is an 18-item survey with four distinct subscales. Each question is on a 5-point Likert scale of 1-5. To score each subscale, calculate the average of the scores for each subscale. The higher score on a subscale indicates more support. To obtain an overall support index, average the scores for the 18 items.

Self-management was measured by the Self-Management Ability Scale (SMAS). This scale has 30 items that measure self-management ability. Cronbach's alpha reported an overall internal consistency of .90. Confirmatory analysis revealed indices of fit. Construct validity documented. The 
SMAS-S is a short version of the scale that is an alternate to the instrument to measure self-

management abilities. This shorter instrument decreases participant burden and makes it more practicable to assess self-management abilities in a broader number of people. This is an 18-item questionnaire that measures self-management ability. There are six 3-item subscales. The higher the score, the better the person is able to self-manage. (Cramm et. al., 2012).

Loneliness was assessed by the Revised UCLA Loneliness Scale Version 3 (Russell, 1996). The UCLA is a 20-item scale used to measure feelings of loneliness and social isolation. It is based on 4-point Likert scale of 1-4. Reverse score nine items 1, 5, 6, 9, 10, 15, 16, 19, and 20. Scores range from 20-80 with 40 being considerate moderate loneliness. Higher scores indicated greater degrees of loneliness. Cronbach's alpha is .96. Concurrent and construct validity are established (Russell, 1996). Coping was assessed by the Brief COPE. Brief COPE was developed in 1997 by Carver and is conceptually defined the same as COPE Inventory. COPE Inventory was based on the conceptual analysis of stress and coping offered by Lazarus in 1966. Brief COPE is to be applied in settings that need to minimize demands of time on participants. Brief COPE is a new scale developed from the full COPE (Carver, 1997).

Brief COPE is a 28 -item questionnaire. Respondents answer the question based on what extent you've been doing what the question says. Each question is based upon a 4-point Likert scale of 1-4: (1) I haven't been doing this at all, (2) I've been doing this a little bit, (3) I've been doing this a medium amount, and (4) I've been doing this a lot. Each number is associated with a scale and there are two questions per scale. The fourteen scales are self-distraction, active coping, denial, substance use, use of emotional support, use of instrumental support, behavioral disengagement, venting, positive reframing, planning, humor, acceptance, religion, and self-blame. Each scale is looked at separately when scoring to see what its relation is to the variables. The higher the score on the scale identifies the respondent uses that style of coping (Carver, 1997). 
Initial psychometrics was obtained from Carver (1997). The reliability was assessed with Cronbach's alphas ranging from .50-.90. Eleven of the scales were greater than .60 . The validity was established by exploratory factor analysis on the item set using oblique rotation to allow correlations among factors. The analysis yielded nine factors with eigenvalues greater than 1.0. The factor structure of Brief COPE was relatively similar to COPE Inventory (Carver, 1997). Brief COPE is free to use and in the public domain.

\section{Data Collection}

After IRB approval, the PI contacted Davis Health System to complete all necessary requirements to conduct research at the primary care clinic. Flyers were posted, and participants were solicited in Davis Family Care.

All study personnel were educated on proper procedure, inclusion and exclusion criteria, and training for research compliance and protection of human subjects. In the event recruitment did not result in 80 participants, word of mouth and posting flyers in the community at churches, Kroger, and Walmart would have been utilized.

Once the participant agreed to participate then inclusion criteria was assessed. If the participant is eligible then the purpose of the study was explained. Upon agreeing to participate the participant was assigned a study number, which was placed on the packet of questionnaires. Participants had the opportunity to complete the packet of questionnaires in a private space located in Davis Family Care. Measures of the participant's last A1C and BMI were obtained from the nurses at Davis Family Care. Demographic data were collected with a self-report form that was in the packet. The participant put the completed surveys in an envelope and returned to the PI. Once the packet was returned the participant received a $\$ 15$ gift card.

The questionnaires were transported in a sealed confidential file to the PI's home, where the files were locked. Data were entered into SPSS on and stored on an encrypted USB as the data were 
obtained. Only those identified on the approved IRB had access to the study data. All data collection forms will be kept for three years in the same private and secure location.

\section{Data Analysis}

All quantitative data were entered into SPSS, Version 26 (IBM, 2017). All quantitative data were cleaned prior to analysis. All variables were explored for missing data and only one $\mathrm{A} 1 \mathrm{C}$ was found to be missing. An average was imputed for this one value. The loneliness scale includes reverse coding for questions $1,5,6,9,10,15,16,19$, and 20 so these were recoded per scoring instructions and a new total was computed for total loneliness score. For other continuous scales new variables were computed to be sum totals. For categorical variables, data were explored for frequencies and categories with less than five per cell were collapsed so the data could be analyzed and interpreted. Age categories were collapsed and recoded to be: 18-44, 45-49, 50-54, 55-59, and 60-64. Marital status was collapsed and recoded to three categories: married with spouse present and partnered; separated, divorced, widowed, and married with spouse absent; and was never married. Income was also recategorized to be: $\$ 30,000$ or less (below poverty), $\$ 30,000-59,000$ (low income), and greater than $\$ 60,000$ (high income). Education categories became less than high school, General Educational Development (GED), high school diploma, some college, and bachelor's degree or higher. Education and income were subsequently recoded into two variables. Education as less than high school, GED and high school as one variable and some college and Bachelor's degree or higher as the second variable. Income as $\$ 30,000$ or less and $\$ 30,000$ and above. Linear regression was then employed with the independent variables that were identified significant to the categorical and the continuous outcome variables. The enter method was investigated first and then the stepwise method. Finally, when seeking predictors of religious coping age had to be recoded as two categories: aged 18-54 or aged 55-64.

Descriptive statistics of the demographic variables were used to describe the sample. Demographic variables were obtained from the self-report demographic sheet. Frequency tables to 
include numbers and percentages were generated for categorical data such as sex, age, ethnicity, marital status, education, income, and employment status, and comorbidities. Means, range, and standard deviations were calculated for continuous variables of height, weight, number of people living in the home, duration of illness, distance from clinic, A1C, BMI, and number of medications. Anxiety, depression, diabetes distress, social support, self-management, loneliness, and coping subscales are continuous variables.

\section{Comparative Analysis by Sex}

Chi-square test for independence was used to explore differences between categorical variables of sex with person factors. Chi-square tests were used for sex and categorical data (age, ethnicity, marital status, education, income, employment, individual comorbidities of hypertension, lung disease, hyperlipidemia, depression, anxiety, coronary artery disease, stroke and arthritis).

Independent-Sample $t$ tests were conducted on continuous variables to compare means for sex and continuous variables of: height, weight, A1C, BMI, living situations, miles from the clinic, how long have you had diabetes, number of regularly prescribed medications and total number of chronic conditions. Independent-Sample $t$ tests were also conducted on Self-Management Ability subscales, Medical Outcome Survey Social Support subscales, and Brief COPE subscales.

\section{Data analysis by Research Question}

Research Question (1): What are the relationships among person factors (age, sex, income, education, employment status, marital status, and living situation), psychosocial factors (perceived stress including anxiety, depression, diabetes distress, social support, self-management, and loneliness) and coping patterns in patients living with type 2 diabetes mellitus in north central Appalachia?

Data Analysis for Research Question 1 and corresponding hypotheses 1-4. Person factors are categorical and psychosocial factors are continuous variables. Preliminary analyses were performed and revealed no violation of the assumption of normality, linearity and homoscedasticity. Loneliness (as 
measured by UCLA Loneliness Scale Version 3), depression (as measured by the PHQ-9), and selfmanagement ability (as measured by SMAS-S) were normally distributed so Pearson's $r$ was utilized. Preliminary analyses were performed and revealed a violation of the assumption of normality, linearity and homoscedasticity. Anxiety (as measured by the PROMIS), diabetes distress (as measured by PAID), social support (as measured by Medical Outcomes Survey Social Support) and coping (as measured by Brief COPE) were not normally distributed so Spearman rho was utilized. To adjust for social demographic variables (such as age, sex) and other variables, for continuous variable of the sum score of coping patterns, a general linear model (GLM) was employed.

Research Question 2: What are the sex differences between adult men and women on psychosocial factors (perceived stress including anxiety, depression, diabetes distress, social support, self-management, and loneliness) and coping patterns in patients living with type 2 diabetes mellitus in north central Appalachia?

Data Analysis for Research Question 2 and corresponding hypotheses 5-8. Initially, an Independent-Sample $t$ Test was used to test a significant difference between male and female group on the variables. Test for Equality of Variances was used to test the assumption that the variances for the two groups are equal. Furthermore, to test the effects of sex, an interaction term between sex and other factors was added in the multivariate GLMs. Then, multivariate GLMs stratified by sex was applied to adjust for potential factors.

\section{Analysis for Predictors of Coping Patterns}

GLM was used to identify predictors of each dependent variable. Each coping subscale was entered one at a time as the dependent variable. Bivariable GLM was used to examine the association of each independent variable with single outcome. Variables with $p$ value less than 0.2 in bivariable GLM were entered in multivariable GLM. Categorical variables were entered as fixed factors and continuous variables were entered as covariates. Variables with significance less than 0.2 under corrected model on 
tests of between subject effects were obtained. Correlation analysis was performed to check to see if any of the continuous variables had strong correlation coefficients $(r)$ values with $<-0.9$ or $>0.9$ showing multicollinearity. Multicollinearity was addressed by removing variables that had moderate to high intercorrelation. Models were explored that included the interrelated variables and without the interrelated variables and the predictors did not change. Variables that were significantly related to each other were removed. Multivariable GLM was used for each outcome to identify predictors. Variables with significance at .05 or less under corrected model on tests of between subject effects were then placed in the model. Height was not included because it cannot be modified and therefore would not be useful as a predictor. Subsequent analysis included multiple general linear models to explore each predictor of coping.

To adjust for social demographic variables (such as age, sex) and other variables, for continuous variable of the sum score of coping patters, a GLM was employed. Originally data analysis was planned to test effects of sex, an interaction between sex and other factors added in the multivariate GLMs. Multivariate GLMs stratified by sex was not available because the statistical program does not provide a $p$ value, only a mean value. No further exploration was possible for those coping patterns that indicated sex as a predictor. Finally, reliability of all study instruments were examined using Cronbach's alpha.

\section{Limitations}

Convenience sampling was a limitation of the study. Collecting data from a single state (WV) might limit the generalizability. WV's population is 93\% Caucasian; however, an effort to enroll other underrepresented minorities into the study were made. Recruitment from community health centers would increase the generalizability of the findings to other Appalachian regions. Those who volunteered to complete the packet of questionnaires may be participants who are doing it for the honorarium or be proactive in taking on their diabetes.

\section{Proposed Study Timeline}


The study was completed within the first 6 months: relationships were established with the Chief Medical Officer of Davis Health System, Catherine "Mindy" Chua, Whitney Mayle, BSN, RN, Clinical Nurse Manager for Physician Practices at Davis Medical Center, and Tiffany Auvil, Population Health Nurse Manager. Staff were educated, flyers posted, and a packet of questionnaires was distributed. This packet included instruments to complete. Recruitment, education, and data collection occurred over the months 1 to 6 . Data entry occurred in months 3 to 6 . Data cleaning, analysis, and reporting of preliminary results occurred in months 6 to 8 .

\section{Methods to Assure Rigor}

Quality assurance and data integrity techniques included data management protocols and an audit trail of the data management decisions (Roberts, Anthony, Madigan \& Chen, 1997; Wynd \& Schmidt, 2003). Other data integrity techniques included developing guides for verification of data, coding each subject's data, analyzing for data distributional features and meeting statistical assumptions prior to quantitative analyses, and the need for transformations (Keppel \& Wickens, 2004). Random audits of the data were performed by members of the research team for inter-rater reliability. Reasons for refusal to participate were recorded. Assistance to the participant was provided as the participant completes the questionnaires. The purpose in assisting the participant was to decrease the burden on the participant and allow the participant to ask questions so the participant is clear on how to answer the question.

\section{Summary}

In conclusion, Chapter Three discussed the methods used to complete this study. The research questions, research design, human subjects protection and ethical consideration, sample selection, measures of study variables and instruments, procedures of data collection, the plan for data analysis, and methods to assure rigor were discussed. 
Chapter Four will discuss the results of the analysis of the data collected. Contents of this chapter will include a description of the sample and significant findings of the study. 


\section{CHAPTER FOUR \\ Results}

This study examined relationships among person factors, psychosocial factors, and coping patterns in people living with T2DM in north central Appalachia. Data were collected from a small rural clinic in Elkins, WV. The purpose of this chapter is to provide a description of the sample and present the results of the dataset.

\section{Obtaining the Study Sample}

Participants were recruited over a six-month period from February 2021-August 2021. Contingency plan of direct mailings of flyers, health fairs and Rotary blood draws, and/or newspaper advertisement in regard to COVID-19 was not employed. The sampling goal was reached within the planned time frame with all participants enrolling at Davis Family Care in-person. Due to COVID-19, no participants were able to be recruited from Population Health. In addition, no other recruitment strategies were used or needed.

\section{Sample Description}

All 80 participants indicated that they have a diagnosis of T2DM. Age was recorded in categories because of IRB recommendations due to potential identifier in a small rural clinic, Davis Medical Center. The largest segment of the sample included those aged 60-64 (31.3\%), white (97.5\%), who are married with spouse present or partnered (60\%), with a high school education $(30 \%)$, an income level less than $\$ 30,000(61.3 \%)$, and unemployed (63.7\%). Frequency tables to include numbers and percentages were generated for categorical data such as age, ethnicity, marital status, education, income, and employment status. A detailed description of the sample of categorical variables is in Table 2 . 


\section{Table 2}

Sociodemographic Characteristics of the Sample of Categorical Variables

\begin{tabular}{|c|c|c|}
\hline Variable & Category & $\mathrm{n}(\%)$ \\
\hline \multirow[t]{5}{*}{ Age } & $18-44$ & $12(15)$ \\
\hline & $45-49$ & $8(10)$ \\
\hline & $50-54$ & $17(21)$ \\
\hline & $55-59$ & $18(23)$ \\
\hline & $60-64$ & $25(31)$ \\
\hline \multirow[t]{3}{*}{ Ethnicity } & White & $78(98)$ \\
\hline & American Indians or Alaskans & $1(1)$ \\
\hline & Other race & $1(1)$ \\
\hline
\end{tabular}

Marital Status

Married with spouse present or partnered $48(60)$

Separated, divorced, widowed, or married with spouse absent $27(34)$

Never Married $5(6)$

Education

Less than High School

$14(18)$

GED

$10(13)$

High School Diploma

$24(30)$

Some College

$18(23)$

Bachelor's Degree or higher

14 (18)

Income

30,000 or less

49 (61)

30,000-59,000

$18(23)$

Greater than 60,000

$13(16)$

Employment Status

Not Employed

$51(64)$

Employed

$29(36)$

Note. Percentages may not equal $100 \%$ exactly due to rounding.

The most common eight comorbidities collected by National data collection efforts such as those from the National Health and Nutrition Examination Survey (NHANES) were collected in this study. Data were collected and ordered based on most common comorbidities were high blood pressure (55\%), hyperlipidemia (53.8\%), depression (27.5\%), lung disease (20\%), anxiety (17.5\%), coronary artery disease (12.5\%), arthritis (12.5\%), and stroke (1.3\%). Nineteen people had zero comorbidities and one 
person had all eight comorbidities. Average number of comorbidities in addition to T2DM was 2.11 with a Standard Deviation of 1.916.

The largest part of the sample had a mean A1C of 8.2114, BMI of 37.3849, live with 1.45 people in the home, live 10.2188 miles from Davis Family Care, have had T2DM for 8.6178 years, and are prescribed 9.4 medications a day. All participants have a diagnosis of T2DM and live in West Virginia. Means, range, and standard deviation were calculated for continuous variables of height, weight, number of people living in the home, duration of illness, distance from clinic, A1C, BMI and number of daily prescribed medications. A detailed description of the sociodemographic characteristics of continuous variables can be found in Table 3.

\section{Table 3}

Sociodemographic Characteristics of the Sample of Continuous Variables.

\begin{tabular}{lcc}
\hline & Mean (SD) & Range \\
\hline Height in inches & $67.0(4.45)$ & $57-75$ \\
Weight in pounds & $241.4(65.73)$ & $113-408$ \\
Living Situation & $1.5(1.18)$ & $0-4$ \\
$\begin{array}{l}\text { Years lived with } \\
\text { T2DM }\end{array}$ & $8.6(7.97)$ & $.08-30$ \\
$\begin{array}{l}\text { Miles from clinic } \\
\text { A1C }\end{array}$ & $10.2(11.31)$ & $1-48$ \\
$\begin{array}{l}\text { BMI } \\
\text { Number of daily } \\
\text { prescribed } \\
\text { medications }\end{array}$ & $37.4(8.74)$ & $20.45-65.56$ \\
\end{tabular}


Participants were on at least one medication and up to 28 medications a day. Below is a chart of the most common medications prescribed. A detailed description of the daily prescribed medications can be found in Table 4.

\section{Table 4}

Daily Prescribed Medications

\begin{tabular}{|l|l|l|}
\hline \multicolumn{1}{|c|}{ Medication classification } & $\begin{array}{c}\text { Most Commonly Prescribed Medication } \\
\text { Generic (Brand) }\end{array}$ & Participants (n) \\
\hline Biguanides antidiabetics & Metformin (Glucophage) & 49 \\
\hline Statin HMG-CoA reductase inhibitor & Atorvastatin (Lipitor) & 42 \\
\hline Proton Pump Inhibitor (PPI) & Omeprazole (Prilosec) & 31 \\
\hline Ace inhibitor & Lisinopril (Zestril) & 27 \\
\hline Beta blocker & Metoprolol (Lopressor) & 24 \\
\hline Calcium channel blocker & Amlodipine (Norvasc) & 21 \\
\hline $\begin{array}{l}\text { Selective Serotonin reuptake inhibitor } \\
\text { (SSRI) }\end{array}$ & Escitalopram (Lexapro) & 19 \\
\hline Antiseizure/anticonvulsant & Gabapentin (Neurontin) & 18 \\
\hline T4 synthetic & Levothyroxine (Synthroid) & 15 \\
\hline Angiotensin receptor blocker (ARB) & Losartan (Cozaar) & 14 \\
\hline $\begin{array}{l}\text { Sulfonylureas } \\
\text { antidiabetics }\end{array}$ & $\begin{array}{l}\text { Glipizide (Glucotrol) } \\
\text { Glimepiride (Amaryl) }\end{array}$ \\
\hline Sitagliptin (Januvia) & 21 \\
\hline
\end{tabular}

\section{Differences in Psychosocial Variables and Coping Styles by Sex}

\section{Differences by Sex in Categorical Variables}

Chi-square test for independence indicated significant differences between sex and all of the other person factors including age, ethnicity, marital status, education, income, employment, individual comorbidities of hypertension, lung disease, hyperlipidemia, depression, anxiety, coronary artery 
disease, stroke and arthritis. There was minimal variability with ethnicity as 78 out of the 80 participants were white. Chi-square was also not available for looking for differences between stroke and sex because only one participant answered yes to have a stroke. More women belonged to the age group 60-64, had a high school diploma, and were unemployed. More men were married or married with spouse absent, had higher incomes, had more comorbidities. Ethnic groups were primarily white for both males and females. Hypertension, hyperlipidemia, and depression were seen more commonly in women. Coronary artery disease and stroke were seen more commonly in men. Lung disease and anxiety were equally distributed in men and women. A detailed description of the differences between categorical variables can be found in Table 5 . 


\section{Table 5}

Chi-Square of Categorical Variables

\begin{tabular}{|c|c|c|c|c|}
\hline Variable & Category & $\begin{array}{l}\text { Male\% } \\
(n=40)\end{array}$ & $\begin{array}{l}\text { Female\% } \\
(n=40)\end{array}$ & $\begin{array}{l}\text { Chi-Square } \\
\text { ( } p-\text { value) }\end{array}$ \\
\hline \multirow[t]{6}{*}{ Age } & $18-44$ & $5(13)$ & $7(18)$ & \\
\hline & $45-49$ & $6(15)$ & $2(5)$ & \\
\hline & $50-54$ & $8(20)$ & $9(23)$ & \\
\hline & $55-59$ & $11(28)$ & $7(18)$ & \\
\hline & $60-64$ & $10(25)$ & $15(38)$ & \\
\hline & & & & $4.281 p=0.369$ \\
\hline \multirow[t]{4}{*}{ Marital Status } & $\begin{array}{l}\text { Married with } \\
\text { spouse present } \\
\text { or partnered }\end{array}$ & $27(68)$ & $21(16)$ & \\
\hline & $\begin{array}{l}\text { Separated, } \\
\text { Divorced, } \\
\text { Widowed, or } \\
\text { Married with } \\
\text { Spouse absent }\end{array}$ & $11(28)$ & $16(40)$ & \\
\hline & Never married & $2(5)$ & $3(8)$ & \\
\hline & & & & $1.876, p=0.391$ \\
\hline \multirow[t]{8}{*}{ Education } & $\begin{array}{l}\text { Less than high } \\
\text { school }\end{array}$ & $8(20)$ & $6(15)$ & \\
\hline & GED & $5(13)$ & $5(13)$ & \\
\hline & High School & $7(18)$ & $17(43)$ & \\
\hline & Diploma & & & \\
\hline & Some College & $12(30)$ & $6(15)$ & \\
\hline & Bachelor's & $8(20)$ & & \\
\hline & $\begin{array}{l}\text { Degree or } \\
\text { Higher }\end{array}$ & & $6(15)$ & \\
\hline & & & & $6.738, p=0.150$ \\
\hline \multirow[t]{5}{*}{ Income } & 30,000 or less & $19(48)$ & $30(75)$ & \\
\hline & $30,000-59,000$ & $11(28)$ & $7(18)$ & \\
\hline & Greater than & $10(25)$ & $3(8)$ & \\
\hline & 60,000 & & & \\
\hline & & & & $7.81, p=0.028$ \\
\hline Are you & Yes & $17(43)$ & $12(30)$ & \\
\hline \multirow[t]{2}{*}{ Employed } & No & $23(58)$ & $28(70)$ & \\
\hline & & & & $1.352, p=0.245$ \\
\hline Other health & Yes & $34(85)$ & $36(90)$ & \\
\hline
\end{tabular}




\begin{tabular}{|c|c|c|c|c|}
\hline Variable & Category & $\begin{array}{l}\text { Male\% } \\
(n=40)\end{array}$ & $\begin{array}{l}\text { Female\% } \\
\qquad(n=40)\end{array}$ & $\begin{array}{l}\text { Chi-Square } \\
(p-\text { value) }\end{array}$ \\
\hline \multirow{2}{*}{$\begin{array}{l}\text { Conditions } \\
\text { (comorbidities) }\end{array}$} & No & $6(15)$ & $4(10)$ & \\
\hline & & & & $.457 p=0.499$ \\
\hline \multirow[t]{3}{*}{ Hypertension } & Yes & $21(53)$ & $23(58)$ & \\
\hline & No & $19(48)$ & $17(43)$ & \\
\hline & & & & $.202 p=0.653$ \\
\hline \multirow[t]{3}{*}{ Lung disease } & Yes & $8(20)$ & $8(20)$ & \\
\hline & No & $32(80)$ & $32(80)$ & \\
\hline & & & & $.000 p=1.000$ \\
\hline \multirow[t]{3}{*}{ Hyperlipidemia } & Yes & $21(53)$ & $22(55)$ & \\
\hline & No & $19(48)$ & $18(45)$ & \\
\hline & & & & $.050 p=0.823$ \\
\hline \multirow[t]{3}{*}{ Depression } & Yes & $9(23)$ & $13(33)$ & \\
\hline & No & $31(78)$ & $27(68)$ & \\
\hline & & & & $1.003 p=0.317$ \\
\hline \multirow[t]{3}{*}{ Anxiety } & Yes & $7(18)$ & $7(18)$ & \\
\hline & No & $33(83)$ & $33(83)$ & \\
\hline & & & & $.000 p=1.000$ \\
\hline Coronary & Yes & $7(18)$ & $3(8)$ & \\
\hline Artery & No & $33(83)$ & $37(93)$ & \\
\hline \multicolumn{5}{|l|}{ Disease } \\
\hline & & & & $1.829 p=0.176$ \\
\hline \multirow[t]{3}{*}{ Arthritis } & Yes & $5(13)$ & $5(13)$ & \\
\hline & No & $35(88)$ & $35(88)$ & \\
\hline & & & & $.000 p=1.000$ \\
\hline
\end{tabular}

Note. Percentages may not equal $100 \%$ exactly due to rounding.

A chi-square test for independence indicated a significant difference between sex and income was the only statistically significant finding in categorical variables, $\left[x^{2}(2, n=80)=7.128, p=.028\right.$, Cramer's V =.298]. Men were more likely to have an income of $\$ 30,000$. See Figure 2 for a bar chart of sex and income. 
There was no significance for the remaining variables of age, ethnicity, marital status, education, employment, other comorbidities yes/no, and individual comorbidities of hypertension, lung disease, hyperlipidemia, depression, anxiety, coronary artery disease, stroke, and arthritis.

\section{Figure 2}

Sex and Income

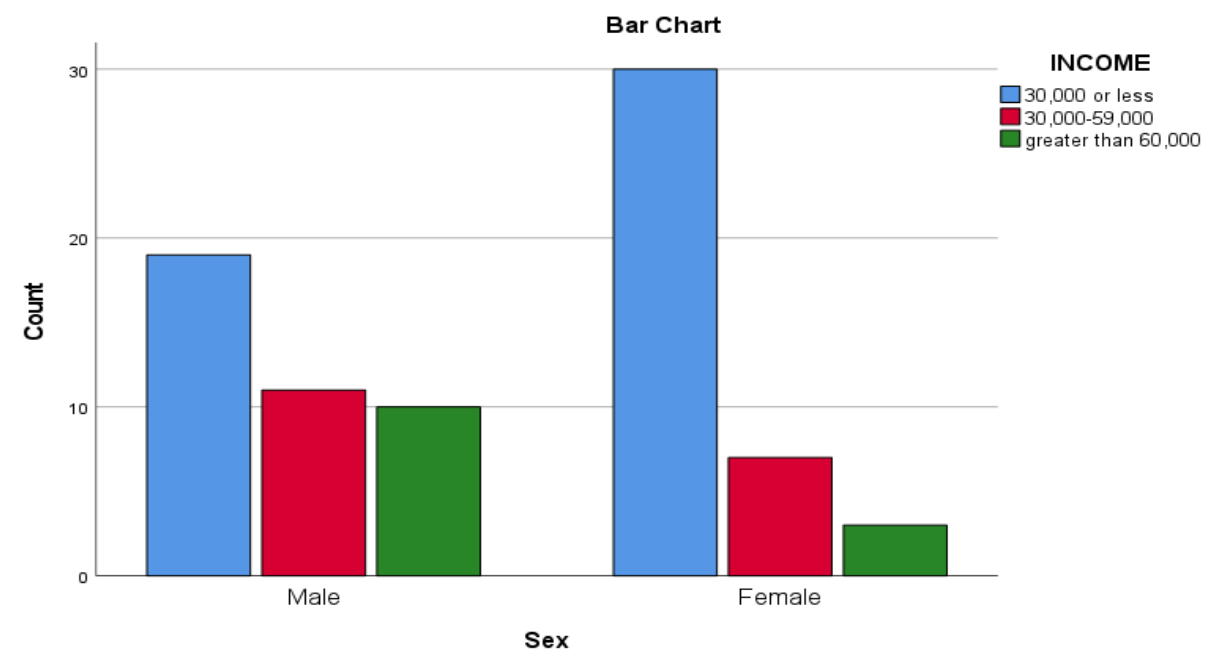

\section{Mean Comparisons Based on Sex for Continuous Variables}

An Independent-samples $t$ - test was conducted to compare height, weight, A1C, BMI, living situations, miles from the clinic, how long have you had diabetes, number of regularly prescribed medications, total number of chronic conditions, Self-Management Ability subscales, Medical Outcome Survey Social Support subscales, and Brief COPE subscales for males and females. There were no significant differences in scores for males and females except for height in inches, weight in pounds, Total PAID, and Brief COPE subscales of planning, positive reframing, religion, use of instrumental support, venting, and self-blame.

There was a significant difference in scores for height in inches for males $(M=70.04, S D=3.371$ and females $(\mathrm{M}=64.03, \mathrm{SD}=3.192 ; \mathrm{t}(78)=.774, p=.000$, two-tailed $)$. The magnitude of the 
differences in the means (mean difference $=6.012,95 \% \mathrm{Cl}: 4.551$ to 7.474 ) was large (eta squared $=$ $.774)$.

There was a significant difference in scores for weight in pounds for males $(M=262.08, S D=$ 64.678 and females $(M=220.72, S D=64.674 ; t(78)=.179, p=.004$, two-tailed $)$. The magnitude of the differences in the means (mean difference $=41.357,95 \% \mathrm{Cl}: 14.427$ to 69.288 ) was large (eta squared $=$ $.179)$.

There was a significant difference in the total scores for PAID for males ( $M=12.47, S D=13.615$ and females $(M=27.22, S D=20.744 ; t(67.341)=-3.760, p=<.001$, two-tailed $)$. The magnitude of the differences in the means (mean difference $=-14.750,95 \% \mathrm{Cl}:-6.920$ to -22.580 ) was small (eta squared $=$ $.034)$.

There was a significant difference in scores for Brief COPE subscale planning coping for males (M $=4.5500, \mathrm{SD}=1.89399$ and females $(\mathrm{M}=5.4000, \mathrm{SD}=1.90546 ; \mathrm{t}(77.997)=-2.001, p=.049$, two-tailed $)$. The magnitude of the differences in the means (mean difference $=-.85000,95 \% \mathrm{Cl}:-.00430$ to 1.69570 ) was large (eta squared $=.980$ ).

There was a significant difference in scores for Brief COPE subscale positive reframing coping for males $(M=4.1250, S D=1.74220$ and females $(M=5.1750, S D=1.99856 ; t(76.575)=-2.505, p=.014$, two-tailed). The magnitude of the differences in the means (mean difference $=-1.05000,95 \% \mathrm{Cl}$ : -.21517 to 1.88483 ) was large (eta squared $=.310$ ).

There was a significant difference in scores for Brief COPE subscale religion coping for males ( $M$ $=3.8250, \mathrm{SD}=2.07411$ and females $(\mathrm{M}=5.3250, \mathrm{SD}=2.44307 ; \mathrm{t}(75.999)=-2.960, p=.004$, two-tailed $)$. The magnitude of the differences in the means (mean difference $=-1.50000,95 \% \mathrm{Cl}:-.49078$ to -2.50922 ) was moderate (eta squared $=.079$ ).

There was a significant difference in scores for Brief COPE subscale use of instrumental support coping for males $(M=3.8750, S D=1.53902$ and females $(M=4.7500, S D=2.08474 ; t(5.159)=-2.136, p$ 
$=.036$, two-tailed). The magnitude of the differences in the means (mean difference $=-.87500,95 \% \mathrm{Cl}$ :

-.05820 to -1.69180 ) was small (eta squared $=.026$ ).

There was a significant difference in scores for Brief COPE subscale venting coping for males ( $M$ $=3.1500, \mathrm{SD}=1.45972$ and females $(\mathrm{M}=3.9000, \mathrm{SD}=1.70670 ; \mathrm{t}(76.169)=-2.112, p=.038$, two-tailed $)$. The magnitude of the differences in the means (mean difference $=-.75000,95 \% \mathrm{Cl}:-.04307$ to -1.45720 ) was moderate (eta squared $=.094)$.

There was a significant difference in scores for Brief COPE subscale self-blame coping for males $(M=2.9500, S D=1.51826$ and females $(M=4.1000, S D=2.15787 ; t(70.013)=-2.757, p=.007$, twotailed). The magnitude of the differences in the means (mean difference $=.41718,95 \% \mathrm{Cl}:-.31946$ to -1.98054 ) was very small (eta squared $=.001)$.

There was no significance mean differences in the following variables: $\mathrm{A} 1 \mathrm{C}, \mathrm{BMI}$, living situations, miles from the clinic, how long have you had diabetes, number of regularly prescribed medications and total number of chronic conditions and all subscales. A detailed description of mean comparisons of all continuous variables can be found in Table 6. 


\section{Table 6}

Mean comparisons for height, weight, A1C, BMI, living situations, miles from the clinic, how long have you had diabetes, number of regularly prescribed medications, total number of chronic conditions, SelfManagement Ability subscales, Medical Outcome Survey Social Support subscales, and Brief COPE subscales by sex

\begin{tabular}{|c|c|c|c|c|c|}
\hline \multirow[t]{2}{*}{ Outcome } & \multirow[t]{2}{*}{ Group } & \multicolumn{2}{|c|}{ Baseline } & \multirow[t]{2}{*}{$\boldsymbol{t}$} & \multirow[t]{2}{*}{$p$} \\
\hline & & Mean & SD & & \\
\hline \multirow{2}{*}{ Height } & Female & 64.03 & 3.192 & \multirow{2}{*}{8.190} & \multirow{2}{*}{$.000^{* * *}$} \\
\hline & Male & 70.04 & 3.371 & & \\
\hline \multirow{2}{*}{ Weight } & Female & 220.72 & 60.748 & \multirow{2}{*}{2.948} & \multirow{2}{*}{$.004^{*}$} \\
\hline & Male & 262.08 & 64.674 & & \\
\hline \multirow{2}{*}{$\mathrm{A} 1 \mathrm{C}$} & Female & 8.4678 & 2.81189 & \multirow{2}{*}{-.902} & \multirow{2}{*}{.370} \\
\hline & Male & 7.9550 & 2.24202 & & \\
\hline \multirow{2}{*}{ BMI } & Female & 37.5030 & 7.80581 & \multirow{2}{*}{-.120} & \multirow{2}{*}{.905} \\
\hline & Male & 37.2668 & 9.67599 & & \\
\hline \multirow{2}{*}{ Living situation } & Female & 1.30 & 1.244 & \multirow{2}{*}{1.140} & \multirow{2}{*}{.258} \\
\hline & Male & 1.60 & 1.105 & & \\
\hline \multirow{2}{*}{ Miles from the clinic } & Female & 10.4875 & 12.35038 & \multirow{2}{*}{-.211} & \multirow{2}{*}{.833} \\
\hline & Male & 9.9500 & 10.30982 & & \\
\hline \multirow{2}{*}{ How long have you had diabetes } & Female & 8.8418 & 8.07295 & \multirow{2}{*}{-.250} & \multirow{2}{*}{.803} \\
\hline & Male & 8.3938 & 7.96858 & & \\
\hline \multirow{2}{*}{$\begin{array}{l}\text { Number of regularly prescribed } \\
\text { medications }\end{array}$} & Female & 10.03 & 6.777 & \multirow{2}{*}{-0.56} & 395 \\
\hline & Male & 8.78 & 6.278 & & .390 \\
\hline Total number of chronic & Female & 2.0250 & 1.77573 & 406 & 686 \\
\hline conditions & Male & 2.2000 & 2.06559 & .400 & \\
\hline Total PROMIS & Female & 18.43 & 8.970 & -2812 & 006 \\
\hline Iotal PRUIVIS & Male & 13.45 & 6.687 & -2.812 & .006 \\
\hline Total PAID & Female & 27.22 & 20.744 & -3.760 & $<001^{* *}$ \\
\hline TOLd PAIV & Male & 12.47 & 13.615 & -3.100 & $<.001$ \\
\hline Totall ONF & Female & 42.48 & 13.303 & 1007 & 060 \\
\hline TOLal LUIVE & Male & 37.28 & 10.978 & -1.907 & .000 \\
\hline Total PHO-9 & Female & 9.00 & 7.031 & -2814 & 006 \\
\hline roldring-y & Male & 5.15 & 5.041 & -2.014 & .000 \\
\hline Taking Initiatives & Female & 8.7949 & 2.92160 & -980 & 330 \\
\hline & Male & 8.1000 & 3.35735 & -9.80 & \\
\hline Investment Behavior & Female & 9.175 & 3.47804 & & 873 \\
\hline Investment Benavior & Male & 9.3000 & 3.50969 & .160 & $.8 / 3$ \\
\hline Variety & Female & 7.7000 & 2.86625 & 039 & 969 \\
\hline varrecy & Male & 7.7250 & 2.87329 & .039 & .969 \\
\hline Multifunctionality & Female & 8.4250 & 2.44831 & 647 & 519 \\
\hline IVIuititunctionality & Male & 8.7500 & 2.02231 & .647 & .519 \\
\hline Self-Efficacy & Female & 10.2250 & 2.08151 & .054 & .957 \\
\hline
\end{tabular}




\begin{tabular}{|c|c|c|c|c|c|}
\hline \multirow[t]{2}{*}{ Outcome } & \multirow[t]{2}{*}{ Group } & \multicolumn{2}{|c|}{ Baseline } & \multirow[t]{2}{*}{$t$} & \multirow[t]{2}{*}{$p$} \\
\hline & & Mean & SD & & \\
\hline & Male & 10.2500 & 2.06000 & & \\
\hline \multirow{2}{*}{ Positive Frame of Mind } & Female & 8.5750 & 3.03727 & \multirow{2}{*}{-.076} & \multirow{2}{*}{.940} \\
\hline & Male & 8.5250 & 2.84639 & & \\
\hline \multirow{2}{*}{ Emotional Support } & Female & 3.7857 & 1.83803 & \multirow{2}{*}{.465} & \multirow{2}{*}{.643} \\
\hline & Male & 3.9429 & 1.09075 & & \\
\hline \multirow{2}{*}{ Tangible Support } & Female & 4.1500 & 2.49538 & \multirow{2}{*}{.303} & \multirow{2}{*}{.763} \\
\hline & Male & 4.2813 & 1.12971 & & \\
\hline \multirow{2}{*}{ Affectionate Support } & Female & 4.1583 & 1.14476 & \multirow{2}{*}{1.700} & \multirow{2}{*}{.093} \\
\hline & Male & 4.5500 & .90125 & & \\
\hline \multirow{2}{*}{ Positive Social Interaction } & Female & 3.733 & 1.32519 & \multirow{2}{*}{2.704} & \multirow{2}{*}{.008} \\
\hline & Male & 4.4333 & 1.32519 & & \\
\hline \multirow{2}{*}{ Active Coping } & Female & 5.1750 & 1.63123 & \multirow{2}{*}{-1.972} & \multirow{2}{*}{.052} \\
\hline & Male & 4.4250 & 1.76704 & & \\
\hline \multirow{2}{*}{ Planning Coping } & Female & 5.4000 & 1.90546 & \multirow{2}{*}{-2.001} & \multirow{2}{*}{$.049^{*}$} \\
\hline & Male & 4.5500 & 1.89399 & & \\
\hline Positive Reframino Coning & Female & 5.1750 & 1.99856 & -2505 & $014^{*}$ \\
\hline Positive KeIraming coping & Male & 4.1250 & 1.74220 & -2.505 & \\
\hline & Female & 5.9500 & 1.95527 & & \\
\hline Acceptance Copıng & Male & 5.1500 & 1.75339 & -1.921 & .058 \\
\hline & Female & 3.3750 & 1.70501 & 066 & 948 \\
\hline Humor coping & Male & 3.4000 & 1.69161 & .066 & .948 \\
\hline & Female & 5.3250 & 2.44307 & & $0^{*}$ \\
\hline Religion Coping & Male & 3.8250 & 2.07411 & -2.960 & .004 \\
\hline Ucino Emotional cunnort Coning & Female & 4.9250 & 1.95527 & 601 & 518 \\
\hline Using Emotional support Coping & Male & 4.6500 & 1.75339 & -.604 & .548 \\
\hline Using Instrumental Support & Female & 4.7500 & 2.08474 & 2126 & ${ }^{*}$ \\
\hline Coping & Male & 3.8750 & 1.53902 & -2.136 & .036 \\
\hline Self-Distraction Coning & Female & 4.8000 & 1.72760 & -2295 & 024 \\
\hline sell-Ulstraction Coping & Male & 3.9000 & 1.78023 & & \\
\hline & Female & 3.2000 & 1.89737 & -2125 & 037 \\
\hline Denıal Copıng & Male & 2.4500 & 1.17561 & -2.125 & $.03 /$ \\
\hline Ventino Coning & Female & 3.9000 & 1.70670 & 2112 & $020^{*}$ \\
\hline venting coping & Male & 3.1500 & 1.45972 & -2.112 & .038 \\
\hline & Female & 2.3500 & 1.29199 & & \\
\hline Substance Use Coping & Male & 2.3750 & 1.00480 & .096 & .924 \\
\hline Behavioral Disengagement & Female & 3.1750 & 1.58337 & 1855 & 067 \\
\hline Coping & Male & 2.6250 & 1.00480 & -1.855 & $.06 /$ \\
\hline Self_Blame Coning & Female & 4.1000 & 2.15787 & -2757 & $007 * *$ \\
\hline selt-Blame coping & Male & 2.9500 & 1.51826 & -2.151 & .007 \\
\hline
\end{tabular}




\section{Specific Aims}

\section{Specific Aim 1: Relationships among Person Factors, Psychosocial Factors and Coping Patterns}

\section{Correlation among Perceived Stress of Anxiety, Depression, Diabetes Distress, and Loneliness}

There was a strong positive correlation between anxiety, depression $(r=.685, \mathrm{n}=80, p<.000)$, diabetes distress $(r=.575, \mathrm{n}=80, p<.001)$, and loneliness $(r=.668, \mathrm{n}=80, p<.000)$. There was a strong positive correlation between depression, diabetes distress $(r=.616, \mathrm{n}=80, p<.000)$ and loneliness $(r=$ $.646, \mathrm{n}=80, p<.000)$. There was a moderate positive correlation between diabetes distress and loneliness

$(r=.467, \mathrm{n}=80, p<.000)$. Hypothesis one of a positive correlation among perceived stress of anxiety, depression, diabetes distress, and loneliness was supported. The results are reported in Table 7. 
Table 7

Correlations of Anxiety, Depression, Diabetes Distress, Loneliness

\begin{tabular}{|c|c|c|c|c|c|c|c|}
\hline Variable & $\mathrm{N}$ & $M$ & SD & 1 & 2 & 3 & 4 \\
\hline 1. Anxiety & 80 & 15.94 & 8.250 & _- & & & \\
\hline 2. Depression & 80 & 7.08 & 6.380 & $0.685^{* *}$ & - & & \\
\hline 3. Diabetes Distress & 80 & 19.84 & 18.948 & $0.575^{* *}$ & $0.616^{* *}$ & _ & \\
\hline 4. Loneliness & 80 & 39.88 & 12.398 & $0.668 * *$ & $0.646 * *$ & $0.467 * *$ & \\
\hline
\end{tabular}

Note. ${ }^{*}$ means $p$ value was $\leq .05,{ }^{* *}$ means $p$ value was $\leq .01$

Note. Anxiety was measured with PROMIS, depression was measured with PHQ-9, Diabetes Distress measured with PAID, and loneliness measured with UCLA Loneliness Scale Version 3. 
Association of Perceived Stress of Anxiety, Depression, Diabetes Distress, and Loneliness with Social Support and Self-Management Ability

Hypothesis two of perceived stress of anxiety, depression, diabetes distress, and loneliness will be inversely associated with social support and self-management ability was partially supported. Anxiety was positively associated with depression, diabetes distress, and loneliness and inversely associated with emotional support, affectionate support, positive social interaction, taking initiatives, investment behavior, variety, multifunctionality, self-efficacy, and positive frame of mind. Depression was positively associated with diabetes distress, and loneliness and was inversely associated with emotional support, tangible support, affectionate support, positive social interaction, taking initiatives, investment behavior, variety, and self-efficacy. Emotional support correlates significantly with tangible support, affectionate support, positive social interaction, taking initiatives, investment behavior, variety, multifunctionality, self-efficacy, and positive frame of mind. Tangible support correlates significantly with affectionate support, positive social interaction, investment behavior, multifunctionality, and selfefficacy. Affectionate support correlates significantly with positive social interaction, investment behavior, self-efficacy, and positive frame of mind. Positive social interaction correlates significantly with taking initiatives, investment behavior, variety, multifunctionality, self-efficacy, and positive frame of mind. Taking initiatives correlates significantly with investment behavior, variety, multifunctionality, self-efficacy, and positive frame of mind. Investment behavior correlates significantly with variety, multifunctionality, self-efficacy, and positive frame of mind. Variety correlates significantly with multifunctionality, self-efficacy, and positive frame of mind. Multifunctionality correlates significantly with self-efficacy and positive frame of mind. Self-Efficacy correlates significantly with positive frame of mind. Correlation of anxiety, depression, diabetes distress, and loneliness with social support and selfmanagement ability. The results are reported in Table 8. 


\section{Table 8}

Correlations of Anxiety, Depression, Diabetes Distress, and Loneliness with Social Support and Self-Management Ability

\begin{tabular}{|c|c|c|c|c|c|c|c|c|c|c|c|c|c|c|}
\hline Variable & 1 & 2 & 3 & 4 & 5 & 6 & 7 & 8 & 9 & 10 & 11 & 12 & 13 & 14 \\
\hline 1. Anxiety & - & & & & & & & & & & & & & \\
\hline 2. Depression & $0.685^{* *}$ & - & & & & & & & & & & & & \\
\hline $\begin{array}{l}\text { 3. Diabetes } \\
\text { Distress }\end{array}$ & $0.564^{* *}$ & $0.616^{* *}$ & - & & & & & & & & & & & \\
\hline 4. Loneliness & $0.668 * *$ & $0.656^{* *}$ & $0.467^{* *}$ & - & & & & & & & & & & \\
\hline $\begin{array}{l}\text { 5. Emotional } \\
\text { Support }\end{array}$ & $-.363^{* *}$ & $-.412 * *$ & $-.221 *$ & $-.601 * *$ & - & & & & & & & & & \\
\hline $\begin{array}{l}\text { 6. Tangible } \\
\text { Support }\end{array}$ & -.127 & $-.242 *$ & -.189 & $-.431 * *$ & $.581 * *$ & - & & & & & & & & \\
\hline $\begin{array}{l}\text { 7. Affection } \\
\text { ate } \\
\text { Support }\end{array}$ & $-.388 * *$ & $-.402 * *$ & $-.286^{*}$ & $-.631 * 0$ & $.573^{* *}$ & $.602^{* *}$ & - & & & & & & & \\
\hline $\begin{array}{l}\text { 8. Positive } \\
\text { Social } \\
\text { Interaction }\end{array}$ & $-.423 * *$ & $-.432 * *$ & $-.395 * *$ & $-.616 * *$ & $.628^{* *}$ & $.588^{* *}$ & $.745^{* *}$ & - & & & & & & \\
\hline $\begin{array}{l}\text { 9. Taking } \\
\text { Initiatives }\end{array}$ & $-.278^{*}$ & $-.314 * *$ & -.181 & $-.396 * 0$ & $.354 * *$ & .154 & .162 & $.304 * *$ & - & & & & & \\
\hline $\begin{array}{l}\text { 10. Invest } \\
\text { ment } \\
\text { Behavior }\end{array}$ & $-.261^{*}$ & $-.229^{*}$ & $-.225^{*}$ & $-.442^{* *}$ & $.372 * *$ & $.254^{*}$ & $.316^{* *}$ & $.394^{* *}$ & $.709 * *$ & - & & & & \\
\hline 11. Variety & $-.429 * *$ & $-.284^{*}$ & -.187 & $-.441 * *$ & $.310^{* *}$ & .142 & .215 & $.267^{*}$ & $.511^{* *}$ & $.580 * *$ & - & & & \\
\hline $\begin{array}{l}\text { 12. Multifun } \\
\text { ctionality }\end{array}$ & $-.221 *$ & -.185 & -.153 & $-.346 * *$ & $.275^{*}$ & $.240^{*}$ & .144 & $.255^{*}$ & $.348^{* *}$ & $.392^{* *}$ & $.386 * *$ & - & & \\
\hline $\begin{array}{l}\text { 13. Self- } \\
\text { Efficacy }\end{array}$ & $-.463 * *$ & $-.364^{* *}$ & $-.275^{*}$ & $-.579 * *$ & $.372 * *$ & $.312 * *$ & $.333^{* *}$ & $.374 * *$ & $.542^{* *}$ & $.486 * *$ & $.548^{* *}$ & $.488^{* *}$ & - & \\
\hline $\begin{array}{l}\text { 14. Positive } \\
\text { Frame of } \\
\text { Mind }\end{array}$ & $-.346 * *$ & -.208 & -.028 & $-.337 * *$ & $.259^{*}$ & .111 & $.230^{*}$ & $.246^{*}$ & $.494^{* *}$ & $.301 * *$ & $.383^{* *}$ & $.375^{* *}$ & $.351 * *$ & - \\
\hline
\end{tabular}

Note. ${ }^{*}$ means $p$ value was $\leq .05, * *$ means $p$ value was $\leq .01$

Note. Anxiety was measured with PROMIS, depression was measured with PHQ-9, Diabetes Distress measured with PAID, loneliness measured with UCLA Loneliness Scale Version 3, Social Support was measured with Medical Outcome Survey (MOS) Social Support, and SelfManagement ability was measured with Self-Management Ability Scale-Short Scale. 


\section{Perceived Stress of Anxiety, Depression, Diabetes Distress, and Loneliness associated with Coping Patterns}

Hypothesis three of perceived stress of anxiety, depression, diabetes distress, and loneliness will be associated with poorer coping patterns was partially supported. Anxiety correlates significantly with depression, diabetes distress, loneliness, Brief COPE subscale denial, Brief COPE subscale selfdisengagement, and Brief COPE subscale self-blame. Depression correlates statistically significant with anxiety, diabetes distress, loneliness, and Brief COPE subscale self-disengagement, and Brief COPE subscale self-blame. Diabetes distress correlates statistically significant with anxiety, depression, loneliness, Brief COPE subscale denial, Brief COPE subscale behavioral disengagement, and Brief COPE subscale self-blame. Loneliness correlates statistically significant with anxiety, depression, diabetes distress, Brief COPE subscale denial, Brief COPE subscale behavioral disengagement, and Brief COPE subscale self-blame. Brief COPE subscale denial correlates statistically significant with anxiety, depression, diabetes distress, loneliness, Brief COPE subscale behavioral disengagement, and Brief COPE subscale self-blame. Brief COPE subscale substance use correlates statistically significant with Brief COPE subscale behavioral disengagement. Brief COPE subscale behavioral disengagement correlates statistically significant with anxiety, depression, diabetes distress, loneliness, Brief COPE denial, Brief COPE substance use, and Brief COPE self-blame. Brief COPE subscale self-blame correlates statistically significant with anxiety, depression, diabetes distress, loneliness, Brief COPE subscale denial, and Brief COPE subscale behavioral disengagement. Correlation of anxiety, depression, diabetes distress, and loneliness with Brief COPE negative coping subscales of denial, substance use, behavioral disengagement, and self-blame coping. The results are reported in Table 9. 
Table 9

Correlations of Anxiety, Depression, Diabetes Distress, Loneliness, and BRIEF COPE Subscales

\begin{tabular}{|c|c|c|c|c|c|c|c|c|c|c|c|}
\hline Variable & $n$ & $M$ & SD & 1 & 2 & 3 & 4 & 5 & 6 & 7 & 8 \\
\hline 1. Anxiety & 80 & 15.94 & 8.250 & - & & & & & & & \\
\hline 2. Depression & 80 & 7.08 & 6.380 & $.685^{* *}$ & - & & & & & & \\
\hline 3. Diabetes Distress & 80 & 19.84 & 18.948 & $.575^{* *}$ & $.616^{* *}$ & - & & & & & \\
\hline 4. Loneliness & 80 & 39.88 & 12.398 & $.668^{* *}$ & $.656^{* *}$ & $.467^{* 8}$ & - & & & & \\
\hline 5. Denial Coping & 80 & 2.8250 & 1.61304 & $.338^{* *}$ & $.282^{*}$ & $.251^{*}$ & $.423^{* *}$ & - & & & \\
\hline $\begin{array}{l}\text { 6. Substance Use } \\
\text { Coping }\end{array}$ & 80 & 2.3625 & 1.16101 & .118 & .039 & .039 & .104 & .144 & - & & \\
\hline $\begin{array}{l}\text { 7. Behavioral } \\
\text { Disengagement } \\
\text { Coping }\end{array}$ & 80 & 2.9000 & 1.34635 & $.380^{* *}$ & $.369^{* *}$ & $.370^{* *}$ & $.480^{* *}$ & $.334^{* *}$ & $.332^{* 8}$ & - & \\
\hline 8. Self-Blame Coping & 80 & 3.5250 & 1.94204 & $.544^{* *}$ & $.568^{* *}$ & $.659^{* *}$ & $.472^{* *}$ & $.454^{* *}$ & .159 & $.369^{* *}$ & - \\
\hline
\end{tabular}

Note. * means $p$ value was $\leq .05,{ }^{* *}$ means $p$ value was $\leq .01$.

Note. Anxiety was measured with PROMIS, depression was measured with PHQ-9, Diabetes Distress measured with PAID, and loneliness

measured with UCLA Loneliness Scale Version 3. Coping was measured with Brief COPE. Denial, Substance Use, Behavioral

Disengagement, and Self-Blame are negative coping subscales.| 


\section{Coping Patterns related to Social Support and Self-Management Ability}

Hypothesis four of positive coping patterns will be positively related to social support and selfmanagement ability was partially supported. Correlations of positive coping subscales of active, planning, positive reframing, and acceptance with social support and self-management ability. The results are reported in Table 10.

Active coping correlates statistically significant with planning coping, positive reframing coping, acceptance coping, investment behavior, and positive frame of mind. Planning coping correlates statistically significant with positive reframing coping, acceptance coping, taking initiatives, investment behavior, variety, multifunctionality, and positive frame of mind. Positive reframing coping correlates statistically significant with acceptance coping, taking initiatives, investment behavior, self-efficacy, and positive frame of mind. Acceptance coping correlates statistically significant with taking initiatives, invest behavior, variety, self-efficacy, and positive frame of mind. Emotional support correlates statistically significant with tangible support, affectionate support, positive social interaction, taking initiatives, investment behavior, variety, multifunctionality, self-efficacy, and positive frame of mind. Tangible support correlates statistically significant with affectionate support, positive social interaction, investment behavior, multifunctionality, and self-efficacy. Affectionate support correlates statistically significant with positive social interaction, investment behavior, self-efficacy, and positive frame of mind. Positive social interaction correlates statistically significant with taking initiatives, investment behavior, variety, multifunctionality, self-efficacy, and positive frame of mind. Taking initiatives correlates statistically significant with investment behavior, variety, multifunctionality, self-efficacy, and positive frame of mind. Investment behavior correlates statistically significant with variety, multifunctionality, self-efficacy, and positive frame of mind. Variety correlates statistically significant with multifunctionality, self-efficacy, and positive frame of mind. Multifunctionality correlates 
statistically significant with self-efficacy, and positive frame of mind. Self-efficacy correlates statistically significant positive frame of mind. 


\section{Table 10}

Correlations of Positive Coping of Active, Planning, Positive Reframing, and Acceptance with Social Support and Self-Management Ability

\begin{tabular}{|c|c|c|c|c|c|c|c|c|c|c|c|c|c|c|}
\hline Variable & 1 & 2 & 3 & 4 & 5 & 6 & 7 & 8 & 9 & 10 & 11 & 12 & 13 & 14 \\
\hline 1. Active & - & & & & & & & & & & & & & \\
\hline 2. Planning & $.552^{* *}$ & - & & & & & & & & & & & & \\
\hline $\begin{array}{l}\text { 3. Positive } \\
\text { Reframing }\end{array}$ & $.498^{* *}$ & $.572 * 0$ & - & & & & & & & & & & & \\
\hline 4. Acceptance & $.359^{* *}$ & $.616^{* *}$ & $.476 * *$ & - & & & & & & & & & & \\
\hline $\begin{array}{l}5 \text { Emotional } \\
\text { Support }\end{array}$ & .059 & .190 & .178 & .120 & - & & & & & & & & & \\
\hline $\begin{array}{l}\text { 6. Tangible } \\
\text { Support }\end{array}$ & .158 & .123 & .077 & .130 & $.581^{* *}$ & - & & & & & & & & \\
\hline $\begin{array}{l}\text { 7. Affectionate } \\
\text { Support }\end{array}$ & .024 & .097 & .097 & .118 & $.573^{* *}$ & $.602^{* *}$ & - & & & & & & & \\
\hline $\begin{array}{l}\text { 8. Positive } \\
\text { Social } \\
\text { Interaction }\end{array}$ & .026 & .142 & .142 & .138 & $.628^{* *}$ & $.588^{* *}$ & $.745^{* *}$ & - & & & & & & \\
\hline $\begin{array}{l}\text { 9. Taking } \\
\text { Initiatives }\end{array}$ & .175 & $.266^{*}$ & $.350^{* *}$ & .176 & $.354^{* *}$ & .154 & .162 & $.304 * *$ & - & & & & & \\
\hline $\begin{array}{l}\text { 10. Invest } \\
\text { ment } \\
\text { Behavior }\end{array}$ & $.274^{*}$ & $.281^{\circ}$ & $.244^{*}$ & $.238^{\circ}$ & $.372^{* *}$ & $.254^{*}$ & $.316^{* 0}$ & $.394 * *$ & $.720^{* *}$ & - & & & & \\
\hline 11. Variety & .208 & $.231^{\circ}$ & .194 & $.282^{\circ}$ & $.310 * 0$ & .142 & .215 & $.267^{*}$ & $.446 * *$ & $.538 * *$ & - & & & \\
\hline $\begin{array}{l}\text { 12. Multi- } \\
\text { functionality }\end{array}$ & .170 & $.236^{*}$ & .188 & .197 & $.275^{*}$ & $.240^{*}$ & .144 & $.255^{*}$ & $.361^{* *}$ & $.378^{* *}$ & $.416^{* *}$ & - & & \\
\hline $\begin{array}{l}\text { 13. Self- } \\
\text { Efficacy }\end{array}$ & .180 & .197 & $.237^{*}$ & $.302^{* *}$ & $.372^{* *}$ & $.312^{* *}$ & $.333^{* *}$ & $.374^{*}$ & $.517^{* *}$ & $.492^{* *}$ & $.555^{* *}$ & $.577^{* *}$ & - & \\
\hline $\begin{array}{l}\text { 14. Positive } \\
\text { Frame of } \\
\text { Mind }\end{array}$ & $.287^{* *}$ & $.366^{* *}$ & $.532 * *$ & $.391^{* *}$ & $.259^{*}$ & .111 & $.230^{*}$ & $.246^{*}$ & $.414^{* *}$ & $.259^{*}$ & $.367^{* *}$ & $387^{* *}$ & $.329^{* 0}$ & - \\
\hline
\end{tabular}

Note. ${ }^{*}$ means $p$ value was $\leq .05,{ }^{* *}$ means $p$ value was $\leq .01$

Note. Positive Coping was measured by Brief COPE subscales of Active, Planning, Positive reframing, and Acceptance. Social Support was

measured with Medical Outcome Survey (MOS) Social Support, and Self-Management ability was measured with Self-Management Ability Scale-

Short Scale. 


\section{Specific Aim 2: Sex Differences for Psychosocial Factors and Coping Patterns}

\section{Sex and Anxiety, Depressive Symptoms, and Social Support}

Hypothesis five of women will have higher reports of anxiety, depressive symptoms, and social support when compared to men was partially supported. Females have higher reports of anxiety and depression. The only significance found in social support was men and social support subscale positive social interaction. No statistical significance was found in social support subscales Emotional Support items, Tangible Support items, and Affectionate Support items.

There was a significant difference in anxiety scores for males $(M=13.45, S D 6.687)$ and females $(\mathrm{M}=18.43, \mathrm{SD} 8.970 ; \mathrm{t}(72.120)=-2.812, p=.006$ two-tailed $)$. The magnitude of the differences in means (mean difference $=-4.975,95 \% \mathrm{Cl}:-8.501$ to -1.1449 ) was very small (eta squared $=.007$ )

There was a significant difference in depression scores for males ( $M=5.15$, SD 5.041) and females $(\mathrm{M}=9.00, \mathrm{SD} 7.031 ; \mathrm{t}(78)=-2.814, p=.006$ two-tailed). The magnitude of the differences in means (mean difference $=-3.850,95 \% \mathrm{Cl}:-6.578$ to -1.122 ) was very small (eta squared $=.017$ ).

There was a significant difference in positive social interaction scores for males ( $M=4.4333, S D$ $.96136)$ and females $(M=3.7333, \mathrm{SD} 1.32519 ; \mathrm{t}(78)=2.704, p=.008$ two-tailed $)$. The magnitude of the differences in means (mean difference $=.70000,95 \% \mathrm{Cl}: .18387$ to 1.21613 ) was very small (eta squared $=.004)$. A detailed description of mean comparisons for anxiety, depression, and social support based on sex for details can be found in Table 11. 


\section{Table 11}

Mean comparisons for anxiety, depression, and social support by sex

\begin{tabular}{|c|c|c|c|c|c|c|}
\hline \multirow[t]{2}{*}{ Outcome } & \multirow[t]{2}{*}{ Group } & \multicolumn{2}{|c|}{ Baseline } & \multirow[t]{2}{*}{$t$} & \multirow[t]{2}{*}{$p$} & \\
\hline & & Mean & SD & & & \\
\hline \multirow{2}{*}{ Anxiety } & Female & 18.43 & 8.970 & \multirow{2}{*}{-2.812} & \multirow{2}{*}{.006} & \multirow[t]{2}{*}{$* *$} \\
\hline & Male & 13.45 & 6.687 & & & \\
\hline \multirow{2}{*}{ Depression } & Female & 9.00 & 7.031 & \multirow{2}{*}{-2.814} & \multirow{2}{*}{.006} & $* *$ \\
\hline & Male & 5.15 & 5.041 & & & \\
\hline \multirow{2}{*}{ Emotional Support } & Female & 3.7857 & 1.83803 & \multirow{2}{*}{.465} & \multirow{2}{*}{.643} & \\
\hline & Male & 3.9429 & 1.09075 & & & \\
\hline \multirow{2}{*}{ Tangible Support } & Female & 4.1500 & 2.49538 & \multirow{2}{*}{.303} & \multirow{2}{*}{.763} & \\
\hline & Male & 4.2813 & 1.12971 & & & \\
\hline \multirow{2}{*}{ Affectionate Support } & Female & 4.1583 & 1.14476 & \multirow{2}{*}{1.700} & \multirow{2}{*}{.093} & \\
\hline & Male & 4.5500 & .90125 & & & \\
\hline \multirow{2}{*}{ Positive Social Interaction } & Female & 3.7333 & 1.32519 & \multirow{2}{*}{2.704} & \multirow{2}{*}{$.008^{* *}$} & $* *$ \\
\hline & Male & 4.4333 & .96136 & & & \\
\hline
\end{tabular}

Note. ${ }^{*}=p \leq .05,{ }^{* *}=p \leq .01$.

\section{Sex and Loneliness}

Hypothesis six of men will have higher reports of loneliness when compared to women was not supported. Women had higher reports of loneliness, but not significant at .06. There was no significant difference in scores for males $(M=37.28, S D 10.978)$ and females $(M=42.48, S D 13.303 ; F=3.635, p=$ .06 two-tailed). The magnitude of the differences in means (mean difference $=-5.2,95 \% \mathrm{Cl}:-10.632$ to .232 ) was very small (eta squared $=.045$ ).

\section{Sex and Diabetes Distress and Self-Management Ability}

Hypothesis seven of there will be no sex differences in diabetes distress and self-management ability was partially supported. There was significance for women with diabetes distress. There was no significance for self-management ability including subscales of Taking Initiatives, Investment Behavior, Variety, Multifunctionality, Self-Efficacy, and Positive Frame of Mind based on sex.

There was a significant difference in diabetes-related distress scores for males ( $M=12.47$, SD 13.615) and females $(M=27.22, \mathrm{SD} 20.744 ; \mathrm{t}(67.341)=-3.760, p=<.001$ two-tailed $)$. The magnitude of 
the differences in means (mean difference $=-414.750,95 \% \mathrm{Cl}:-22.580$ to -6.920 ) was very small (eta squared $=<.001)$. A detailed description of mean comparisons for diabetes-related distress and selfmanagement ability by sex for details can be found in Table 12 .

\section{Table 12}

Mean comparisons for diabetes-related distress and self-management ability by sex

\begin{tabular}{|c|c|c|c|c|c|c|}
\hline \multirow[t]{2}{*}{ Outcome } & \multirow[t]{2}{*}{ Group } & \multicolumn{2}{|c|}{ Baseline } & \multirow[t]{2}{*}{$\boldsymbol{t}$} & \multirow{2}{*}{\multicolumn{2}{|c|}{$p$}} \\
\hline & & Mean & SD & & & \\
\hline \multirow{2}{*}{ Diabetes-Related Distress } & Female & 27.22 & 20.744 & \multirow{2}{*}{-3.760} & \multirow{2}{*}{$<.001$} & $* *$ \\
\hline & Male & 12.47 & 13.615 & & & \\
\hline \multirow{2}{*}{ Taking Initiatives } & Female & 8.7949 & 2.92160 & \multirow{2}{*}{-.982} & \multirow{2}{*}{\multicolumn{2}{|c|}{.329}} \\
\hline & Male & 8.1000 & 3.35735 & & & \\
\hline \multirow{2}{*}{ Investment Behavior } & Female & 9.1750 & 3.47804 & \multirow{2}{*}{.160} & \multirow{2}{*}{\multicolumn{2}{|c|}{.873}} \\
\hline & Male & 9.3000 & 3.50969 & & & \\
\hline \multirow{2}{*}{ Variety } & Female & 7.7000 & 2.86625 & \multirow{2}{*}{.039} & \multirow{2}{*}{\multicolumn{2}{|c|}{.969}} \\
\hline & Male & 7.7250 & 2.87329 & & & \\
\hline \multirow{2}{*}{ Multifunctionality } & Female & 8.4250 & 2.44831 & \multirow{2}{*}{.647} & \multirow{2}{*}{\multicolumn{2}{|c|}{.519}} \\
\hline & Male & 8.7500 & 2.02231 & & & \\
\hline \multirow{2}{*}{ Self-Efficacy } & Female & 10.2250 & 2.08151 & \multirow{2}{*}{.054} & \multirow{2}{*}{\multicolumn{2}{|c|}{.957}} \\
\hline & Male & 10.2500 & 2.06000 & & & \\
\hline \multirow{2}{*}{ Positive Frame of Mind } & Female & 8.5750 & 3.03727 & \multirow{2}{*}{-.76} & \multirow{2}{*}{\multicolumn{2}{|c|}{.940}} \\
\hline & Male & 8.5250 & 2.84639 & & & \\
\hline
\end{tabular}

Note. ${ }^{*}=p \leq .05, * *=p \leq .01$.

\section{Sex and Coping Patterns}

Hypothesis eight of women will display more positive coping patterns when compared to men was partially supported. There were significant differences in scores for males and females for Brief COPE subscale planning and Brief COPE subscale positive reframing. There was no statistical significance for Brief COPE subscales active and acceptance.

There was a significant difference in planning coping scores for males ( $M=4.5500, S D 1.89399)$ and females ( $M=5.4000, S D 1.90546 ; t(78)=-2.001, p=.049$ two-tailed). The magnitude of the differences in means (mean difference $=-.85000,95 \% \mathrm{Cl}:-1.69570$ to -.00430 ) was large (eta squared $=$ $.980)$. 
There was a significant difference in positive reframing scores for males $(M=4.1250, S D$ 1.74220) and females $(M=5.1750, S D 1.99856 ; t(78)=-2.505, p=.014$ two-tailed). The magnitude of the differences in means (mean difference $=-1.05000,95 \% \mathrm{Cl}:-1.88483$ to -.21517 ) was small (eta squared $=.310)$.

A detailed description of mean comparisons of positive coping subscales of active, planning, positive reframing, and acceptance can be found in Table 13.

\section{Table 13}

Mean comparisons for positive coping subscales of active coping, planning coping, positive reframing coping, and acceptance coping by sex

\begin{tabular}{|c|c|c|c|c|c|c|}
\hline \multirow[t]{3}{*}{ Outcome } & \multirow[t]{2}{*}{ Group } & \multicolumn{2}{|c|}{ Baseline } & \multirow[t]{3}{*}{$t$} & \multirow[t]{3}{*}{$p$} & \\
\hline & & Mean & SD & & & \\
\hline & Male & 12.47 & 13.615 & & & \\
\hline \multirow{2}{*}{ Active Coping } & Female & 5.1750 & 1.63123 & \multirow{2}{*}{-1.972} & \multirow{2}{*}{.052} & \\
\hline & Male & 4.4250 & 1.76704 & & & \\
\hline \multirow{2}{*}{ Planning Coping } & Female & 5.4000 & 1.90546 & \multirow{2}{*}{-2.001} & \multirow{2}{*}{.049} & $*$ \\
\hline & Male & 4.5500 & 1.89399 & & & \\
\hline \multirow{2}{*}{ Positive Reframing Coping } & Female & 5.1750 & 1.95527 & \multirow{2}{*}{-2.505} & \multirow{2}{*}{.014} & $*$ \\
\hline & Male & 4.1250 & 1.74220 & & & \\
\hline \multirow{2}{*}{ Acceptance Coping } & Female & 5.9500 & 1.75339 & \multirow{2}{*}{-1.927} & \multirow{2}{*}{.058} & \\
\hline & Male & 5.1500 & 1.95527 & & & \\
\hline
\end{tabular}

Note. ${ }^{*}=p \leq .05, * *=p \leq .01$. 
A detailed description of whether the hypotheses were supported, partially support or not supported can be found in Table 14.

Table 14

Hypotheses

\begin{tabular}{|c|c|c|c|c|}
\hline & Hypotheses for Specific Aim \#1 & Supported & $\begin{array}{l}\text { Partially } \\
\text { Supported }\end{array}$ & $\begin{array}{l}\text { Not } \\
\text { Supported }\end{array}$ \\
\hline 1. & $\begin{array}{l}\text { There will be a positive correlation among perceived } \\
\text { stress of anxiety, depression, diabetes distress, and } \\
\text { loneliness. }\end{array}$ & $\checkmark$ & & \\
\hline 2. & $\begin{array}{l}\text { Perceived stress of anxiety, depression, diabetes } \\
\text { distress, and loneliness will be inversely associated with } \\
\text { social support and self-management ability. }\end{array}$ & & $\checkmark$ & \\
\hline 3. & $\begin{array}{l}\text { Perceived stress of anxiety, depression, diabetes } \\
\text { distress, and loneliness will be associated with poorer } \\
\text { coping patterns. }\end{array}$ & & $\checkmark$ & \\
\hline \multirow[t]{2}{*}{4.} & $\begin{array}{l}\text { Positive coping patterns will be positively related to } \\
\text { social support and self-management ability. }\end{array}$ & & $\checkmark$ & \\
\hline & Hypotheses for Specific Aim \#2 & Supported & $\begin{array}{l}\text { Partially } \\
\text { Supported }\end{array}$ & $\begin{array}{l}\text { Not } \\
\text { Supported }\end{array}$ \\
\hline 5. & $\begin{array}{l}\text { Women will have higher reports of anxiety, depressive } \\
\text { symptoms, and social support when compared to men. }\end{array}$ & & $\checkmark$ & \\
\hline 6. & $\begin{array}{l}\text { Men will have higher reports of loneliness when } \\
\text { compared to women. }\end{array}$ & & & $\mathrm{X}$ \\
\hline 7. & $\begin{array}{l}\text { There will be no sex differences in diabetes distress and } \\
\text { self-management ability. }\end{array}$ & & $\checkmark$ & \\
\hline 8. & $\begin{array}{l}\text { Women will display more positive coping patterns when } \\
\text { compared to men. }\end{array}$ & & $\checkmark$ & \\
\hline
\end{tabular}


Cronbach's alpha was used as a measure of internal consistency, a measure of scale reliability.

See Table 15 for details.

Table 15

Reliability of Instruments measured by Cronbach's alpha

\begin{tabular}{|l|l|l|}
\hline Instrument & Number of items & Cronbach's alpha \\
\hline PROMIS Questions & 8 & .949 \\
\hline PAID Questions & 20 & .940 \\
\hline PHQ-9 Questions & 8 & .859 \\
\hline Self-Management Ability Scale-Short Scale & 18 & .871 \\
\hline Taking Initiatives & 3 & .691 \\
\hline Investment Behavior & 3 & .784 \\
\hline Variety & 3 & .499 \\
\hline Multifunctionality & 3 & .729 \\
\hline Self-Efficacy & 3 & .692 \\
\hline Positive Frame of Mind & 3 & .776 \\
\hline Loneliness & 2 & .929 \\
\hline Brief COPE & 2 & .825 \\
\hline Active Coping & 20 & .701 \\
\hline Planning Coping & 2 & \\
\hline Positive Reframing Coping & 2 & \\
\hline Acceptance Coping & 2 & \\
\hline Denial & & \\
\hline
\end{tabular}




\begin{tabular}{|l|l|l|}
\hline Instrument & Number of items & Cronbach's alpha \\
\hline Substance Use & 2 & .881 \\
\hline Behavioral Disengagement & 2 & .403 \\
\hline Self-Blame & 2 & .800 \\
\hline Self-Distraction & 2 & .508 \\
\hline Use of Emotional Support & 2 & .751 \\
\hline Use of Instrumental Support & 22 & .622 \\
\hline Venting & 2 & .563 \\
\hline Humor & 2 & .751 \\
\hline Religion & 2 & .856 \\
\hline Medical Outcomes Social Support & 17 & .800 \\
\hline Emotional Support Items & 7 & .688 \\
\hline Tangible Support Items & 3 & .433 \\
\hline Affectionate Support Items & 3 & .926 \\
\hline Positive Social Interaction Items & & \\
\hline
\end{tabular}

\section{Predictors of Coping Patterns}

\section{Positive Coping Pattern Predictors}

For active coping, potential predictors were identified as arthritis, height, miles from clinic, investment behavior, positive frame of mind, and tangible support. GLM revealed miles from clinic, $p$ value .023 and positive frame of mind, $p$ value .018 as predictive of active coping.

For planning coping, potential predictors were identified as sex, hyperlipidemia, height, total PAID, taking initiatives, investment behavior, positive frame of mind, and emotional support. GLM 
revealed total PAID, $p$ value .003 and positive frame of mind, $p$ value .007 as predictive of planning coping.

For positive reframing coping, potential predictors were identified as sex, coronary artery disease, taking initiatives, investment behavior, self-efficacy, and positive frame of mind. GLM revealed sex, $p$ value .007 and positive frame of mind $<.001$ as predictive of reframing coping.

For acceptance coping, potential predictors were identified as weight, BMI, investment behavior, variety, and positive frame of mind. GLM revealed BMI, $p$ value .019 and positive frame of mind, $p$ value $<.001$ as predictive of acceptance coping. See Figure 3. 


\section{Figure 3}

\section{Positive Coping Pattern Predictors}

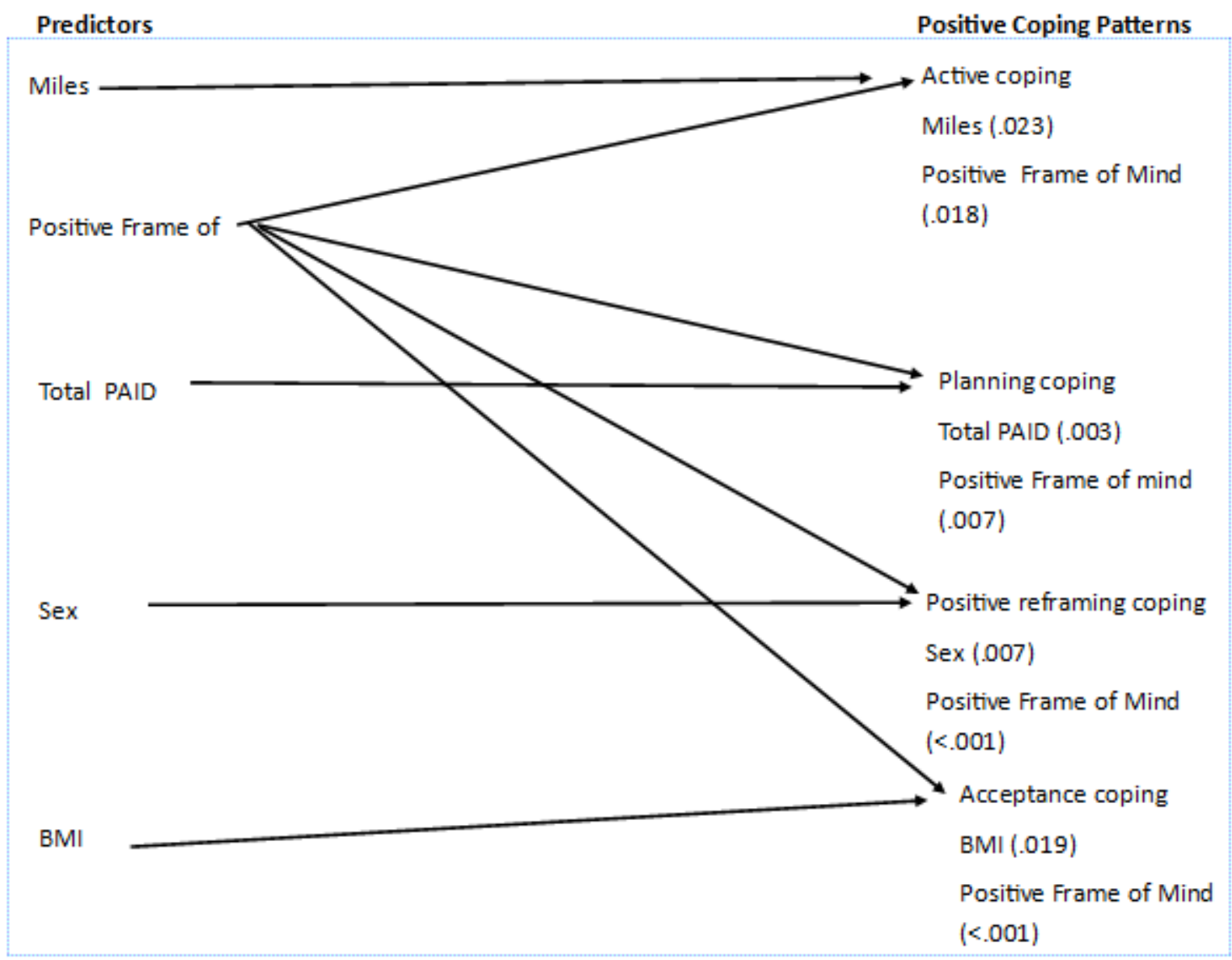




\section{Negative Coping Patterns Predictors}

For denial coping, potential predictors were identified as sex, education, lung disease, arthritis, height, number of regularly prescribed medications, total PROMIS, total PIAD, total loneliness, and selfefficacy. GLM revealed sex, $p$ value .038 , education, $p$ value .035 , arthritis, $p$ value .031 , and selfefficacy, $p$ value .009 as predictive of denial coping.

For substance use coping, potential predictors were identified as ethnicity, anxiety, and A1C. GLM revealed ethnicity, $p$ value .003 , anxiety, $p$ value .021 , and $A 1 C, p$ value .027 as predictive of substance use coping.

For behavioral disengagement coping, potential predictors were identified as ethnicity, depression, anxiety, total PROMIS, total PAID, total loneliness, taking initiatives, variety, positive frame of mind, and positive social interaction. GLM revealed ethnicity, $\mathrm{p}$ value .005 , total PAID, $\mathrm{p}$ value .038 , and positive frame of mind, $p$ value .028 as predictive of behavioral disengagement coping.

For self-blame coping, potential predictors were identified as sex, ethnicity, income, depression, anxiety, arthritis, A1C, number of regularly prescribed medications, total PROMIS, total PAID, total loneliness, total PHQ-9, and self-efficacy. GLM revealed total PAID, $p$ value $<.001$ as predictive of selfblame coping. Since only one predictor was found, linear regression was employed. Total PAID was still the only significant predictor for self-blame coping. See Figure 4. 


\section{Figure 4}

\section{Negative Coping Pattern Predictors}

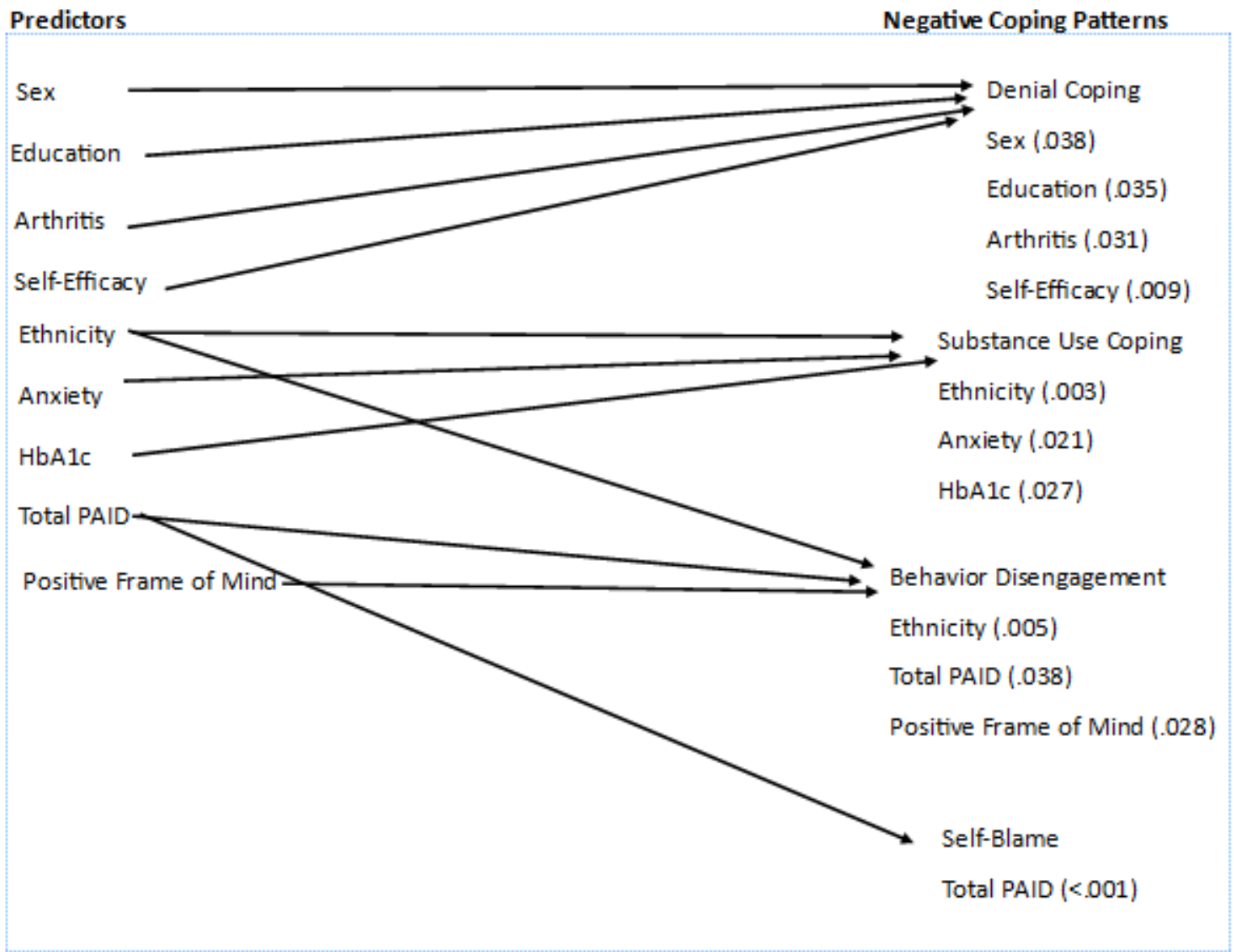




\section{Uncategorized Coping Pattern Predictors}

For self-distraction coping, potential predictors were identified as sex, depression, anxiety, arthritis, BMI, total PROMIS, total loneliness, and affectionate support. Linear regression revealed sex, $p$ value .003 and depression, $p$ value .043 in the model as predictive of self-distraction coping.

For use of emotional support coping, potential predictors were identified as education, investment behavior, variety, emotional support, tangible support, affectionate support, and positive social interaction. Linear regression revealed positive emotional support, $p$ value .008 and variety, $p$ value .027 in the model as predictive of use of emotional support coping.

For use of instrumental support coping, potential predictors were identified as sex, coronary artery disease, taking initiatives, investment behavior, positive frame of mind, emotional support, tangible support, and positive social interaction. Linear regression revealed tangible support, $p$ value $<.001$ and coronary artery disease, $p$ values .002 in the model as predictive of use of instrumental support coping.

For venting coping, potential predictors were identified as sex, lung disease, depression, anxiety, number of regularly prescribed medications, total chronic illnesses, total PROMIS, total PAID, total loneliness, and total PHQ-9. Linear regression revealed total PAID, $p$ value .008 and number of regularly prescribed medications, $p$ value .005 in the model as predictive of venting coping.

For humor coping, potential predictors were identified as coronary artery disease and positive frame of mind. Linear regression revealed positive frame of mind, $p$ value .011 in the model as a predictive of humor coping.

For religion coping, potential predictors were identified as age, sex, hypertension, height, taking initiatives, self-efficacy, positive frame of mind and emotional support. Linear regression revealed sex, $p$ value $<.001$, positive frame of mind, $p$ value $<.001$, hypertension, $p$ value .036 , and age, $p$ value .037 in the model as predictive for religion coping. 
See Figure 5 for details.

\section{Figure 5}

Uncategorized Coping Pattern Predictors

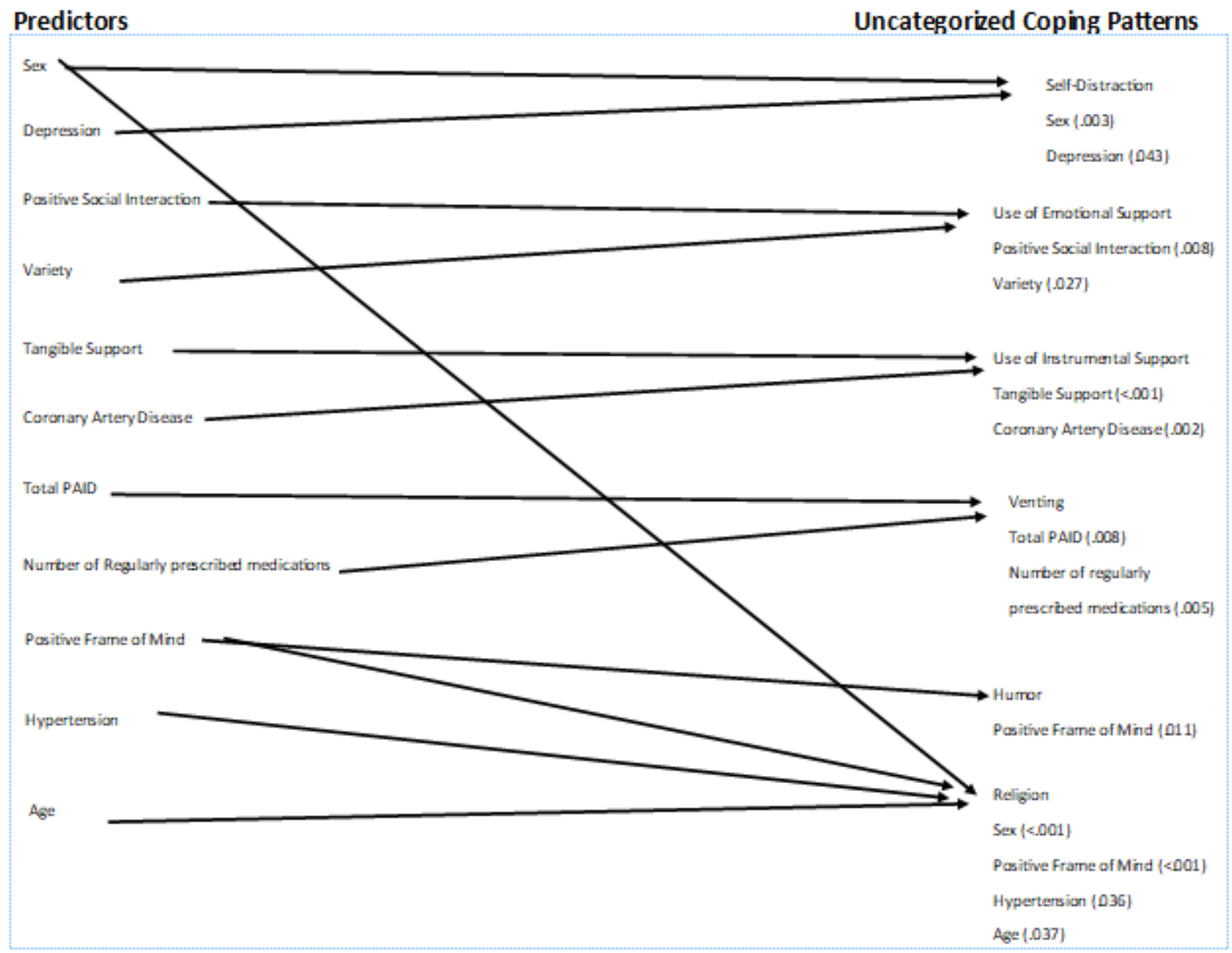

\section{Summary}

In summary, Chapter 4 presented the results of the data analyses. Chapter 5 presents strengths and limitations of the current study and a summary and discussion of the results as the relate to current health and social science literature. In addition, implications of future research and clinical implications are discussed. 


\section{CHAPTER FIVE \\ Discussion}

\section{Introduction}

The purpose of Chapter 5 is to provide a discussion of main findings in relation to current health and social science literature, study findings and the PNI, clinical implications, implications of future research, research study strengths and limitations, and conclusion. This study employed a quantitative, descriptive, prospective, cross-sectional design to examine relationships among person factors, psychosocial factors, and coping patterns in people living with T2DM in north central Appalachia. The findings for the study are meaningful for future research and in clinical settings.

\section{Statement of the Problem}

This completed study serves to fill a recognized gap in the literature when seeking to understand how people in rural Appalachia cope with T2DM. The study further advances knowledge on the topic by exploring sex differences, person factors, psychosocial factors and coping patterns in a sample of 80 participants from Davis Family Care located in Elkins, WV.

\section{Challenges in Recruitment}

There were many challenges recruiting research participants in a new rural clinic site located in a hospital setting. Since no prior researcher had been present in this small rural clinic, additional work was required to meet all the guidelines of the Health System and WVU IRB. The study research team had to be approved after submitting a physical, criminal background check, urine drug screen, immunizations, titers, basic life support certification, orientation to the facility, virtual continuing education requirements, baseline TB assessment, nonemployee confidentiality and security agreement, patient rights and responsibilities, and standards of behavior. a virtual information repository to upload the supporting documentation to prove compliance with health system requirements.

Weather and time were influential factors of recruitment. Days when it was warm and sunny or days where it was cold and rainy yielded no shows and canceled appointments. Potential participants 
often did not want to stay after their provider appointment to participate in research. Time was often cited as a factor for not wanting to participate. Alternative days and times were offered, yet potential participants did not want to return to the clinic to complete the packet of questionnaires.

The team took into consideration that the COVID-19 pandemic may have impacted recruitment. Though it was not verbalized that COVID-19 was a factor some potential participants declined. Protocols from Davis Health System were followed and protective precautions such as face masking, goggles, using hand sanitizer, social distancing and providing participants with their own ink pen to complete the packet of questionnaires were instituted. Despite these challenges recruitment was successful. The sampling goal was reached within the planned time frame, a six month period from February 2021August 2021, with all participants enrolling at Davis Family Care in person. Though contingency plans were in place they were not needed.

\section{Main Findings}

The major findings of this study include information about relationships between person factors, psychosocial factors and coping patterns of people living with T2DM in rural Appalachia which fills a gap in the current scientific literature. This study uncovered a cluster of psychological factors that people living with T2DM in Appalachia experience. The study further refined predictors for each coping pattern and sex differences in both psychosocial variables and coping patterns.

T2DM is more prevalent in the Appalachian region than in any other Region of the United States. Appalachians are 1.4 times more likely to have diabetes than non-Appalachians (Carpenter, 2012; CDC, 2019). This is problematic because people living in Appalachia are faced with complex health challenges, including T2DM, which are known to be influenced by social and behavioral determinants of health (ARC, 2019, CDC, 2019). The findings of this research study will be discussed in relation to what is found in the literature. 


\section{Person Factors}

The participants at Davis Family Care are representative of adults in the Appalachian region in relation to ethnicity, marital status, education, income and employment status. The general description of the sample is white, married, high school education, income less than $\$ 30,000$, and unemployed, which is congruent with the population of Appalachia. The Appalachian region has a population with low income and high unemployment (Tessaro, Smith, \& Rye, 2005). Appalachia has a high prevalence of obesity and chronic disease illnesses such as heart disease, stroke, and diabetes (Crespo, Christiansen, Tieman, K., \& Wittberg, 2020). Similar to other studies of Appalachia, participants had above average A1C, elevated BMI and reported similar chronic morbidities that were prevalent in women (Misra, Fitch, Roberts, \& Wright, 2016).

T2DM is a complex, chronic, and debilitating illness that elicits stress and imposes a financial burden on individuals, families, and society (ADA, 2019). This is particularly important because of the social determinant of health of income. One example of the financial burden is related to medications. Knowing the participants averaged over 9 medications a day, the sample had a high medication burden. Getting to care is costly in addition to medications. Another financial burden is the cost of transportation. Currently in 2021, gas prices are high and there is the consideration of additional costs associated with transportation. Previous studies reported cost of diabetes each year is $\$ 9,601$ which includes provider visits, medication, diabetic supplies, and hospital in-patient care (ADA, 2018). Globally, women are more vulnerable, have lower income, and receive less support to manage and cope with the consequences of diabetes (Kapur \& Seshiah, 2017).

Person factors of sex differences in the study population were identified as women having more diabetes distress (Kalra, Kalra, Singh Balhara, Verma, Azam, \& Shaikh, 2019). Study findings were concerning related to women with diabetes distress and coping. Women were shown to have more 
diabetes distress and used diverse coping patterns. Gender-specific interventions specific to women who use more diverse coping patterns are needed to fill this gap in care.

\section{Psychosocial Factors}

Anxiety, depression, loneliness, and diabetes distress were all intercorrelated with participants reporting symptoms of mild anxiety, mild depression, moderate loneliness, and moderate diabetes distress. Managing four negative psychosocial stressors while living with T2DM is problematic because the interaction of these stressors likely impacts their health outcomes related to their diabetes. The prevalence of anxiety, depression, loneliness, and diabetes distress are congruent or slightly higher in this population compared to other studies (McCoy \& Theeke, 2019).

Loneliness is a key psychosocial factor that has a major impact on the health outcomes of patients with chronic illnesses in rural Appalachians (Theeke, Carpenter, Mallow, \& Theeke, 2019; Theeke, Mallow, Moore, McBurney, Rellik \& VanGilder, 2016; Theeke \& Mallow, 2013). Participants were found to be moderately lonely on average. Current scientific literature has delegated loneliness as a global priority. There is beginning literature on how loneliness impacts metabolic syndrome in people living with diabetes resulting in hyperglycemia, hypertension and hyperlipidemia. The HUNT study reported individuals with higher levels of loneliness were also at a higher risk for metabolic syndrome (Henriksen, Nilsen, \& Strandberg, 2019). Another study noted that loneliness was associated with cardiovascular disease and identified as a risk factor for T2DM (Hackett, Hudson, \& Chilcot, 2020). Lastly, studies of loneliness and social isolation are revealing evidence of associations between cardiovascular mortality, metabolic health, and mental health outcomes (Winterton, Rødevand, Westlye, Steen, Andreassen, \& Quintana, 2019).

There are known sex differences in psychosocial factors and coping patterns. Participants who self-identified as female sex reported higher levels of anxiety, depression, and diabetes distress factors that are known to negatively impact health outcomes (Theeke, Carpenter, Mallow, \& Theeke, 2019; 
Theeke, Mallow, Moore, McBurney, Rellik \& VanGilder, 2016; Theeke \& Mallow, 2013). Sex differences further complicate the care of people living with T2DM because of the differences in coping patterns. Women had more diverse coping patterns than men and both sexes identified coping patterns that could be problematic. However, these problematic coping patterns are modifiable

Poor health outcomes have been found in people living with T2DM with lower social support. Men reported more positive social interaction. Knowing women have been found to have lower social support in the literature makes it imperative to build a strong social support system. Overall, it is consistently reported that greater social support from family, friends, and community is linked to better outcomes in people with diabetes (Rad, Bakht, Feizi \& Mohebi, 2013). It is reasonable to conclude that employment status correlates with income and with social support because of interaction with work colleagues. Some studies reported an inverse relationship between social support and A1C levels (Shayeghian et. al., 2015) and emotional distress. The findings in this study on loneliness, depression, social support and self-management are congruent with findings in the literature that identified a link between depression and decreased social support that could lead to loneliness (Petitte, Mallow, Barnes, Petrone, Barr, \& Theeke, 2015).

\section{Predictors of Coping Patterns}

Knowing that stress is related to the ability to cope and that stress can negatively influence health outcomes in people with T2DM, there is a critical need to understand coping. Positive frame of mind was predictive of all four positive coping subscales (active, planning, positive reframing, and acceptance), and for humor and religion coping. Optimism has been found to be helpful in physical and psychological health in people living with T2DM. It is thought to be protective against stress, metabolic syndrome, cardiovascular disease and immune function (Puig-Perez, Hackett, Salvador, \& Steptoe, 2016). There is likely a link between optimism, planning coping, and self-management. Optimism is a mindset that may be supportive in improving diabetes-related self-care activities such as taking care of 
oneself and controlling the progression of diabetes (Zhao, Suhonen, Katajisto, \& Leino-Kilpi, 2019).

Additionally, optimism has been shown to be significantly associated with quality of life in people living with diabetes (Kaveh, Ghahremani, Nazari, \& Zare, 2018).

The findings of negative coping patterns in this study are not surprising but need addressed. The associations among anxiety, depression, diabetes distress, and loneliness with negative coping patterns of denial, behavioral disengagement, and self-blame coping highlight a need for integrated behavioral health in primary care settings. It may be particularly important to target diabetes distress. Ignoring diabetes, diverting from the stressor or blaming oneself can be problematic and lead to poor outcomes of uncontrolled diabetes such as diabetic neuropathy, potential loss of limb, immune compromise, renal failure, diabetic retinopathy and poorer cardiovascular health.

\section{Utility of the PNI and Chronic Illness Research}

The PNI was a very useful framework for studying coping in this population. This paradigm enhances the understanding of how living with T2DM as a stressor leads to physiological, psychosocial, and behavioral responses that ultimately affect health. Physiological responses include activation of the hypothalamic-pituitary-adrenal (HPA) axis which includes increased cortisol level, diminished ability for restorative capacity in the cells, and obesity (Diz-Chaves, Gil-Lozano, Toba, Fandiño, Ogando, GonzálezMatías, \& Mallo 2016). Chronic stress of T2DM and psychological stress can compromise immune function affecting health (McCain et. al., 2005).

People living with T2DM already have neuroinflammation of the brain. Neuroinflammation can lead to depressive symptoms, thus causing a problem with coping (Asslih, Damri \& Agam, 2021). Psychosocial responses including anxiety, depressive symptoms, diabetes distress, and loneliness were identified as co-occurring and influential to coping. Recognizing that these responses can be impacting both brain and behavior will be key to improving health outcomes. 
Coping patterns are formed over a course of a lifetime and learned in the context of family and community systems. It is known that coping is modifiable and plays a fundamental influential role in physical and psychological well-being (Coelho, Amorim, \& Prata, 2003). It was previously known that coping patterns differ by sex (Gåfvels, \& Wändell, 2006), but this study is particularly important because it highlights predictors of coping so that more targeted sex-specific interventions can be developed.

The PNI framework has been utilized in people with Human Immunodeficiency Virus (HIV) disease, cancer, loneliness and chronic illnesses with similar findings. In studies of people with HIV disease, relationships among stress and HIV infection influenced disease progression potentially through reactivation of other latent viral infections thus, activating the immune cells infected with HIV. Similar findings were found in studies of people with cancer that reported an association of psychological distress and disease progression in cancer. Higher psychological distress with reduced Natural Killer (NK) cell, a type of lymphocyte, cytotoxicity causing stress-related immunosuppression (McCain, Gray, Walter, \& Robins, 2005). In past studies of loneliness, the framework was used to demonstrate that reducing loneliness improved health outcomes (Theeke, Mallow, Moore, McBurney, Rellik, \& VanGilder, 2016). Given these results, it is reasonable to conclude that the PNI will provide a useful framework for future studies in people living with T2DM.

\section{Clinical Implications}

Knowing that stress and coping patterns have the ability to influence health outcomes makes it critical that healthcare providers are aware of this information in practice. Deliberate screening of these cluster of emotions at provider visits would help establish comprehensive holistic care for people living with T2DM. The prevalence of depression symptoms is higher in Appalachia (de Groot, Doyle, Averyt, Risaliti, \& Shubroo, 2014). Knowing the prevalence of anxiety and depression in this sample, it is critical that we screen for and plan for treatment of psychological problems in people living with T2DM. One way to facilitate the inclusion of these assessments would be the use of the electronic health records 
which have the ability to have built-in prompts to allow for reminders of screening. Depression and diabetes distress are often undiagnosed resulting in poor health outcomes in people living with T2DM. If negative psychosocial factors are assessed or diagnosed, then a plan for treatment needs to be instituted because the interaction of these stressors likely impacts their health outcomes related to their diabetes. Identification of these negative emotions could be treated during routine chronic care management appointments of their diabetes (CDC, 2017). Diminishing negative psychosocial factors while facilitating coping is essential to improved health outcomes for people with T2DM (McCoy \& Theeke, 2019). Identifying effective interventions for diminishing negative psychosocial factors while facilitating coping is essential.

\section{Implications for Future Research}

Future research needs to include studies that are designed to target the collection of emotions and build evidence on enhancing coping in persons with T2DM, including the design and testing of new interventions. Studies that target the way people live with T2DM perceive their illness may be valuable. Interventions are needed to minimize negative coping patterns for women and facilitate a positive a frame of mind in people living with T2DM to take on this life altering change. Further, knowing that sex differences exist in coping, studies are needed that incorporate sex as a biological variable, recognize differences in coping between men and women, and contribute to knowledge about sex specific interventions for coping in adults with T2DM (McCoy \& Theeke, 2019). It would also be valuable to evaluate any developed intervention for impact on outcomes based on sex and cultural competence to determine scalability and/or sustainability to people with T2DM in Appalachia. Future analysis types could include cluster analysis or path analysis. Lastly, use of telehealth and home monitoring where the blood glucose is automatically downloaded to the provider may prove to be beneficial. 


\section{Research Study Strengths and Limitations}

This completed study had several strengths and limitations. The study included the use of theoretically sound instruments with good psychometric properties. Though the study sample lacked diversity, it is representative of the Appalachian population and the sample is divided equally by sex. Another strength of the study was the rigor in which the analysis was conducted. Several research study limitations have been identified. Convenience sampling was used which may limit generalizability to other populations. There was minimal variability with ethnicity as 78 out of the 80 participants were white yet, ethnicity was predictive for substance use coping and behavior disengagement coping. All data collected were self-reported and participants were commonly from the geographic region of Randolph County, WV which limits generalizability to urban populations. It is noted though many participants experienced the same social determinants of health as those who live in impoverished urban areas.

\section{Conclusion}

T2DM is a chronic disease that imposes adjustments in the patient's lifestyle and behaviors and is linked to poor health outcomes. This study exposed that people with T2DM in Appalachia are living with a cluster of psychological factors including anxiety, depression, diabetes distress, and loneliness. These factors, along with the known sex differences in coping further complicate the care of persons with T2DM. Developing an intervention that is sex precise and targets the problematic coping patterns identified in people living with T2DM would have the potential for impacting the long-term health outcomes associated with diabetes. 


\section{REFERENCES}

Ahlin, K., \& Billhult, A. (2012). Lifestyle changes - a continuous, inner struggle for women with type 2 diabetes: A qualitative study. Scandinavian Journal of Primary Health Care, 30(1), 4147. doi:10.3109/02813432.2011.654193

Al-Amer, R., Ramjan, L., Glew, P., Randall, S., \& Salamonson, Y. (2016). Self-Efficacy, Depression, and Self-Care Activities in Adult Jordanians with Type 2 Diabetes: The Role of Illness Perception. Issues Ment Health Nurs, 37(10), 744-755. doi:10.1080/01612840.2016.1208692

American Diabetes Association (2018). Economic costs of diabetes in the U.S. in 2017. Diabetes Care, 41(5), 917-928. https://doi.org/10.2337/dci18-0007

American Diabetes Association (2019). Standards for medical care in diabetes-2019. Abridged for primary care providers. Diabetes Care 2018; 42 (Suppl. 1): S1-S194.

American Psychiatric Association (2019). What is Depression? Retrieved March 24, 2020, from https://www.psychiatry.org/patients-families/depression/what-is-depression

Anderson, R. J., Freeland, K. E., Clouse, R. E., \& Lustman, P. J. (2001). The prevalence of comorbid depression in adults with diabetes: A meta-analysis. Diabetes Care, 24(6), 1069-1078.

Appalachian Regional Commission. (2019). https://www.arc.gov/index.asp. County Economic Status and Number of Distressed Areas in West Virginia, Fiscal Year 2019. Available from: https://www.arc.gov/images/appregion/economic statusFY2019/CountyEconomicStatusandDis tressAreasFY2019WestVirginia.pdf

Appalachian Regional Commission (2017). https://www.arc.gov. Creating a Culture of Health in Appalachia. Disparities and Bright Spots. Available from: https://www.arc.gov/images/appregion/fact sheets/HealthDisparities2017/WVHealthDisparitie sKeyFindings8-17.pdf 
Appalachian Regional Commission (2019). https://www.arc.gov/index.asp. Distressed

Designation and County Economic Status Classification System, FY 2007 - FY 2018.

Available from:

https://www.arc.gov/research/SourceandMethodologyCountyEconomicStatusFY2007FY2018.as

$\underline{p}$

Asslih, S., Damri, O., \& Agam, G. (2021). Neuroinflammation as a common denominator of complex diseases (cancer, diabetes type 2, and neuropsychiatric disorders). International Journal of Molecular Sciences, 22(11), 6138. https://doi.org/10.3390/ijms22116138

Bonilla, G. S., Rodriguez-Gutierrez, R., \& Montori, V. M. (2016). What We Don't Talk About When We Talk About Preventing Type 2 Diabetes-Addressing Socioeconomic Disadvantage. JAMA Internal Medicine, 176(8), 1053. doi: 10.1001/jamainternmed.2016.2952

Burns, R. J., Deschenes, S. S., \& Schmitz, N. (2016). Associations between coping strategies and mental health in individuals with type 2 diabetes: Prospective analyses. Health Psychol, 35(1), 78-86. doi:10.1037/hea0000250

Cacioppo, J. T., Hawkley, L. C., \& Thisted, R. A. (2010). Perceived social isolation makes me sad: 5-year cross-lagged analyses of loneliness and depressive symptomatology in the Chicago Health, Aging, and Social Relations Study. Psychology and Aging, 25(2),453-463. doi: 2010-11857-019[pii]10.1037/a0017216

CardioSmart. (2016). Diabetes Outcomes Strongly Influenced by Income and Education. https://www.cardiosmart.org. American College of Cardiology. Available from: https://www.cardiosmart.org/News-and-Events/2016/07/Diabetes-Outcomes-StronglyInfluenced-by-Income-and-Education

Carpenter, R. (2012). Appraisal of Perceived Threat of Diabetes and the Relation to Adherence for Adults in Appalachia. Journal of Health Care for the Poor and Underserved, 23(2), 726-728. 
doi:10.1353/hpu.2012.0049

Carpenter, R \& Theeke, L. A. (2018). Strategies for recruiting a sample of adults with type 2 diabetes from primary care clinics in rural Appalachia: Incorporating cultural competence. International Journal of Nursing Sciences. 5, 230-237.

Carpenter, R. D., Theeke, L. A., Mallow, J. A., Theeke, E., \& Gilleland, D. (2017). Relationships among Distress, Appraisal, Self-Management Behaviors, and Psychosocial Factors in a Sample of Rural Appalachian Adults with Type 2 Diabetes. Online Journal of Rural Nursing and Health Care, 17(2), 34-64. doi:10.14574/ojrnhc.v17i1.446

Carver, C. S. (1997). You want to measure coping but your protocol's too long: consider the brief COPE. Int J Behav Med, 4(1), 92-100. doi:10.1207/s15327558ijbm0401_6

Centers for Disease Control (2019). https://www.cdc.gov/ Appalachian Diabetes Control and Translation Project. Available from: https://www.cdc.gov/diabetes/programs/appalachian.html Centers for Disease Control (2019). https://www.cdc.gov/ Diabetes and Mental Health. Available from: https://www.cdc.gov/diabetes/managing/mental-health.html

Centers for Disease Control (2017). https://www.cdc.gov/ Screening for depression and diabetes distress in adults with type 2 diabetes. Available from: https://www.cdc.gov/diabetes/pdfs/managing/Depression Diabetes Distress Brief 508.pdf

Coelho, R., Amorim, I., \& Prata, J. (2003). Coping styles and quality of life in patients with non-insulindependent diabetes mellitus. Psychosomatics, 44(4), 312-318. doi:10.1176/appi.psy.44.4.312

Clayton, J. A. (2018). Applying the new SABV (sex as a biological variable) policy to research and clinical care. Physiol Behav. 187, 2-5.

Cramm, J. M., Strating, M. M., Vreede, P. L., Steverink, N., \& Nieboer, A. P. (2012). Validation of the self-management ability scale (SMAS) and development and validation of a shorter scale (SMAS-S) among older patients shortly after hospitalization. Health and Quality of 
Life Outcomes, 10(1), 9. doi:10.1186/1477-7525-10-9

Crespo, R., Christiansen, M., Tieman, K., \& Wittberg, R. (2020). An emerging model for community health worker-based chronic care management for patients with high health care costs in rural Appalachia. Preventing Chronic Disease, 17. https://doi.org/10.5888/pcd17.190316

Decoster, V. A., \& Cummings, S. (2005). Coping with Type 2 Diabetes. Social Work in Health Care, 40(2), 37-53. doi:10.1300/J010v40n02_03

de Groot, M., Doyle, T., Averyt, J., Risaliti, C., \& Shubroo, J. (2014). Depressive symptoms and type 2 diabetes mellitus in rural Appalachia: An 18-month follow-up study. The International Journal of Psychiatry in Medicine, 48(4), 263-277. https://doi.org/10.2190/pm.48.4.c

Disease DoHPaC. Statistics about the population of West Virginia, West Virginia Behavioral Risk Factor Surveillance System https://dhhr.wv.gov: West Virginia Department of Health and Human Resources Bureau for Public health; 2019 [Statistics about the population of West Virginia]. Available from: https://dhhr.wv.gov/hpcd/data reports/Pages/Fast-Facts.aspx.

Diz-Chaves, Y., Gil-Lozano, M., Toba, L., Fandiño, J., Ogando, H., González-Matías, L. C., \& Mallo, F. (2016). Stressing diabetes? the hidden links between insulinotropic peptides and the HPA axis. Journal of Endocrinology, 230(2). https://doi.org/10.1530/joe-16-0118

Duangdao, K. M., \& Roesch, S. C. (2008). Coping with diabetes in adulthood: a meta-analysis. J Behav Med, 31(4), 291-300. doi:10.1007/s10865-008-9155-6

Dupre, M. E., Silberberg, M., Willis, J. M., \& Feinglos, M. N. (2015). Education, glucose control, and mortality risks among U.S. older adults with diabetes. Retrieved from https://www.sciencedirect.com/science/article/pii/S0168822715000339

Gåfvels, C., \& Wändell, P. E. (2006). Coping strategies in men and women with type 2 diabetes in Swedish primary care. Diabetes Research and Clinical Practice, 71(3), 280-289. doi:10.1016/j.diabres.2005.07.001 
Garay-Sevilla, M. E., Porras, J. S. \& Malacara, J.M. (2011). Coping strategies and adherence to treatment in patients with type 2 diabetes mellitus. Rev Invest Clin, 63(2), 155-161

Gonzalez J.S., Wittenberg E., Safern S.A., Blais M.A., Cagliero E., Meigs J.B. (2007). Depression, self-care, and medication adherence in type 2 diabetes: relationships across the full range of symptoms severity. Diabetes Care; 30: 2222-2227.

Gonzalez-Zacarias, A. A., Mavarez-Martinez, A., Arias-Morales, C. E., Stoicea, N., \& Rogers, B. (2016). Impact of Demographic, Socioeconomic, and Psychological Factors on Glycemic SelfManagement in Adults with Type 2 Diabetes Mellitus. Retrieved from https://www.ncbi.nlm.nih.gov/pmc/articles/PMC5018496/

Hackett, R. A., Hudson, J. L., \& Chilcot, J. (2020). Loneliness and type 2 diabetes incidence: findings from the English Longitudinal Study of Ageing. Diabetologia, 63(11), 2329-2338.

\section{https://doi.org/10.1007/s00125-020-05258-6}

Handron, D. S., \& Leggett-Frazier, N. K. (1994). Utilizing Content Analysis of Counseling Sessions to Identify Psychosocial Stressors Among Patients With Type II Diabetes. The Diabetes Educator, 20(6), 515-520. doi: 10.1177/014572179402000609

Henriksen, R. E., Nilsen, R. M., \& Strandberg, R. B. (2019). Loneliness as a risk factor for metabolic syndrome: Results from the HUNT study. Journal of Epidemiology and Community Health, 73(10), 941-946. https://doi.org/10.1136/jech-2019-212335

Hornsten, A., Sandstrom, H., \& Lundman, B. (2004). Personal understandings of illness among people with type 2 diabetes. Journal of Advanced Nursing, 47(2), 174-182. doi: 10.1111/j.13652648.2004.03076.x

Huang, C., Lai, H., Lu, Y., Chen, W., Chi, S., Lu, C., \& Chen, C. (2016). Risk Factors and Coping Style Affect Health Outcomes in Adults with Type 2 Diabetes. Biological Research for Nursing, 18(1), 82-89. doi:10.1177/1099800415569845 
Hood, S., Irby-Shasanmi, A., de Groot, M., Martin, E., \& LaJoie, A. S. (2018). Understanding DiabetesRelated Distress Characteristics and Psychosocial Support Preferences of Urban African American Adults Living With Type 2 Diabetes: A Mixed-Methods Study. Diabetes Educ, 44(2), 144-157. doi:10.1177/0145721718754325

Hughes, L. C., Keith, S. E., Byars, A., \& Wiginton, K. L. (2012). Cognitive Mapping in Persons Newly Diagnosed with Type 2 Diabetes. The Diabetes Educator, 38(6), 845-854. doi:10.1177/0145721712460100

Innovation Enterprise Channels. (2019). https://www.channels.the innovationenterprise.com. Why is it important to understand the four types of innovation? Available from:

https://channels.theinnovationenterprise.com/articles/do-you-understand-the-4-types-ofinnovation

Kalka, D. (2014). The quality of life, symptoms of depression and coping with stress among individuals with type 2 diabetes-preliminary study. Psychiatr. Pol, 48(5), 931-940.

Kalra, B., Kalra, S., Singh Balhara, Y. P., Verma, K., Azam, A. A. S., \& Shaikh, F. A. (2019). The glucocoper an exploratory study to assess coping mechanisms of women diagnosed with diabetes mellitus. European Endocrinology, 15(1), 53. https://doi.org/10.17925/ee.2019.15.1.53

Kapur, A., \& Seshiah, V., (2017). Women \& diabetes: Our right to a healthy future. Indian Journal of Medical Research, 46(5), 553-556. doi: 10.4103/ijmr.IJMR 169517

Karlsen, B., Oftedal, B., \& Bru, E. (2012). The relationship between clinical indicators, coping styles, perceived support and diabetes-related distress among adults with type 2 diabetes. J Adv Nurs, 68(2), 391-401. doi:10.1111/j.1365-2648.2011.05751.x

Kaveh, M.H., Ghahremani, L., Nazari, M. \& Zare, S. (2018). Quality of Life in Diabetic Patients: The Predicting Role of Personal Resources. Journal of Health Sciences \& Surveillance System. 6 (3), 142-148. https://jhsss.sums.ac.ir/article_45926_b14901a963a0312f85e379036c80be90.pdf 
Kendall-Tackett, K. (2010). The psychoneuroimmunology of chronic disease exploring the links between inflammation, stress, and illness. Washington, DC: American Psychological Association.

Keppel, G. \& Wickens, T. D. (2004). Design \& Analysis: A Researcher's Handbook, $4^{\text {th }}$ ed. NJ: Prentice Hall.

Koopmanschap, M. (2002). Coping with Type II diabetes: The patient's perspective.

Diabetologia, 45(S1). doi:10.1007/s00125-002-0861-2

Kroenke, K., Spitzer, R. L., \& Williams, J. B. (2001). The PHQ-9. Journal of General Internal Medicine, 16(9), 606-613. doi:10.1046/j.1525-1497.2001.016009606.x

Lanting, S., Saffer, B., Koehle, M., Iverson, G. (2013, June). Reliability and Validity of the PROMIS-57 Health Outcome Measures. Poster presented at the annual convention of the Canadian Psychological Association, Quebec City, Quebec, Canada. Abstract retrieved from https://www.researchgate.net/publication/256326767 Reliability and Validity of the PROMI S- 57_Health_Outcome_Measures

Lazarus, R. S., \& Folkman, S. (1984). Stress, appraisal, and coping. New York: NY. Springer Publishing, Inc.

Lazarus, R. S. \& Folkman, S. (1987). Transactional theory and research on emotions and coping. European Journal of Personality. 1: 141-169.

Leustek, J. \& Theiss, J. A. (2018). Features of Illness Versus Features of Romantic Relationships as Predcitors of Cognitive and Behavioral Coping among Individuals with Tyoe 2 Daibetes. Health Communication, 33(12), 1549-1559.

Macrodimitris, S. D., \& Endler, N. S. (2001). Coping, control, and adjustment in type 2 diabetes. Health Psychology, 20(3), 208-216. doi:10.1037/0278-6133.20.3.208

McCain, N. L., Gray, D. P., Walter, J. M., \& Robins, J. (2005). Implementing a Comprehensive Approach to the Study of Health Dynamics Using the Psychoneuroimmunology 
Paradigm. Advances in Nursing Science, 28(4), 320-332. doi:10.1097/00012272200510000-00004

McCoy, M.A. \& Theeke, L.A. (2019). Systematic review of quantitative studies of the relationships among psychosocial factors and coping in adult men and women with type 2 diabetes mellitus. International Journal of Nursing Sciences. https://doi.org/10.1016/i.ijnss.2019.09.003

Misra, R., Fitch, C., Roberts, D., \& Wright, D. (2016). Community-based diabetes screening and risk assessment in rural West Virginia. Journal of Diabetes Research, 2016, 1-9.

\section{https://doi.org/10.1155/2016/2456518}

Mocan A.Ş., Iancu S.Ş., \& Băban A.S. (2018). Association of cognitive-emotional regulation strategies to depressive symptoms in type 2 diabetes patients. Rom J Intern Med. 56(1):34-40. doi:10.1515/rjim-2017-0037

Nakahara, R., Yoshiuchi, K., Kumano, H., Hara, Y., Suematsu, H., \& Kuboki, T. (2006). Prospective study on influence of psychosocial factors on glycemic control in Japanese patients with type 2 diabetes. Psychosomatics, 47(3), 240-246. doi:10.1176/appi.psy.47.3.240

National Commission for the Protection of Human Subjects of Biomedical and Behavioral Research. (1978). The Belmont report. Retrieved August 14, 2018, from https://www.hhs.gov/ohrp/regulations-and-policy/belmont-report/index.html

National Institute of Health (2015). https://www.nih.gov/ Consideration of Sex as a Biological Variable in $\mathrm{NIH}$-funded Research. Available from:

https://grants.nih.gov/grants/guide/notice-files/not-od-15-102.html

Page-Carruth, A., Windsor, C., \& Clark, M. (2014). Rural self-reliance: The impact on health experiences of people living with type II diabetes in rural Queensland, Australia. International Journal of Qualitative Studies on Health and Well-being, 9(1), 24182. 
doi:10.3402/qhw.v9.24182

Patient-Reported Outcome Measurement Information System (PROMIS)-Anxiety. Retrieved on July 30, 2018.

http://www.healthmeasures.net/images/PROMIS/manuals/PROMIS Anxiety Scoring Manual.p $\underline{\mathrm{df}}$

Peplau L. A., Perlman D.: Perspectives on loneliness; in Peplau LA, Perlman D (eds): Loneliness: A Sourcebook of Current Theory, Research and Therapy. New York, Wiley, 1982, pp 1-8.

Petitte, T., Mallow, J., Barnes, E., Petrone, A., Barr, T., \& Theeke, L. (2015). A Systematic Review of Loneliness and Common Chronic Physical Conditions in Adults. The Open Psychology Journal, 8(1), 113-132. doi:10.2174/1874350101508010113

Pipernik-Okanovic, M., Roglic, G., \& Metelko, Z. (1996). Emotional adjustment and metabolic control in newly diagnosed diabetic persons. Diabetes Research and Clinical Practice. 34(2). 99-105

Polit, D. F. \& Beck, C. T. (2012). Nursing Research. Generating and Assessing Evidence for Nursing Practice ( $9^{\text {th }}$ ed.). Philadelphia, PA: Wolters Kluwer. Lippincott Williams \& Wilkins.

Polonsky, W. H., Anderson, B. J., Lohrer, P. A., Welch, G., Jacobson, A. M., Aponte, J. E., \& Schwartz, C. E. (1995). Assessment of Diabetes-Related Distress. Diabetes Care, 18(6), 754-760. doi:10.2337/diacare.18.6.754

Powers, M. A., Bardsley, J., Cypress, M., Duker, P., Funnell, M. M., Fischl, A. H., Maryniuk, M. D., Siminerio, L., \& Vivian E. (2015). Diabetes self-management education and support in type 2 diabetes: A joint position statement of the American diabetes association, the American association of diabetes educators, and the academy of nutrition and dietetics. Diabetes Care 
$2015 ;$ 38:1372-1382.

Puig-Perez, S., Hackett, R. A., Salvador, A., \& Steptoe, A. (2016). Optimism moderates psychophysiological responses to stress in older people with type 2 diabetes. Psychophysiology, 54(4), 536-543. https://doi.org/10.1111/psyp.12806

Rad, G. S., Bakht, L. A., Feizi, A., Mohebi, S. (2013). Importance of social support in diabetes care. J Educ Health Promot, 2(62).

Ramkisson, S., Pillay, B.J., \& Sibanda, W. (2017). Social support and coping in adults with type 2 diabetes. African Journal of Primary Health Care \& Family Medicine, 9(1). Doi:10.4102/phcfm.

Roberts, B. L., Anthony, M. K., Madigan, E., \& Chen, Y. (1997). Data management: Cleaning and checking. Nursing Research, 46(6), 350-352.

Roberts, C., \& Hyatt, L. (2019). The dissertation journey: a practical and comprehensive guide to planning, writing, and defending your dissertation. Thousand Oaks, CA: Corwin, a SAGE Company.

Rodriguez, H. G., Wallace, D. D., \& Barrington, C. (2018). Contextualizing Experiences of DiabetesRelated Stress in Rural Dominican Republic. Qualitative Health Research, 29(6), 857-867. doi: $10.1177 / 1049732318807207$

Russell, D. (1996). UCLA Loneliness Scale (Version 3): Reliability, validity, and factor structure. Journal of Personality Assessment, 66, 20-40.

Sahler, O. J. \& Carr, J. E. (2009). Developmental-Behavioral Pediatrics. (4th ed.). Chapter 50. New York, NY: Elsevier. https://doi.org/10.1016/B978-1-4160-3370-7.00050-X

Sandén-Eriksson, B. (2000). Coping with type-2 diabetes: The role of sense of coherence compared with active management. Journal of Advanced Nursing, 31(6), 1393-1397. doi:10.1046/j.1365-2648.2000.01410.x 
Shah, B. M., Gupchup, G. V., Borrego, M. E., Raisch, D. W., \& Knapp, K. K. (2012). Depressive symptoms in patients with type 2 diabetes mellitus: do stress and coping matter? Stress Health, 28(2), 111122. doi:10.1002/smi.1410

Selye, H. (1936). A syndrome produced by diverse nocuous agents. Nature, 138, 32.

Shamsalinia, A., Pourghaznein, T., \& Parsa, M. (2015). The Relationship Between Hope and Religious Coping Among Patients with Type 2 Diabetes. Global Journal of Health Science, 8(1), 208. doi:10.5539/gjhs.v8n1p208

Shayeghian, Z., Aguilar-Vafaie, M. E., Besharat, M. A., Amiri, P., Parvin, M., Gillani, K. R., \& Hassanabadi, H. (2015). Self-care activities and glycated haemoglobin in Iranian patients with type 2 diabetes: can coping styles and social support have a buffering role? Psychol Health, 30(2), 153-164. doi:10.1080/08870446.2014.951651

Sherbourne, C. D., \& Stewart, A. L. (1991). The MOS social support survey. Social Science \& Medicine, 32(6), 705-714. doi:10.1016/0277-9536(91)90150-b

Smalls, B. L., Walker, R. J., Hernandez-Tejada, M. A., Campbell, J. A., Davis, K. S., \& Egede, L. E. (2012). Associations between coping, diabetes knowledge, medication adherence and self-care behaviors in adults with type 2 diabetes. Gen Hosp Psychiatry, 34(4), 385-389. doi:10.1016/j.genhosppsych.2012.03.018

Smith K. J., Beland M., Clyde M., Gariepy G., Page V., Badawi G., et al. (2013). Association of diabetes with anxiety: a systematic review and meta-analysis. J Psychosom Res, 74(2):89e99.

Smith, M. C. (2019). Regenerating Nursing's Disciplinary Perspective. Advances in Nursing Science, 42 (1), 3-16.

Stuckey, H. L., Mullan-Jensen, C. B., Reach, G., Burns, K. K., Piana, N., Vallis, M., Wens, J., Willaing, I., Skovlund, S. E., \& Peyrot, M. (2014). Personal Accounts of the Negative and Adaptive Psychosocial Experiences of People with Diabetes in the Second Diabetes Attitudes, 
Wishes and Needs (DAWN2) Study. Diabetes Care, 37(9), 2466-2474. doi:10.2337/dc13-2536

Tanenbaum, M. L., Ritholz, M. D., Binko, D. H., Baek, R. N., Shreck, M. S., \& Gonzalez, J. S. (2013). Probing for depression and finding diabetes: a mixed-methods analysis of depression interviews with adults treated for type 2 diabetes. J Affect Disord, 150(2), 533-539.

doi:10.1016/j.jad.2013.01.029

Tessaro, I., Smith, S. L., \& Rye, S. (2005). Knowledge and perceptions of diabetes in an Appalachian population. Preventing chronic disease, 2(2), A13.

Theeke, L., Carpenter, R. D., Mallow, J. \& Theeke, E. (2019). Gender differences in loneliness, anger, depression, self-management ability and biomarkers of chronic illness in chronically ill mid-life adults in Appalachia. Applied Nursing Research 45 (2019) 55-62.

Theeke, L. A., Goins, R. T., Moore, J., \& Campbell, H. (2012). Loneliness, Depression, Social Support, and Quality of Life in Older Chronically III Appalachians. The Journal of Psychology, 146(1-2), 155-171. doi:10.1080/00223980.2011.609571

Theeke, L. \& Mallow, J. (2013). Loneliness and Quality of Life in Chronically III Rural Older Adults Findings from a pilot study. American Journal of Nursing, 113(9), 28-38.

Theeke, L. A., Mallow, J. A., Moore, J. McBurney, A., Rellik S., \& VanGilder, R. (2016). Effectiveness of LISTEN on loneliness, neuroimmunological stress response, psychosocial functioning, quality of life, and physical health measures of chronic illness. International journal of Nursing Sciences. $3,242-251$.

Thorpe, C. T., Fahey, L. E., Johnson, H., Deshpande, M., Thorpe, J. M., \& Fisher, E. B. (2013). Facilitating healthy coping in patients with diabetes: a systematic review. Diabetes Educ, 39(1), 33-52. doi:10.1177/0145721712464400

van Dijk-de Vries, A., van Bokhoven, M. A., de Jong, S., Metsemakers, J. F., Verhaak, P. F., van der 
Weijden, T., \& van Eijk, J. T. (2016). Patients' readiness to receive psychosocial care during nurse-led routine diabetes consultations in primary care: A mixed methods study. Int J Nurs Stud, 63, 58-64. doi:10.1016/j.ijnurstu.2016.08.018

Vitaliano, P. P., Russo, J., Carr, J. E., Maiuro, R. D., \& Becker, J. (1985). The ways of coping checklist: Revision and psychometric properties. In Multivariate Behavioral Research, Volume 20. pp. 3-26.

Walker, R. J., Smalls, B. L., \& Egede, L. E. (2015). Social determinants of health in adults with type 2 diabetes--Contribution of mutable and immutable factors. Retrieved from https://www.ncbi.nlm.nih.gov/pmc/articles/PMC4681588/

Welch, G. W., Jacobson, A. M., \& Polonsky, W. H. (1997). The Problem Areas in Diabetes Scale: An evaluation of its clinical utility. Diabetes Care, 20(5), 760-766. doi:10.2337/diacare.20.5.760

West Virginia Department of Health and Human Resources (2017). West Virginia Behavioral Risk Factor Surveillance System Report 2017. Available from: http://www.wvdhhr.org/bph/hsc/pubs/brfss/2017/BRFSS2017.pdf

Whitebird, R. R., Kreitzer, M. J., Vazquez-Benitez, G., Ensatd, C. J. (2018). Reducing diabetes distress and improving self-management with mindfulness. Soc Work Health Care, 57(1):48e65.

Winterton, A., Rødevand, L., Westlye, L. T., Steen, N. E., Andreassen, O. A., \& Quintana, D. S. (2019). Associations of loneliness and social isolation with cardiovascular and Metabolic Health: A systematic review and meta-analysis protocol. https://doi.org/10.31219/osf.io/vfxs3

World Health Organization (2019). https://www.who.int/ Health impact assessment: Determinants of health. Available from: http://www.who.int/hia/evidence/doh/en/

Wynd, C. A., \& Schmidt B. (2003). Two quantitative approaches for estimating content validity. 
Western Journal of Nursing Research, 25(5), 508-518.

Yamakawa, M., \& Makimoto, K. (2008). Positive experiences of type 2 diabetes in Japanese patients: An exploratory qualitative study. International Journal of Nursing Studies, 45(7), 1032-1041. doi: 10.1016/j.ijnurstu.2007.05.003

Zhang, C. X., Tse, L. A., Ye, X. Q., Lin, F. Y., Chen, Y. M., \& Chen, W. Q. (2009). Moderating effects of coping styles on anxiety and depressive symptoms caused by psychological stress in Chinese patients with Type 2 diabetes. Diabet Med, 26(12), 1282-1288. doi:10.1111/j.14645491.2009.02840.x

Zhao, F. F., Suhonen, R., Katajisto, J., \& Leino-Kilpi, H. (2019). Factors associated with subsequent diabetes-related self-care activities: The role of social support and optimism. Nursing Open, 7(1), 195- 205. https://doi.org/10.1002/nop2.379 


\section{APPENDIX}

\section{Socio-demographics Questionnaire}

What is your age? Please circle the selection below.

18-24

25-29

30-34

35-39

40-44

45-49

50-54

55-59

60-64

65-69

70-74

75-79

80 or older

Are you Male or Female?

What is your Height?

What is your Weight?

What is your Ethnicity? Please circle the selection below.

1) White

2) Black or African American

3) American Indians or Alaskan

4) Asian

5) Native Hawaiian or other Pacific Islander

6) Other race

7) No preferred race 
What is your marital status? Please circle the selection below.

1) Married

2) Married with spouse absent

3) Partnered

4) Separated

5) Divorced

6) Widowed

7) Never married

What is the highest level of education you received? Please circle the selection below.

1) Less than High School

2) GED

3) High School Diploma

4) Some College

5) Completed Bachelor's Degree

6) Completed Graduate degree

What is your estimated yearly income? Please circle the selection below.

1) $10,000-15,000$

2) $15,000-20,000$

3) $20,000-30,000$

4) $30,000-40,000$

5) $40,000-50,000$

6) $50,000-60,000$

7) $60,000-70,000$

8) $70,000-80,000$

9) $80,000-90,000$

10) $90,000-100,000$

11) 100,000 or greater

Tell me about your living situation. Please circle the selection below.

I live alone

I live with people (write in the number of people who live with you) 
Are you employed?

Yes

No

How far do you live from the clinic in miles?

What is your zip code?

How long have you had diabetes?

Please list your medications.

Do you have any other health conditions (comorbidities)?

Yes

No

If yes, please list the other health conditions that you have: 


\section{PROMIS---Emotional Distress---Anxiety----Short Form A}

Please respond to each question or statement by marking one box per row. In the past 7 days......

\begin{tabular}{|l|l|l|l|l|l|}
\hline & Never & Rarely & Sometimes & Often & Always \\
\hline I felt fearful & & & & & \\
\hline $\begin{array}{l}\text { I found it hard to focus on } \\
\text { anything other than my } \\
\text { anxiety }\end{array}$ & & & & & \\
\hline My worries overwhelmed me & & & & & \\
\hline I felt uneasy & & & & & \\
\hline I felt nervous & & & & & \\
\hline $\begin{array}{l}\text { I felt like I needed help for my } \\
\text { anxiety }\end{array}$ & & & & & \\
\hline I felt anxious & & & & & \\
\hline I felt tense & & & & & \\
\hline
\end{tabular}




\section{Patient Health Questionnaire-9 (PHQ-9)}

Over the last $\mathbf{2}$ weeks, how often have you been bothered by any of the following problems?

(Use " $\checkmark$ " to indicate your answer)

\begin{tabular}{|c|c|c|c|c|c|}
\hline & & $\begin{array}{l}\text { Not at } \\
\text { all }\end{array}$ & $\begin{array}{l}\text { Several } \\
\text { days }\end{array}$ & $\begin{array}{l}\text { More } \\
\text { than half } \\
\text { the days }\end{array}$ & $\begin{array}{l}\text { Nearly } \\
\text { every } \\
\text { day }\end{array}$ \\
\hline & Little interest or pleasure in doing things & 0 & 1 & 2 & 3 \\
\hline & Feeling down, depressed, or hopeless & 0 & 1 & 2 & 3 \\
\hline & $\begin{array}{l}\text { Trouble falling or staying asleep, or sleeping too } \\
\text { much }\end{array}$ & 0 & 1 & 2 & 3 \\
\hline & Feeling tired or having little energy & 0 & 1 & 2 & 3 \\
\hline & Poor appetite or overeating & 0 & 1 & 2 & 3 \\
\hline & $\begin{array}{l}\text { Feeling bad about yourself---or that you are a } \\
\text { failure or have let yourself or your family down }\end{array}$ & 0 & 1 & 2 & 3 \\
\hline & $\begin{array}{l}\text { Trouble concentrating on things, such as reading } \\
\text { the newspaper or watching television }\end{array}$ & 0 & 1 & 2 & 3 \\
\hline 8. & $\begin{array}{l}\text { Moving or speaking so slowly that other people } \\
\text { could have noticed? Or the opposite-being so } \\
\text { fidgety or restless that you have been moving } \\
\text { around a lot more than usual }\end{array}$ & 0 & 1 & 2 & 3 \\
\hline & $\begin{array}{l}\text { Thoughts that you would be better off dead or of } \\
\text { hurting yourself in some way }\end{array}$ & 0 & 1 & 2 & 3 \\
\hline
\end{tabular}

$$
\begin{aligned}
& \text { For Office Coding } \underline{0}^{+} \underline{-}^{+} \\
& =\text {Total Score }
\end{aligned}
$$

If you checked off any problems, how difficult have these problems made it for you to do your work, take care of things at home, or get along with other people?

$\begin{array}{lcll}\text { Not difficult } & \text { Somewhat } & \text { Very } & \text { Extremely } \\ \text { at all } & \text { difficult } & \text { difficult } & \text { difficult }\end{array}$
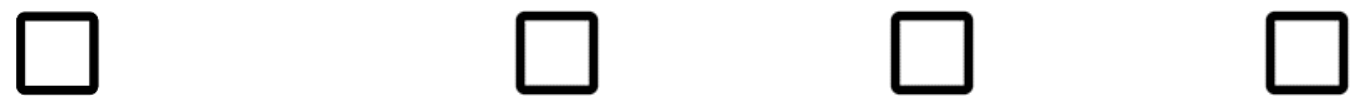
Problem Area in Diabetes (PAID) Questionnaire)

\begin{tabular}{|l|l|l|l|l|l|}
\hline & $\begin{array}{l}\text { Not a } \\
\text { problem }\end{array}$ & $\begin{array}{l}\text { Minor } \\
\text { Problem }\end{array}$ & $\begin{array}{l}\text { Moderate } \\
\text { problem }\end{array}$ & $\begin{array}{l}\text { Somewhat } \\
\text { serious } \\
\text { problem }\end{array}$ & $\begin{array}{l}\text { Serious } \\
\text { problem }\end{array}$ \\
\hline $\begin{array}{l}\text { 1. Not having clear and } \\
\text { concrete goals for your } \\
\text { diabetes care? }\end{array}$ & 0 & 1 & 2 & 3 & 4 \\
\hline $\begin{array}{l}\text { 2. Feeling discouraged } \\
\text { with your diabetes } \\
\text { treatment plan? }\end{array}$ & 0 & 1 & 2 & 3 & 4 \\
\hline $\begin{array}{l}\text { 3. Feeling scared when } \\
\text { you think about living } \\
\text { with diabetes? }\end{array}$ & 0 & 1 & 2 & 3 & 4 \\
\hline $\begin{array}{l}\text { 4. Uncomfortable social } \\
\text { situations related to } \\
\text { your diabetes care (e.g., } \\
\text { people telling you what } \\
\text { to eat)? }\end{array}$ & 0 & 1 & 2 & 3 & 4 \\
\hline $\begin{array}{l}\text { 5. Feelings of } \\
\text { deprivation regarding } \\
\text { food and meals? }\end{array}$ & 0 & 1 & 2 & 3 & 4 \\
\hline $\begin{array}{l}\text { 6. Feeling depressed } \\
\text { when you think about } \\
\text { living with diabetes? }\end{array}$ & 0 & 1 & 2 & 3 & 4 \\
\hline $\begin{array}{l}\text { 7. Not knowing if your } \\
\text { mood or feelings are } \\
\text { related to your } \\
\text { diabetes? }\end{array}$ & 0 & 1 & 2 & 3 & 4 \\
\hline $\begin{array}{l}\text { 8. Feeling overwhelmed } \\
\text { by your diabetes? }\end{array}$ & 0 & 1 & 2 & 3 & 4 \\
\hline $\begin{array}{l}\text { 9. Worrying about low } \\
\text { blood sugar reactions? }\end{array}$ & 0 & 1 & 2 & 3 & 4 \\
\hline $\begin{array}{l}\text { 10. Feeling angry when } \\
\text { you think about living } \\
\text { with diabetes? }\end{array}$ & 0 & 1 & 2 & 3 & 4 \\
\hline
\end{tabular}




\begin{tabular}{|l|l|l|l|l|l|}
\hline & $\begin{array}{l}\text { Not a } \\
\text { problem }\end{array}$ & $\begin{array}{l}\text { Minor } \\
\text { Problem }\end{array}$ & $\begin{array}{l}\text { Moderate } \\
\text { problem }\end{array}$ & $\begin{array}{l}\text { Somewhat } \\
\text { serious } \\
\text { problem }\end{array}$ & $\begin{array}{l}\text { Serious } \\
\text { problem }\end{array}$ \\
\hline $\begin{array}{l}\text { 11. Feeling constantly } \\
\text { concerned about food } \\
\text { and eating? }\end{array}$ & 0 & 1 & 2 & 3 & 4 \\
\hline $\begin{array}{l}\text { 12. Worrying about the } \\
\text { future and the } \\
\text { possibility of serious } \\
\text { complications? }\end{array}$ & 0 & 1 & 2 & 3 & 4 \\
\hline $\begin{array}{l}\text { 13. Feelings of guilt or } \\
\text { anxiety when you get } \\
\text { off track with your } \\
\text { diabetes management? }\end{array}$ & 0 & 1 & 2 & 3 & 4 \\
\hline $\begin{array}{l}\text { 14. Not "accepting" } \\
\text { your diabetes? }\end{array}$ & 0 & 1 & 2 & 3 & 4 \\
\hline $\begin{array}{l}\text { 15. Feeling unsatisfied } \\
\text { with your diabetes } \\
\text { physician? }\end{array}$ & 0 & 1 & 2 & 3 & 4 \\
\hline $\begin{array}{l}\text { 16. Feeling that } \\
\text { diabetes is taking up } \\
\text { too much of your } \\
\text { mental and physical } \\
\text { energy every day? }\end{array}$ & 0 & 1 & 2 & 3 & 4 \\
\hline $\begin{array}{l}\text { 17. Feeling alone with } \\
\text { your diabetes? }\end{array}$ & 0 & 1 & 2 & 3 & 4 \\
\hline $\begin{array}{l}\text { 18. Feeling that your } \\
\text { friends and family are } \\
\text { not supportive of your } \\
\text { diabetes management } \\
\text { efforts? }\end{array}$ & 0 & 1 & 2 & 3 & 4 \\
\hline $\begin{array}{l}\text { 19. Coping with } \\
\text { complications of } \\
\text { diabetes? }\end{array}$ & 0 & 1 & 2 & 3 & 4 \\
\hline $\begin{array}{l}\text { 20. Feeling "burned } \\
\text { out" by the constant }\end{array}$ & 0 & 1 & 2 & 3 & \\
\hline
\end{tabular}


effort needed to manage diabetes? 


\section{MOS Social Support Survey}

People sometimes look to others for companionship, assistance, or other types of support. How often is each of the following kinds of support available to you if you need it? Please circle one number on each line.

\begin{tabular}{|l|c|c|c|c|c|}
\hline \multicolumn{1}{|c|}{ Emotional Support Items } & $\begin{array}{c}\text { None of } \\
\text { the time }\end{array}$ & $\begin{array}{c}\text { A little } \\
\text { of the } \\
\text { time }\end{array}$ & $\begin{array}{c}\text { Some } \\
\text { of the } \\
\text { time }\end{array}$ & $\begin{array}{c}\text { Most } \\
\text { of the } \\
\text { time }\end{array}$ & $\begin{array}{c}\text { All of } \\
\text { the } \\
\text { time }\end{array}$ \\
\hline $\begin{array}{l}\text { 1. Someone you can count on } \\
\text { to listen to you when you need } \\
\text { to talk }\end{array}$ & 1 & 2 & 3 & 4 & 5 \\
\hline $\begin{array}{l}\text { 2. Someone to give you } \\
\text { information to help you } \\
\text { understand a situation. }\end{array}$ & 1 & 2 & 3 & 4 & 5 \\
\hline $\begin{array}{l}\text { 3. Someone to give you good } \\
\text { advice about a crisis. }\end{array}$ & 1 & 2 & 3 & 4 & 5 \\
\hline $\begin{array}{l}\text { 4. Someone to confide in or } \\
\text { talk to about yourself or your } \\
\text { problems. }\end{array}$ & 1 & 2 & 3 & 4 & 5 \\
\hline $\begin{array}{l}\text { 5. Someone whose advice you } \\
\text { really want. }\end{array}$ & 1 & 2 & 3 & 4 & 5 \\
\hline $\begin{array}{l}\text { 6. Someone to share your most } \\
\text { worries and fears with. }\end{array}$ & 1 & 2 & 3 & 4 & 5 \\
\hline $\begin{array}{l}\text { 7. Someone who understands } \\
\text { your problems. }\end{array}$ & 1 & 2 & 3 & 4 & 5 \\
\hline \multicolumn{1}{|c|}{ Tangible Support Items } & 1 & 2 & 3 & 4 & 5 \\
\hline $\begin{array}{l}\text { 1. Someone to help you if you } \\
\text { were confined to bed. }\end{array}$ & 1 & 2 & 3 & 4 & 5 \\
\hline $\begin{array}{l}\text { 2. Someone to take you to the } \\
\text { doctor if you needed it. }\end{array}$ & 1 & 2 & 3 & 4 & 5 \\
\hline $\begin{array}{l}\text { 3. Someone to prepare your } \\
\text { meals if you were unable to do } \\
\text { it yourself. }\end{array}$ & 1 & 2 & 3 & 4 & 5 \\
\hline $\begin{array}{l}\text { 4. Someone to help with your } \\
\text { daily chores if you were sick. }\end{array}$ & 1 & & & & 5 \\
\hline \multicolumn{1}{|c|}{ Affectionate Support Items } & 1 & & & & \\
\hline $\begin{array}{l}\text { 1. Someone who shows you } \\
\text { love and affection }\end{array}$ & & & & & 4 \\
\hline
\end{tabular}




\begin{tabular}{|c|c|c|c|c|c|}
\hline $\begin{array}{l}\text { 2. Someone to love you and } \\
\text { make you feel wanted. }\end{array}$ & 1 & 2 & 3 & 4 & 5 \\
\hline 3. Someone who hugs you. & 1 & 2 & 3 & 4 & 5 \\
\hline \multicolumn{6}{|l|}{$\begin{array}{c}\text { Positive Social Interaction } \\
\text { Items }\end{array}$} \\
\hline $\begin{array}{l}\text { 1. Someone to have a good } \\
\text { time with }\end{array}$ & 1 & 2 & 3 & 4 & 5 \\
\hline $\begin{array}{l}\text { 2. Someone to get together } \\
\text { with for relaxation }\end{array}$ & 1 & 2 & 3 & 4 & 5 \\
\hline $\begin{array}{l}\text { 3. Someone to do something } \\
\text { enjoyable with. }\end{array}$ & 1 & 2 & 3 & 4 & 5 \\
\hline \multicolumn{6}{|l|}{ Additional Item } \\
\hline $\begin{array}{l}\text { 1. Someone to do things with } \\
\text { to help you get your mind off } \\
\text { things. }\end{array}$ & 1 & 2 & 3 & 4 & 5 \\
\hline
\end{tabular}

Homecare Item: Do you use any kind of professional in-home care to help manage your illnesses? Yes or No 
Self-Management Assessment Scale

\begin{tabular}{|c|l|c|c|c|c|c|}
\hline $\begin{array}{c}\text { How often do } \\
\text { you take the } \\
\text { initiative to keep } \\
\text { yourself busy? }\end{array}$ & Never & $\begin{array}{c}\text { Hardly } \\
\text { Ever }\end{array}$ & Sometimes & Regularly & Often & $\begin{array}{c}\text { Very } \\
\text { Often }\end{array}$ \\
\hline $\begin{array}{c}\text { How often do } \\
\text { you take the } \\
\text { initiative to get in } \\
\text { touch with } \\
\text { people who are } \\
\text { dear to you? }\end{array}$ & Never & $\begin{array}{c}\text { Hardly } \\
\text { Ever }\end{array}$ & Sometimes & Regularly & Often & $\begin{array}{c}\text { Very } \\
\text { Often }\end{array}$ \\
\hline $\begin{array}{c}\text { How often do } \\
\text { you make an } \\
\text { effort to have } \\
\text { friendly contacts } \\
\text { with other } \\
\text { people? }\end{array}$ & Never & Hardly & Sometimes & Regularly & Often & Very \\
Often
\end{tabular}

\begin{tabular}{|c|l|c|l|l|l|l|}
\hline $\begin{array}{c}\text { Do you ensure } \\
\text { that you have } \\
\text { enough interests } \\
\text { on a regular basis } \\
\text { (such as a hobby) } \\
\text { to keep you } \\
\text { active? }\end{array}$ & Never & $\begin{array}{c}\text { Hardly } \\
\text { Ever }\end{array}$ & Sometimes & Regularly & Often & $\begin{array}{c}\text { Very } \\
\text { Often }\end{array}$ \\
\hline $\begin{array}{c}\text { Do you devote } \\
\text { some time and } \\
\text { attention to } \\
\text { those who are } \\
\text { dear to you in } \\
\text { order to maintain } \\
\text { good contact? }\end{array}$ & Never & $\begin{array}{c}\text { Hardly } \\
\text { Ever }\end{array}$ & Sometimes & Regularly & Often & $\begin{array}{c}\text { Very } \\
\text { Often }\end{array}$ \\
\hline $\begin{array}{c}\text { Do you keep busy } \\
\text { with things you } \\
\text { are good at so }\end{array}$ & Never & $\begin{array}{c}\text { Hardly } \\
\text { Ever }\end{array}$ & Sometimes & Regularly & Often & $\begin{array}{c}\text { Very } \\
\text { Often }\end{array}$ \\
\hline
\end{tabular}




\begin{tabular}{|c|l|l|l|l|l|l|}
\hline $\begin{array}{c}\text { that you stay } \\
\text { good as them? }\end{array}$ & & & & & & \\
\hline
\end{tabular}

\begin{tabular}{|c|c|c|c|c|c|c|}
\hline $\begin{array}{c}\text { How many } \\
\text { hobbies or } \\
\text { activities do you } \\
\text { have on a regular } \\
\text { basis? }\end{array}$ & None & One & Two & $\begin{array}{c}\text { Three or } \\
\text { Four }\end{array}$ & $\begin{array}{c}\text { Five or } \\
\text { Six }\end{array}$ & $\begin{array}{c}\text { Six or } \\
\text { More }\end{array}$ \\
\hline $\begin{array}{c}\text { Do you have } \\
\text { different } \\
\text { occasions on } \\
\text { which you have } \\
\text { friendly contact } \\
\text { with others? }\end{array}$ & None & One & Two & $\begin{array}{c}\text { Three or } \\
\text { Four }\end{array}$ & $\begin{array}{c}\text { Five or } \\
\text { Six }\end{array}$ & $\begin{array}{c}\text { Six or } \\
\text { More }\end{array}$ \\
\hline $\begin{array}{c}\text { Are there certain } \\
\text { things that you } \\
\text { are good at? }\end{array}$ & None & One & Two & $\begin{array}{c}\text { Three or } \\
\text { Four }\end{array}$ & $\begin{array}{c}\text { Five or } \\
\text { Six }\end{array}$ & $\begin{array}{c}\text { Six or } \\
\text { More }\end{array}$ \\
\hline
\end{tabular}

\begin{tabular}{|c|c|c|c|c|c|}
\hline $\begin{array}{c}\text { The activities I } \\
\text { enjoy, I do } \\
\text { together with } \\
\text { others. }\end{array}$ & $\begin{array}{c}\text { Strongly } \\
\text { Disagree }\end{array}$ & Disagree & $\begin{array}{c}\text { Neither } \\
\text { Agree nor } \\
\text { Disagree }\end{array}$ & Agree & $\begin{array}{c}\text { Strongly } \\
\text { Agree }\end{array}$ \\
\hline $\begin{array}{c}\text { I sometimes help } \\
\text { the people I care } \\
\text { about. }\end{array}$ & & & & & \\
\hline $\begin{array}{c}\text { Others benefit } \\
\text { from the things I } \\
\text { do for pleasure. }\end{array}$ & & & & & \\
\hline
\end{tabular}

\begin{tabular}{|l|l|l|l|l|l|}
\hline $\begin{array}{l}\text { Are you able to } \\
\text { find agreeable } \\
\text { activities? }\end{array}$ & $\begin{array}{l}\text { I am certain } \\
\text { that I can } \\
\text { not }\end{array}$ & $\begin{array}{l}\text { I don't } \\
\text { think I } \\
\text { can }\end{array}$ & $\begin{array}{l}\text { Sometimes } \\
\text { I can, } \\
\text { sometimes } \\
\text { I can not }\end{array}$ & $\begin{array}{l}\text { I think I } \\
\text { can }\end{array}$ & $\begin{array}{l}\text { I'm certain } \\
\text { I can }\end{array}$ \\
\hline
\end{tabular}




\begin{tabular}{|l|l|l|l|l|l|}
\hline $\begin{array}{l}\text { Are you able to } \\
\text { have friendly } \\
\text { contacts with } \\
\text { others? }\end{array}$ & $\begin{array}{l}\text { I am certain } \\
\text { that I can } \\
\text { not }\end{array}$ & $\begin{array}{l}\text { I don't } \\
\text { think I } \\
\text { can }\end{array}$ & $\begin{array}{l}\text { Sometimes } \\
\text { I can, } \\
\text { sometimes } \\
\text { I can not }\end{array}$ & $\begin{array}{l}\text { I think I } \\
\text { can }\end{array}$ & $\begin{array}{l}\text { I'm certain } \\
\text { I can }\end{array}$ \\
\hline $\begin{array}{l}\text { Are you able to let } \\
\text { others know that } \\
\text { you care about } \\
\text { them? }\end{array}$ & $\begin{array}{l}\text { I am certain } \\
\text { that I can } \\
\text { not }\end{array}$ & $\begin{array}{l}\text { I don't } \\
\text { think I } \\
\text { can }\end{array}$ & $\begin{array}{l}\text { Sometimes } \\
\text { I can, } \\
\text { sometimes } \\
\text { I can not }\end{array}$ & $\begin{array}{l}\text { I think I } \\
\text { can }\end{array}$ & $\begin{array}{l}\text { I'm certain } \\
\text { I can }\end{array}$ \\
\hline
\end{tabular}

\begin{tabular}{|l|l|l|l|l|l|l|}
\hline $\begin{array}{l}\text { When things } \\
\text { go against } \\
\text { you, how } \\
\text { often do you } \\
\text { think that it } \\
\text { could always } \\
\text { be worse }\end{array}$ & Hardly Ever & Sometimes & Regularly & Often & $\begin{array}{l}\text { Very } \\
\text { Often }\end{array}$ \\
\hline $\begin{array}{l}\text { When you are } \\
\text { having a bad } \\
\text { day, how } \\
\text { often do you } \\
\text { think things } \\
\text { will be better } \\
\text { tomorrow? }\end{array}$ & Hardly Ever & Sometimes & Regularly & Often & $\begin{array}{l}\text { Very } \\
\text { Often }\end{array}$ \\
\hline $\begin{array}{l}\text { When things } \\
\text { are not going } \\
\text { so well, how } \\
\text { often do you } \\
\text { succeed in } \\
\text { thinking } \\
\text { positively? }\end{array}$ & Never & Hardly Ever & Sometimes & Regularly & Often & $\begin{array}{l}\text { Very } \\
\text { Often }\end{array}$ \\
\hline
\end{tabular}




\section{UCLA Loneliness Scale--Version 3}

Daniel W. Russell

Instructions: The following statements describe how people sometimes feel. For each statement, please indicate how often you feel the way described by writing a number in the space provided. Here is an example:

How often do you feel happy?

If you never felt happy, you would respond "never; if you always feel happy, you would respond "always."

$\frac{\text { NEVER }}{1} \quad \frac{\text { RARELY }}{2} \quad \frac{\text { SOMETIMES }}{3} \quad \frac{\text { ALWAYS }}{4}$

1. How often do you feel that you are "in tune" with the people around you?

2. How often do you feel that you lack companionship?

3. How often do you feel that there is no one you can turn to?

4. How often do you feel alone?

5. How often do you feel part of a group of friends?

6. How often do you feel that you have a lot in common with the people around you? 
7. How often do you feel that you are no longer close to anyone?

8. How often do you feel that your interests and ideas are not shared by those around you?

9. How often do you feel outgoing and friendly?

10. How often do you feel close to people?

11. How often do you feel left out?

12. How often do you feel that your relationship with others are not meaningful?

13. How often do you feel that no one really knows you well?

14. How often do you feel isolated from others?

15. How often do you feel you can find companionship when you want it?

16. How often do you feel that there are people who really understand you?

17. How often do you feel shy? 
18. How often do you feel that people are around you but not with you? 19. How often do you feel that there are people you can talk to? 20.How often do you feel that there are people you can turn to?

(C) Daniel W. Russell 


\section{Brief COPE}

\section{S. Carver}

$1=$ I haven't been doing this at all

$2=I^{\prime}$ ve been doing this a little bit

$3=$ I've been doing this a medium amount

$4=I^{\prime}$ ve been doing this a lot

1. I've been turning to work or other activities to take my mind off things.

$\begin{array}{llll}1 & 2 & 3 & 4\end{array}$

2. I've been concentrating my efforts on doing something about the situation I'm in.

$\begin{array}{llll}1 & 2 & 3 & 4\end{array}$

3. I've been saying to myself "this isn't real."

$\begin{array}{llll}1 & 2 & 3 & 4\end{array}$

4. I've been using alcohol or other drugs to make myself feel better.

$\begin{array}{llll}1 & 2 & 3 & 4\end{array}$

5. I've been getting emotional support from others. $\quad \begin{array}{lllll}1 & 2 & 3 & 4\end{array}$

6. I've been giving up trying to deal with it.

$\begin{array}{llll}1 & 2 & 3 & 4\end{array}$

7. I've been taking action to try to make the situation better.

1

8. I've been refusing to believe that it has happened. $\begin{array}{llllll}1 & 2 & 3 & 4\end{array}$

9. I've been saying things to let my unpleasant feelings escape. $\begin{array}{llllll}1 & 2 & 3 & 4\end{array}$

10.I've been getting help and advice from other people. $\begin{array}{lllll}1 & 2 & 3 & 4\end{array}$

11.I've been using alcohol or other drugs to help me get through it.

$\begin{array}{llll}1 & 2 & 3 & 4\end{array}$


$1=I$ haven't been doing this at all

$2=$ I've been doing this a little bit

$3=I^{\prime}$ ve been doing this a medium amount

$4=$ I've been doing this a lot

1

12.I've been trying to see it in a different light, to make it seem more positive.

$\begin{array}{llll}1 & 2 & 3 & 4\end{array}$

13.I've been criticizing myself.

$\begin{array}{llll}1 & 2 & 3 & 4\end{array}$

14. I've been trying to come up with a strategy about what to do. 1

15. I've been getting comfort and understanding from someone. 1

16.I've been giving up the attempt to cope.

$\begin{array}{llll}1 & 2 & 3 & 4\end{array}$

17. I've been looking for something good in what is happening.

18.I've been making jokes about it.

123

4

19.I've been doing something to think about it less, such as going to movies, watching TV, reading, daydreaming, sleeping, or shopping.

$\begin{array}{llll}1 & 2 & 3 & 4\end{array}$

20.I've been accepting the reality of the fact that it has happened.

$\begin{array}{llll}1 & 2 & 3 & 4\end{array}$

21.I've been expressing my negative feelings.

$\begin{array}{llll}1 & 2 & 3 & 4\end{array}$

22.I've been trying to find comfort in my religion or spiritual beliefs.

$\begin{array}{llll}1 & 2 & 3 & 4\end{array}$

23.I've been trying to get advice or help from other people about what to do.

$\begin{array}{llll}1 & 2 & 3 & 4\end{array}$

24.I've been learning to live with it.

$\begin{array}{llll}1 & 2 & 3 & 4\end{array}$




$$
\begin{aligned}
& 1=I \text { haven't been doing this at all } \\
& 2=I \text { 've been doing this a little bit } \\
& 3=\text { I've been doing this a medium amount } \\
& 4=\text { I've been doing this a lot }
\end{aligned}
$$

\begin{tabular}{lllll}
1 & 2 & 3 & 4 \\
\hline
\end{tabular}

$\begin{array}{lllllll}\text { 25.I've been thinking hard about what steps to take. } & 1 & 2 & 3 & 4\end{array}$

$\begin{array}{llllll}\text { 26.I've been blaming myself for things that happened. } & 1 & 2 & 3 & 4\end{array}$

$\begin{array}{llllll}\text { 27.I've been praying or meditating. } & 1 & 2 & 3 & 4\end{array}$

$\begin{array}{llllll}\text { 28.I've been making fun of the situation. } & 1 & 2 & 3 & 4\end{array}$

(C) C. S. Carver 